\title{
Interpreting Early Species Range Descriptions for Pacific Salmon, Oncorhynchus spp., in Coastal California Watersheds: The Historical Context
}

\author{
BRIAN C. SPENCE
}

\section{Introduction}

Scientists and fish and wildlife managers are often asked to determine the historical ranges of species in areas where populations have been extirpated as a result of anthropogenic actions. For Pacific salmonids, Oncorhynchus spp., freshwater or spawning range determinations have been critical in several phases of Endangered Species Act (ESA) implementation. These include the delineation of distinct population segments (DPS's) or evolutionarily significant units (ESU's) considered for ESA listing, designation of critical habitats, development of technical guidance documents that both posited historical population structure and es-

Brian C. Spence is with the Fisheries Ecology Division, Southwest Fisheries Science Center, National Marine Fisheries Service, NOAA, 110 Shaffer Road, Santa Cruz, CA 95060 (email: brian.spence@noaa.gov).

doi: https://doi.org/10.7755/MFR.81.1.1 tablished viability criteria for each listed DPS or ESU, and development of recovery plans for these listed units. Likewise, historical information on the freshwater distribution of Pacific salmon influenced delineation of essential fish habitat under the Magnuson Act (PFMC, 1999).

Misidentification of historical salmonid habitats can have important ramifications. On one hand, failure to accurately identify a portion of a species' natural range could result in underestimation of habitat loss and lead to inadequate protection of habitats that may be important to the longterm recovery, persistence, evolution, or sustained production of an ESU or DPS. Conversely, incorrectly concluding that a species occupied a watershed or region when it did not could lead to costly recovery efforts and restrictions on human activities in watersheds where the likelihood of naturally sustaining populations is negligible. Consequently, assessing the historical range of species should be done with considerable care.

In seeking to define the natural freshwater ranges of Pacific salmon, scientists and managers have often turned to writings and collection records of pioneering ichthyologists to substantiate the historical occurrence in particular regions or watersheds. These early descriptions and accounts are generally assumed to provide evidence of occurrence during periods when the impacts of harvest and habitat degradation were less pervasive. For salmon in California, the writings of David Starr Jordan, Charles Henry Gilbert, John Otterbein Snyder, and other faculty and staff at Stanford University during the late 1800's and early 1900's have been particularly influential (Fig. $1)$. These scientists, as well as collaborators such as Barton Warren Evermann (a former student of Jordan's at Indiana University), worked closely with the United States Commission of Fish and Fisheries (U.S. Fish Com-
ABSTRACT-Scientists and managers implementing endangered species laws often face the task of defining the historical geographic ranges for threatened and endangered species. To do so, they commonly turn to the writings of early biologists seeking accounts of species in regions where they may have been extirpated as a result of anthropogenic activities over the last 150-175 years. In the case of Pacific salmon, Oncorhynchus spp., the writings of David Starr Jordan, Charles Henry Gilbert, John Otterbein Snyder, and other faculty and staff at Stanford University during the late 1800's and early 1900's have been particularly influential, as these scientists were widely recognized as the leading authorities on west coast fishes and salmonids in particular.

Because of the tremendous achievements of these pioneering ichthyologists, scientists and others have often taken these early range descriptions at face value, without critically examining the underlying historical context. When Jordan and his contemporaries first began writing about the ranges of Pacific salmon, scientific exploration of coastal watersheds of California was in its infancy. Additionally, the taxonomy and nomenclature of Pacific salmonids were in states of extreme disarray, with numerous putative species described based on variations due to age, sex, and reproductive condition.

Even after Jordan and Gilbert began to resolve Pacific salmon taxonomy in the 1880 's, confusion in nomenclature, exacerbated by a primitive understanding of Pacific salmon life histories, contributed to frequent misidentification of west coast salmonids and hence inaccurate descriptions of their historical freshwater spawning rang- es. Further confounding interpretation of early reports is that the first systematic explorations of coastal watersheds took place well after significant anthropogenic damage to salmon habitats had already occurred; thus, failure to detect species on these surveys does not necessarily indicate a species was absent, either at the time of the survey or in the years prior to significant human disturbances. As a result, any single writing of Jordan's and his colleagues between the late 1870's and the early 1900's is likely to contain species range information that is equivocal, if not demonstrably inaccurate. This is not to disparage Jordan and his contemporaries in any way or to diminish their extraordinary scientific achievements. However, scientists and managers need to be cognizant of these limitations when using historical writings to guide management of endangered species. 

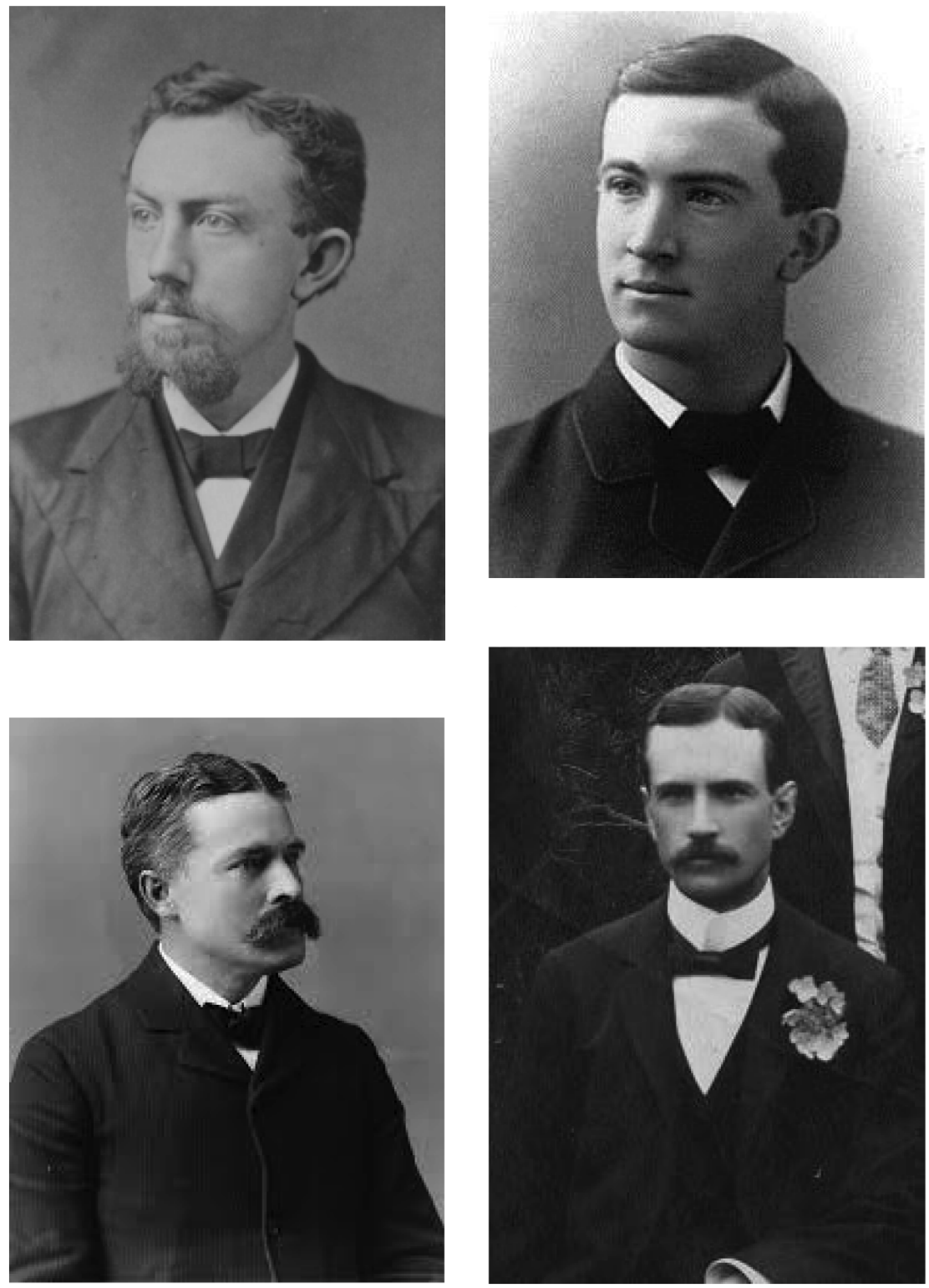

Figure 1.-Renowned ichthyologists of the late 1800s whose writings and explorations of California's fish fauna contained or influenced early range descriptions for Pacific salmon, including (clockwise from top left) David Starr Jordan (ca. 1879), Charles Henry Gilbert (ca. 1880), John Otterbein Snyder (ca. 1900), and Barton Warren Evermann (ca. 1899). (Photos: Jordan, Gilbert, and Snyder from Stanford Historical Photograph Collection (SC1071). Evermann from California Academy of Sciences GSMAEL.)

mission) and were widely recognized as the leading authorities on fishes of North America during this era. Indeed, the Pacific salmon range descriptions of Jordan and his contemporaries from the late 1800 's continue to be referenced, either directly or indirectly, in many books and reports (e.g., McPhail and Lindsey, 1970; Scott and Crossman, 1973; Behnke, 2002; Wydoski and Whitney, 2003; Quinn, 2005).

Owing to the lofty achievements and status these ichthyological luminaries attained, scientists have often taken these early accounts at face value without fully considering the histori- cal context within which these writings and observations were embedded. This context has many dimensions, the understanding of which is critical to proper interpretation (Fig. 2).

First, the earliest descriptions of the distributions of California fishes, including the Pacific salmonids, were based on a very limited number of scientific surveys or collections, with data from coastal watersheds of California being particularly sparse.

Second, prior to the 1900 's, the taxonomy and nomenclature of Pacific salmonids were in complete disarray; hence, not all reports of occurrence of a particular species in either the scientific or popular literature are necessarily reliable.

Third, even after more systematic surveys of California's freshwater fish faunas were initiated and some of the taxonomic ambiguity had been resolved, misidentification of collected specimens remained commonplace, in part because of the poor understanding of salmonid life histories that existed at the time.

Fourth, significant artificial culture and transplanting of certain Pacific salmonids in California began in the 1870's; thus, the potential exists for some early records of salmonid occurrence to be the product of hatchery releases.

Finally, by the mid- to late-1800's, significant alteration of freshwater habitats had already occurred as a result of logging, mining, cattle grazing, dam building, agricultural land conversions, water diversions, release of pollutants, and other human activities. Thus, in many areas local extirpations of salmon and steelhead, $O$. mykiss, populations likely occurred well before any formal scientific surveys of native fish faunas had taken place. All of these issues potentially confound the interpretation of historical evidence.

In this paper, I endeavor to provide historical context for interpreting early Pacific salmon ${ }^{1}$ species distribu-

${ }^{1}$ In this paper, I use the term "Pacific salmon" when referring to the five semelparous species of Pacific salmon (O. tshawytscha, O. kisutch, 
tion information in the coastal regions of California, focusing on the writings and collection records of David Starr Jordan and his contemporaries during the late 1800's and early 1900's. California marks the southernmost limits of the current distributions of both coho salmon, $O$. kisutch, and Chinook salmon, O. tshawytscha. Pink, O. gorbuscha, chum, O. keta, and sockeye salmon, O. nerka, have also been reported in the state, though it remains equivocal as to whether or not persistent populations of these latter three species have occurred in California under climatic conditions that have prevailed in the past 150-200 years.

This paper does not seek to provide definitive answers regarding the historical freshwater ranges of the different species of Pacific salmon in California, or to address the fluctuating ranges over geological time frames (for longer term perspectives on the evolutionary history of Pacific salmonids, see Minckley et al., 1986; Waples et al., 2008; Penaluna et al., 2016). I believe the scarcity of definitive historical records and ambiguity in the written accounts precludes making final judgments with high confidence. Rather, the paper is intended to raise a cautionary flag against over-interpreting these early writings, as there are many examples demonstrating that the scientific foundation for accurately describing the historical freshwater ranges of these species simply did not exist in the 1800 's.

\section{The Nature of Pacific Salmon Range Limits}

Before evaluating early accounts and descriptions of Pacific salmon species in California, it is important to define what I mean by a "species"

O. nerka, O. gorbuscha, and O. keta) that occur on the west coast of North America and the term "Pacific salmonids" when including the $O$. mykiss and $O$. clarkii complexes and members of the genus Salvelinus that enter Pacific coastal watersheds. The history of the taxonomy surrounding the $O$. mykiss and $O$. clarkii species complexes is far more complicated than for the five $\mathrm{Pa}-$ cific salmon species and is beyond the scope of this paper, though some mention of these species is included to illustrate some of the difficulties in establishing species ranges.

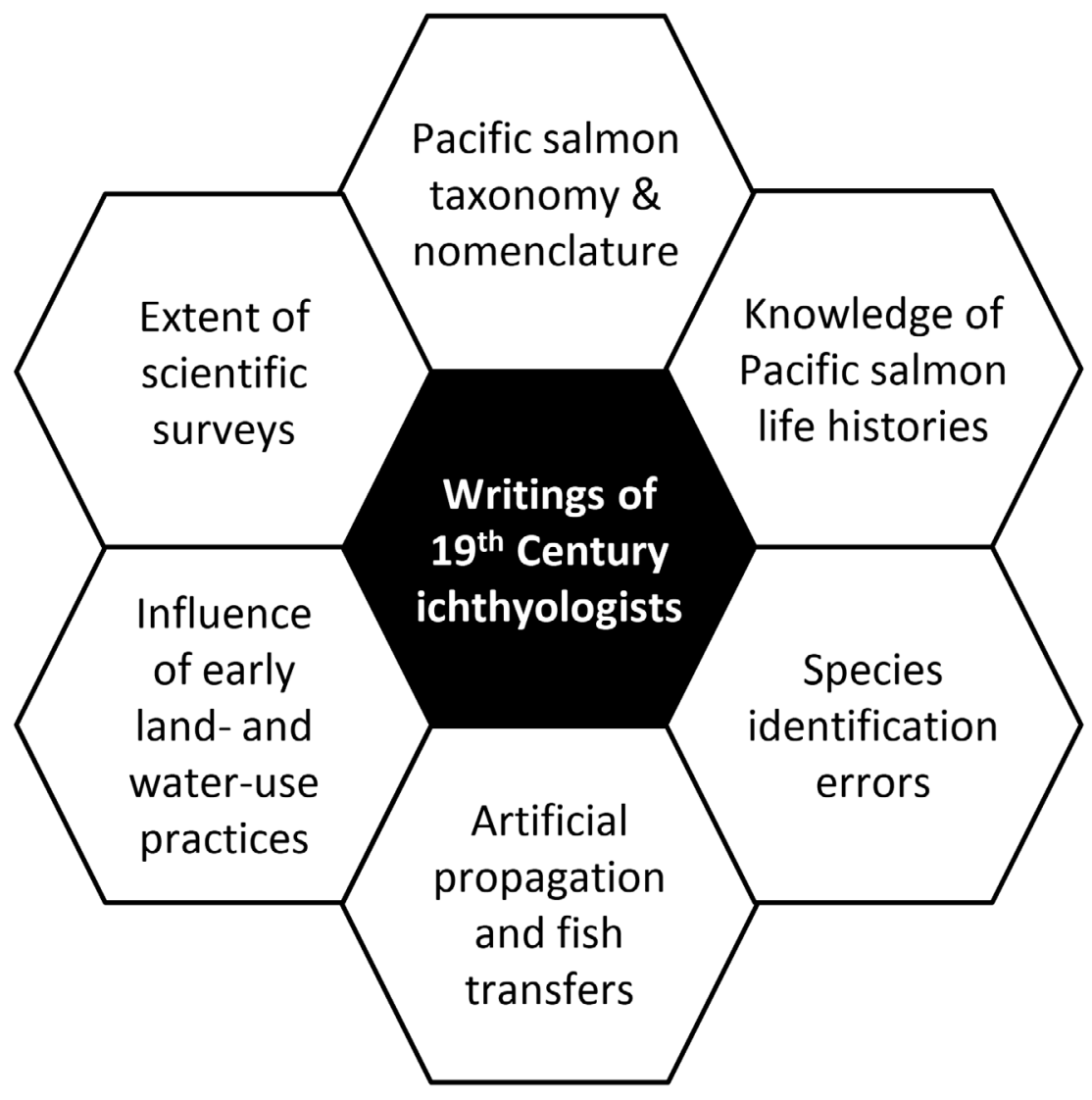

Figure 2.-Primary elements of historical context required for interpreting early descriptions of the ranges of Pacific salmon on the West Coast of North America.

range" in the context of this paper. In the simplest terms, a species' range may be defined as the set of geographic locations at which that species has been observed (in any of its various life stages), as is commonly depicted in species range maps (Brown et al., 1996). For Pacific salmonids (and many other species), this definition is unsatisfying because, by their nature, anadromous salmonids tend to continually test the limits of their distribution through the process of straying, i.e., dispersal of individuals to non-natal streams to reproduce.

Indeed, straying behavior has adaptive value, particularly in populations that live in unstable environments where there is high variation in juvenile survival (Quinn, 1984); hence, we might expect higher rates of straying near the periphery of a species' range. As a result of this behavior, adult fish may periodically be observed in habitats that cannot support persistent populations.

Although salmon most often stray to streams within relatively close proximity to natal streams, this is not always the case. For example, adult pink salmon have periodically (including recently) been observed in streams and rivers of central California including Pescadero Creek in San Mateo Coun$\mathrm{ty}^{2}$, the San Lorenzo River in Santa Cruz County (Scofield, 1916), and the Salinas River and Big Creek in Monterey County (Skiles et al., 2013), sites that are 1,300-1,400 km south of Puget Sound, where the southern-most persistent populations of pink salm-

${ }^{2}$ Jankovitz, Jon. 2017. Summary of annual water quality monitoring, fish sampling, and active management: Pescadero Creek Lagoon. California Department of Fish and Wildlife, Santa Cruz, 39 p. 
on currently reside. ${ }^{3}$ Likewise, chum salmon have occasionally been observed in central California streams and rivers (Scofield, 1916; Ettlinger et al., 2015), even though the nearest persistent extant populations appear to be $850-1,000 \mathrm{~km}$ to the north near Tillamook Bay, Oregon (Johnson et al., 1997).

Sexton et al. (2009) suggested that the challenge in defining species range limits is in identifying environments in which birth rates exceed death rates, how these environments are distributed across the landscape, and how they are connected by dispersal. This conceptualization implies that species ranges are best defined by groups (or populations) of animals, and hence not by the occasional and transient occurrence of a species in a particular watershed. Yet even from this population perspective, defining a species range for salmon remains problematic because environments are inherently dynamic. Expansion and contraction of a species range in response to climatic shifts is a natural process at temporal scales ranging from years to millennia or longer (Brown et al., 1996; Waples et al., 2008). Consequently, any definition of a species range should include a relevant temporal scale; depending on the purpose, this definition can be at geologic, evolutionary, or historical time scales.

Such choices are inevitably somewhat arbitrary. However, for purposes of implementing the Endangered Species and Magnuson acts, perhaps the most useful definition extends that of Sexton et al. (2009) to include individual populations where, at time scales of $\sim 100$ years (i.e., scales most relevant to management ${ }^{4}$, births plus immigration exceeds deaths plus emi-

\footnotetext{
${ }^{3}$ Small numbers of pink salmon are observed at dams along the Columbia River in most years, but it appears that these individuals are likely strays and not members of persistent spawning populations.

${ }^{4}$ The 100 -year time frame is suggested by McElhany et al. (2000) as reasonable for assessing viability and extinction risk of Pacific salmonid populations for Endangered Species Act purposes. The authors acknowledge that longer term processes are important to persistence of an ESU or DPS; however, they note the difficulty in making
}

gration. This definition allows for the fact that sink populations can persist, sometimes indefinitely, in habitats where within-habitat reproduction is insufficient to balance mortality, provided that there is significant immigration (Pulliam, 1988; Holt, 1996; Boughton, 2000). This distinction is important, as some of the earliest freshwater range descriptions appear to consider the southernmost observation of a species as indicative of the range, absent any evidence of population persistence.

Unless otherwise indicated in this paper, the terms "range" or "species range" refer to the freshwater spawning ranges of the Pacific salmon. In the marine environment, the southern extent of the distribution of Pacific salmon varies through time depending on water temperature, food availability, and ocean circulation patterns (Pearcy, 1992). Chinook salmon have been observed as far south as coastal waters off San Diego County (Miller and Lea, 1972), and are still caught with some regularity in the Santa Barbara Channel, south of Point Conception (Winans et al., 2001; Bellinger et al., 2015). Coho salmon have been reported near the Coronado Islands, south of the California-Mexico border (Scofield, 1937). Even pink salmon have been observed as far south as the coast of San Diego County (Hubbs, 1946). Thus, while not discussed further in this paper, the marine distribution of Pacific salmon and the regularity with which ocean conditions favor occurrence may play key roles in determining opportunities for colonization and, hence, changes in the freshwater spawning ranges of salmon over longer periods of time.

\section{Scientific Exploration of California's Fish Fauna: 1850-1879}

Interpreting the early scientific record on the occurrence and distribution of Pacific salmon in California watersheds requires a fundamental understanding of the state of scientific

credible quantitative predictions about viability over longer time spans. knowledge from the 1800 's to the early 1900 's. Critical to this evaluation is an understanding of the spatial extent of scientific surveys conducted during this era. To our good fortune, Evermann and Clark (1931) published an exhaustive review of scientific literature related to the occurrence of fishes in the rivers and lakes of California covering the period from 1850 to the mid-1920's.

The explicit goal of their review was to examine "all literature pertaining to the freshwater fishes of the state, as species or kinds, in order that we might know not only what species are known to occur, in California, but also the geographic distribution of each of those species within the state." From this treatise, it is possible to reconstruct to a substantial degree the spatial extent of scientific exploration in California from 1850 to the late 1870's, when Jordan and his colleagues first began writing about the distribution of Pacific salmonids.

Evermann and Clarks' analysis indicates that scientific investigation of fishes in California began in the early 1850 's. Prior accounts of early Spanish, Russian, and American explorers of California, while sometimes providing indications of habitat conditions in selected rivers at the time of exploration, yield little specific information about the fishes encountered (e.g., Fremont, 1856; Costanso, 1911; Fages, 1937; Brewer, 1974; Jackson and Spence, 1970; Goetzmann, 1993; Crespi, 2001; Beidleman, 2006; Gibson, 2013). Occasionally, these narratives will make mention of "salmon" or "trout," but any descriptions lack sufficient detail for species determination.

The interest in scientific descriptions of fishes and other biota in California that emerged during the early 1850 's was undoubtedly precipitated by the influx of settlers to the state following the discovery of gold at Sutter's Mill in 1848. Still, from 1850 to 1879 , most scientific collections of freshwater fishes were isolated events in which individuals provided specimens to scientists who then published species de- 
scriptions. This is true of both the first freshwater fish described in California, tule perch, Hysterocarpus traski, collected in the lower Sacramento River (Gibbons, 1854), and the first salmonid, Salmo irideus $(=O$. mykiss iride$u s^{5}$ ), which was taken from San Leandro Creek in the east San Francisco Bay region (Gibbons, 1855). Both of these descriptions were read at meetings of the newly formed California Academy of Sciences.

Additional scientific collections were made during the Pacific Railroad surveys conducted between 1853 and 1855 . These surveys sought to discover the most practicable railroad routes from the Mississippi River basin to the Pacific Coast, as well as from San Diego, Calif., northward to Seattle, Wash. (Moore, 1986). At the behest of Smithsonian Institution Assistant Secretary Spencer Fullerton Baird, surgeons and officers were assigned to these expeditions as field naturalists and were provided manuals and materials for making collections (Dall, 1915; Moore, 1986)(see also Rivinus and Youssef (1992) for an account of Baird's life and career at the Smithsonian).

Specimens were returned to the Smithsonian and findings were summarized in a series of zoological reports prepared by French biologist Charles Frédéric Girard, a former student of renowned Swiss geologist and zoologist Louis Agassiz of Harvard University. Girard was recruited by Baird specifically to assist with ichthyological and herpetological collections made during the Pacific Railroad, Northwest Boundary, and Mexican Boundary surveys (Jackson and Kimler, 1999).

Following the Pacific Railroad surveys, there was little scientific attention paid to salmonids of California. Between 1860 and 1864, William H. Brewer led an expedition of the California Geologic Survey that covered

\footnotetext{
${ }^{5}$ Throughout this paper, when citing a scientific name that is no longer considered valid, I adopt the convention of adding a parenthetical with the currently accepted name preceded by an equals sign "=".
}

the coastal region between Los Angeles and San Francisco, as well as portions of Napa, Sonoma, and Lake counties before turning east to the Sacramento River basin (including a short trip to Weaverville in the headwaters of the Trinity River) and the Sierra Nevada. However, the expedition's interest lay primarily in mapping topography, collecting fossils, and documenting mineral resources. Brewer's journals occasionally mention "trout" being caught or eaten by the expedition; ${ }^{6}$ however, the only references to "salmon" include observations of Native Americans catching and drying salmon near Battle Creek, and the expedition trading for salmon near the Pit River (Shasta County) (Brewer, 1974).

It was not until the 1870's that further scientific accounts of salmonids in California were published. Livingston Stone, who in 1872 established the Baird Hatchery (USFC, 1874), the first federally owned hatchery on the west coast, provided information on salmonid fishes from the McCloud River in the northern Sacramento River basin. Additional information was generated by Henry W. Henshaw's explorations of the Sierra Nevada's Kern River Basin and Lake Tahoe, though these accounts were exclusively of resident trout forms (Jordan and Henshaw, 1878).

Collectively, Evermann and Clark (1931) documents 23 unique freshwater or estuarine collection localities ${ }^{7}$ for salmonids in the state between the years 1850 and 1879 (Fig. 3; Supplemental Table S1). All but one of these observations were of what are currently recognized as various subspecies or forms of O. mykiss (i.e., rainbow/ steelhead trout and derivative redband

${ }^{6}$ Locations where Brewer mentioned trout include Battle Creek and the Pit River (Shasta County); the South Fork Kings River (Fresno County); the Middle Fork San Joaquin River (near the border of Madera and Fresno counties) and Lake Pyramid and the Truckee River (likely in Nevada). These lacked any detail that would allow identification to species, though in the latter case, these were almost certainly Lahontan cutthroat trout.

${ }^{7}$ The list of Evermann and Clark is slightly longer than 23; however, several of these are simply duplicates of previous records. and golden trouts), O. clarkii (Lahontan cutthroat trout from Lake Tahoe), or Salvelinus confluentus (bull trout). During this era, the only collection record for salmon reported by Evermann and Clark (1931) was of specimens of O. quinnat (=O. tshawytscha) taken by Stone at the McCloud River near the site of the Baird Hatchery (Bean, 1880). Equally important, scientific effort was focused almost exclusively in the San Francisco Bay area, the Sacramento Valley, and the Sierra Nevada. The coastal watersheds of California outside of the San Francisco Bay area were essentially unexplored, with only isolated records of salmonids from Humboldt Bay, the Mendocino Coast, and the Ventura River in southern California having been reported, with none of those collections involving $\mathrm{Pa}$ cific salmon (Fig. 3). The collection of Chinook salmon from the McCloud River stood as the only documented record of any of the Pacific salmon species in California. Obviously, fishermen were aware of the presence of salmon in California, as commercial fishing on the Sacramento had begun in the 1850's (Collins, 1892) and accelerated with the advent of canning technology pioneered by Hume and Company (McEvoy, 1986). Nevertheless, whatever local knowledge of different salmon species may have existed at the time, it had not made its way into the scientific literature before the 1880's.

\section{Salmonid Taxonomy and Nomenclature: 1850-1879}

In addition to being a period of limited scientific exploration, the pre1880 era was also a period of tremendous confusion with respect to the taxonomy and nomenclature of the $\mathrm{Pa}$ cific salmonids. The five species of $\mathrm{Pa}$ cific salmon were originally described by German naturalist Georg Wilhelm Steller based on observations made in Kamchatka during the 1700's. ${ }^{8}$

\footnotetext{
${ }^{8}$ Jordan (1892b) implied that the Steller's original descriptions of the five Pacific salmon species were based on observations made in Alaska circa 1731; however, this is incorrect. Steller was in fact present on Russia's American Expedition
} 
The Russian vernacular names given by Steller were adopted by Walbaum as scientific names in 1792 (Jordan, 1888). However, over the next 90 or so years, this taxonomic clarity disintegrated, as numerous putative species were described in North America based on variations in morphology due to sex, life stage, and breeding condition. Jordan (1888) described the resulting taxonomic chaos as follows:

"Since Steller's time, writers of all degrees of incompetence, and writers with scanty material or with no material at all, have done their worst to confuse our knowledge of these salmon, until it became evident that no exact knowledge of any of the species remains. In the current system of a few years ago, ${ }^{9}$ the breeding males of the five species known by Steller constituted a separate genus of many species (Oncorhynchus Suckley); the females were placed in the genus Salmo, and the young formed still other species of a third genus, called Fario, supposed to be a genus of trout. The young breeding males (grilse) of one of the species (Oncorhynchus ner$k a$ ) made still a fourth genus, designated as Hypsifario. Not one of the writers on these fishes of twenty-five years ago knew a single species definitely, at sight, or used knowingly in their descriptions a single character by which species

(June 1741-August 1742); however, the expedition did not reach Alaska (Kayak Island) until July 1741, and Steller spent just ten hurried hours on the island, primarily collecting plant specimens (Ford, 1966; Littlepage, 2006). Although Steller did report finding dried "red salmon" in a Native American "cellar" on the island and concluded that they were the same species as the "nerka" of Kamchatka, his brief stay on the island was clearly not the basis for his Pacific salmon descriptions, which include not only the characteristics of various species, but aspects of their life histories as well. Rather, Steller's descriptions likely resulted from observations that both he and his assistant, Stepan Krasheninnikov, made in Kamchatka both before and after the American Expedition. Steller died before he was able to publish these descriptions, but they were published subsequently by Krasheninnikov (1764).

${ }^{9}$ Jordan inserted a footnote referencing the report of the U.S. Pacific Railroad Explorations, 1858.

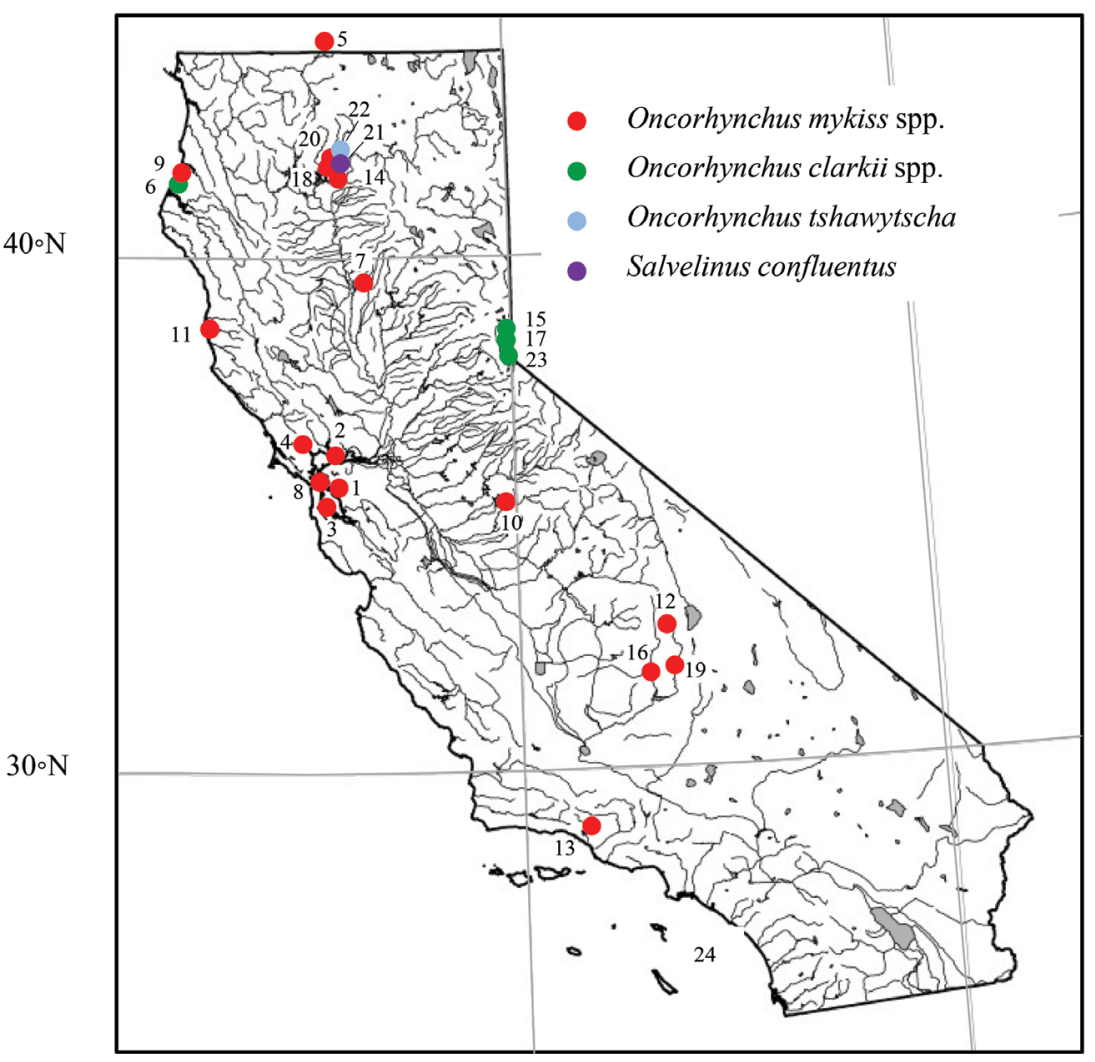

Figure 3.-California locations where scientific collections of salmonids were made in the period from 1850 to 1879 . Numbers correspond to observations in Supplemental Table S1.

are really distinguished. Not less than thirty-five nominal species of Oncorhynchus have already been described from the North Pacific, although, so far as is now known, only the five originally noticed by Steller really exist. The descriptive literature of the Pacific salmon is among the very worst extant in science. This is not, however, altogether the fault of the authors, but it is in great part due to the extraordinary variability in appearance of the different species of salmon. These variations are, as will be seen, due to several different causes, notably to differences in surroundings, in sex, and in age, and in conditions connected with the process of reproduction."

Although not explicitly acknowledged in this paper, the primary target of Jordan's scathing indictment was George Suckley, a surgeon and naturalist appointed to the Pacific Railroad Survey of the 47th and 49th parallels. Suckley inherited the task of preparing a report (Suckley, $1874^{10}$ ) on the salmon and trout based on work of Caleb Burwell Rowan Kennerly. Kennerly was likewise a physician and naturalist who participated in both the Pacific Railroad and Northwestern Boundary surveys but who died in 1861 before completing his report. Suckley's report described no fewer than 27 nominal species of salmon and trout in rivers that drain into the Pacific Ocean, including 17 he classified as anadromous "salmon" (Table 1). ${ }^{11}$

\footnotetext{
${ }^{10}$ Suckley's report was written in 1861 , but was not formally published until 1874 , five years after his death.

${ }^{11}$ Jordan did call out Suckley by name in a subsequent paper (Jordan 1892b), saying that Suck-
} 
Table 1.-Putative salmon and trout "species" identified in Suckley (1874) ${ }^{1}$ for waters draining to the Pacific Ocean. ${ }^{2}$

\begin{tabular}{|c|c|c|c|}
\hline Scientific name & Common names & Location & Modern identification \\
\hline \multicolumn{4}{|c|}{$\begin{array}{l}\text { I. Anadromous salmon: species running up into fresh water to spawn; the young remaining there for a greater or less time, then returning to the sea, in which they continue to abide, } \\
\text { except during the period of reproduction (Salmon.) }\end{array}$} \\
\hline \multicolumn{4}{|c|}{ a. Intermaxillaries of males long, decurved, projecting, and hooking downward considerably beyond the top or knob of the lower jaw (Subgenus Oncorhynchus) } \\
\hline 1. Salmo scouleri, Richardson & Hook-nosed salmon; fall salmon & Pacific Coast & O. gorbuscha, O. kisutch \\
\hline 2. Salmo proteus, Pallas & Hump-backed salmon & Alaska Coast & O. gorbuscha \\
\hline 3. Salmo cooperi, Suckley & Cooper's salmon; little red salmon; [Ta-ah-nia] & Columbia River & O. tshawytscha, O. nerka ${ }^{3}$ \\
\hline 4. Salmo dermatinus, Richardson & [red-fish, tleukh-ko] & Bering Sea & O. keta \\
\hline 5. Salmo consuetus, Richardson & & Yukon River & O. keta \\
\hline 6. Salmo canis, Suckley & Dog salmon, spotted salmon, [Le Kai] & Puget Sound & O. keta \\
\hline \multicolumn{4}{|c|}{ b. Jaws of adult males when fresh-run, symmetrical and either subequal or the point of the lower jaw received in a notch between premaxillaries. } \\
\hline 8. Salmo quinnat, Richardson & The California salmon & West Coast of U.S. & O. tshawytscha \\
\hline 9. Salmo confluentus, Suckley & Towatl salmon & Northwest Coast & O. tshawytscha \\
\hline 10. Salmo aurora, Girard & Red-char; salmon & Columbia River & O. clarkii \\
\hline 11. Salmo argyreus, Girard & & West Coast & O. tshawytscha \\
\hline 12. Salmo paucidens, Richardson & Weak-toothed salmon & Fraser River & O. nerka \\
\hline 13. Salmo tsuppitch, Richardson & White salmon; silvery-white Salmon trout & Columbia River & O. kisutch, O. clarkii henshawi \\
\hline 14. Salmo clarkii, Richardson & Clark's salmon & Columbia River & O. clarkii \\
\hline 16. Salmo gairdneri, Richardson & Gairdner's salmon & Columbia River & O. mykiss \\
\hline 17. Salmo truncatus, Suckley & The short-tailed salmon & Columbia River & O. mykiss \\
\hline 18. Salmo richardi, Suckley & Richard's salmon; Suk-kegh salmon & Fraser River & O. tshawytscha, O. nerka ${ }^{3}$ \\
\hline \multicolumn{4}{|c|}{ t+Spotted with red; feeding freely in fresh water } \\
\hline 19. Salmo campbelli, Suckley & Campbell's salmon & Columbia River & Salvelinus malma or confluentus \\
\hline \multicolumn{4}{|c|}{ II. Non-anadromous species (not running up from the sea, but living entirely in freshwater or only occasionally passing down to sea. [Trout]). } \\
\hline \multirow{2}{*}{\multicolumn{4}{|c|}{$\begin{array}{l}\text { c. Spotted with red or black; found in flowing fresh water; feeding, spawning, and spending the greater part of the year in the same; retiring to deep, still water in the winter; access } \\
\text { to salt water usually relishes, but not indispensable. }\end{array}$}} \\
\hline $\begin{array}{l}\text { t†Black-spotted } \\
\text { 26. Salmo iridea, Gibbons }\end{array}$ & Pacific brook-trout & California streams & \\
\hline 27. Salmo masoni, Suckley & Mason's trout & Columbia River & O. mykiss irideus \\
\hline 29. Salmo lewisi, Girard & Missouri trout & Rocky Mtn slopes N. of South Pass & O. clarkii \\
\hline 30. Salmo brevicauda, Suckley & Short-tailed trout & Puget Sound waters & O. clarkii \\
\hline \multicolumn{4}{|c|}{ d. Trout found in deep rivers or lakes, ascending shallow streams to spawn } \\
\hline${ }^{\dagger}$ Black-spotted & & & \\
\hline 31. Salmo gibbsii, Suckley & Columbia salmon trout & Columbia River & O. mykiss gairdneri ${ }^{4}$ \\
\hline 33. Salmo kennerlyi, Suckley & Kennerly's trout; Chiloweyuk red salmon-trout & Chiloweyuck Lake; Fraser's River & O. nerka \\
\hline $\begin{array}{l}\text { 34. Salmo warreni, Suckley } \\
\text { t'Red-spotted }\end{array}$ & Warren's trout & Fraser's River & O. tshawytscha (immature) \\
\hline 35. Salmo bairdii, Suckley & Baird's trout; red-spotted Rocky Mtn. trout & Clark's Fork, Columbia River & S. confluentus \\
\hline 36. Salmo parkii, Suckley & Parker's River trout & Kootenay River; Rocky Mtns. & S. confluentus \\
\hline \multicolumn{4}{|l|}{ e. Lake trout: passing lives in deep fres } \\
\hline 43. Salmo newberryi, Girard & Newberry's salmon & Klamath River & O. mykiss newberrii \\
\hline
\end{tabular}

${ }^{1}$ Numbers, as well as spellings of species and geographic locations, are as they appear in Suckley (1874:92-94); species not found on West Coast of North America are omitted.

${ }^{2}$ Redeterminations of species come primarily from Jordan and Evermann (1896), with some corrections based on modern knowledge of species distributions.

${ }^{3}$ Salmo cooperi and Salmo richardi have both been considered synonyms for O. tshawytscha and O. nerka.

${ }^{4} \mathrm{Salmo}$ gibbsii is considered a synonym for O. mykiss gairdneri (Behnke, 2002).

Eventually, these so-called salmon were determined to include a mixture of the five species currently recognized as Pacific salmon (O. gorbuscha, O. keta, O. kisutch, O. tshawytscha, and $O$. nerka), as well as anadromous forms of Pacific trout and char, including O. mykiss, O. clarkii, Salvelinus malma, and $S$. confluentus. Additionally, Suckley identified ten putative non-anadromous "species," several of which were later determined to be immature forms of salmon or steelhead. In their defense, Suckley and Kennerly had a limited number of specimens to

ley "succeeded in carrying the confusion to an extreme, making as many as three genera from a single species of salmon, founded on differences of age and sex." work with, many of which were simply dried skins or specimens damaged by alcohol (Anonymous, 1880).

Resolving the taxonomy of the Pacific salmon complex became a priority of the newly formed U.S. Fish Commission (USFC), to which Baird was appointed as the first Commissioner (Rivinus and Yousef, 1992). Baird (1874) championed the need for improved understanding of the taxonomy and distributions of Pacific salmon species as follows:

"The western salmon (Salmo quinnat $\left.{ }^{12}\right)$ - It is on the West

${ }^{12}$ The question mark following the scientific name is present in Baird's 1874 report and indicates the prevailing uncertainty about whether
Coast of North America alone that salmon occur in anything like the numbers which formerly prevailed in the East, though the species are entirely distinct and peculiar to the Pacific. The waters of California, Oregon, and British Columbia boast of the possession of several kinds, how many of which has not been ascertained, as the different ages and sexes of one have in many instances been described as two or more totally distinct species. One of the objects of the Fish Commission is to solve the problem in question, by securing spec-

the numerous "varieties" of Pacific salmon were all members of the same species. 
imens of all ages and both sexes from all North American localities, and, by critical investigation and comparison, to determine precisely the limitations and relationships of each kind."

Baird asked Jordan to take on this task in 1877 (Jordan, 1922). Jordan's initial work was based on specimens that were collected during the Pacific Railway Survey of the 1850's and housed at the United States National Museum of Natural History (USNM) at the Smithsonian Institution, as well as subsequent collections, the most noteworthy of which were those made at a new hatchery on the Clackamas River in Oregon (described in Jordan, 1878b; Jordan, 1922). Jordan published what he called his "tentative conclusions" about Pacific salmon taxonomy a year later in A Catalogue of the Fishes of the Fresh Waters of North America (Jordan, 1878a). In this book, Jordan recognized five putative species of Oncorhynchus: Oncorhynchus gorbuscha (Walbaum), O. keta (Walbaum), O. quinnat (Richardson; $=O$. tshawytscha), O. nerka (Walbaum), and $O$. kennerlyi $($ Suckley; $=O$. nerka $)$. The latter two "species" were eventually resolved to be the same, $O$. ner$k a$, with $O$. kennerlyi being the landlocked form of sockeye salmon known as "kokanee."

The geographic ranges for $O$. gorbuscha, O. keta, and O. nerka were listed simply as "North Pacific coasts of Asia and America," with the distribution of "O. quinnat" described as the "Coasts of California to British Columbia." Curiously, the range of $O$. kennerlyi is described as "Sacramento River to British Columbia." It is unclear what records of this species led Jordan to conclude it occurred in California, though Jordan (1878b) did remark that the kennerlyi he examined bore resemblance to quinnat salmon; thus, this was perhaps a case of misidentification. ${ }^{13}$

\footnotetext{
${ }^{13}$ Jordan references Suckley in his description of O. kennerlyi; however, Suckley (1874) reports the known localities of $O$. kennerlyi as being Chiloweyuck Lake (likely Chilliwack Lake) and "Fraser's River," both in British Columbia. Sucke-
}

Notably absent from Jordan's 1878 list was $O$. kisutch. Interestingly, Jordan did assign the name Salar tsuppitch to fish that were eventually determined to be $O$. kisutch. The genus $\mathrm{Sa}$ lar included what Jordan referred to as the "Salmon trout," which contained representatives of both the modern $O$. mykiss and $O$. clarkii complexes. In a second paper (Jordan, 1878b), he referred to Salar as a subgenus of the genus Salmo, and called Salmo tsuppitch the "Black Trout of Lake Tahoe," apparently believing it was the same species as both Lahontan cutthroat trout (O. clarkii henshawi) from the Lake Tahoe Basin and O. mykiss from the Kern river drainage. Shortly thereafter, in a letter to Forest and Stream, Jordan (1880) added the name $O$. tsuppitch to the list of Oncorhynchus species, noting that he and Theodore Gill had earlier assigned the name "tsuppitch" to a different fish, which turned out to be "the same as Salmo clarki." Curiously, O. keta is absent from Jordan's 1880 list, despite its mention in the 1878 paper.

From the writings of Jordan between 1878 and 1880, we can see that although all five species of semelparous Pacific salmon occurring in the Pacific Northwest had at various times been identified, there remained lingering uncertainty about how many species were truly present. Moreover, it is abundantly clear, both from the paucity of collection records in California and the lack of complete, unambiguous descriptions of the Pacific salmon species (and particularly coho salmon), that the scientific basis for defining the ranges of Pacific salmon species even in the most general terms was simply lacking at this time.

\section{The 1880 Pacific Coast Expedition}

In 1880, Jordan, accompanied by his assistant and graduate student Gilbert,

ly also reported $O$. kennerlyi under the heading "Species not anadromous, nor running up from the sea, but living entirely in fresh water or only occasionally passing down to the sea." This suggests these were kokanee salmon, though many of Suckley's designations of anadromous versus non-anadromous later proved to be incorrect, so we cannot be certain. undertook an extensive exploration of the fish fauna along the Pacific Coast of North America from San Diego, Calif., to the mouth of the Fraser River, B.C. Jordan was approaching his 29th birthday when the expedition departed; Gilbert had just turned 20. The expedition was initiated at the request of the U.S. Census Bureau in cooperation with the U.S. Fish Commission under the direction of Baird. Including the return trip to San Francisco, the journey took roughly 7 months to complete and, according to Evermann (1930), resulted in "the discovery and describing of more new species than any fishery survey previously made." It remains one of the most remarkable achievements in the history of North American ichthyology. By Jordan's (1922) account, roughly 400 different species were collected, about 80 of which were not previously known to science. ${ }^{14}$ Most of these specimens were shipped to the USNM, where many still reside.

Shortly after the expedition, Jordan and Gilbert (1881a) published Notes on the fishes of the Pacific Coast of the United States, which provided brief descriptions of all known species (including the Pacific salmonids) and their geographic distributions. This marks the first of Jordan and Gilbert's writings that recognized all five species of Pacific salmon found in western North America and correctly assigned them to the genus Oncorhynchus.

It is tempting to assume that information gleaned during the 1880 expedition provided Jordan and Gilbert with a solid scientific basis for establishing the historical spawning distributions of Pacific salmonids along the coast of California, Oregon, and Washington. However, closer scrutiny of the details of the expedition reveals that, for several reasons, this is not

\footnotetext{
${ }^{14}$ It is not entirely clear how Jordan (1922) arrived at these numbers. The list of Pacific Coast fishes compiled by Jordan and Gilbert (1880) contains 270 unique species, of which 262 were observed on the 1880 expedition and 44 were identified as new species; however, it is clear that further splitting of taxa occurred following publication of the 1880 list, which may account for the difference. Regardless, the expedition was clearly a watershed event in the history of North American ichthyology.
} 
likely the case. Foremost, the expedition was focused almost exclusively on marine fishes. Indeed, the specific charge given to Jordan was "... to visit or communicate with every post office within five miles of the coast of California, Oregon, and Washington, to list the various species of fishes and other marine animals [emphasis added] inhabiting adjacent waters, and to report on their habits, food, and value; also to describe in detail the past, present, and probable future of all industries related to the sea" (Jordan, 1922).

The emphasis on marine species is clearly evident in the $\sim 555$ specimen jars attributable to the Pacific Coast Expedition that are currently housed at the USNM (Supplemental Table S2). Of these lots, only 36 were reported as collected from fresh waters, with all but two of these freshwater specimens taken from the lower Sacramento, Columbia, and Fraser rivers. ${ }^{15}$ The USNM electronic database lists 25 collections of Pacific salmonids from the 1880 expedition, and the original USNM ledger identifies another 11 salmonid records from the expedition that have since been lost or destroyed.

Of the 36 total salmonids, 16 were identified as collected from fresh water ${ }^{16}$, including Chinook, coho, chum, and sockeye salmon from the Fraser River; Chinook, sockeye, and pink salmon, as well as steelhead and cutthroat trout, from the Columbia River ${ }^{17}$; Chinook, coho, chum, and pink

\footnotetext{
${ }^{15}$ The two freshwater collections outside of the Fraser, Columbia, and Sacramento rivers include specimens originally identified as Cypriniodon californiensis (=Cypriniodon macularius) from the desert east of San Diego, and Salmo irideus $(=O$. mykiss irideus) collected from the San Luis Rey River. The latter specimen has no collection date but is presumed to be the basis for Jordan and Gilbert's (1881a) description that lists the species as far south as the San Luis Rey River. Another four freshwater collection records are listed in the USNM ledger, but are not in the electronic database due to the fact that the specimens were lost or destroyed (USNM 27307, 27308, 27352, and 27358); all of these were from the Columbia and Sacramento rivers.

${ }^{16}$ Although listed as "fresh water" specimens, the collection localities of Astoria, and the lower Sacramento and Fraser rivers are within the zone of tidal influence.

${ }^{17}$ Jordan and Gilbert's (1880) table also lists $O$. kisutch from the Columbia River, but no record was found in the USNM database or ledger.
}

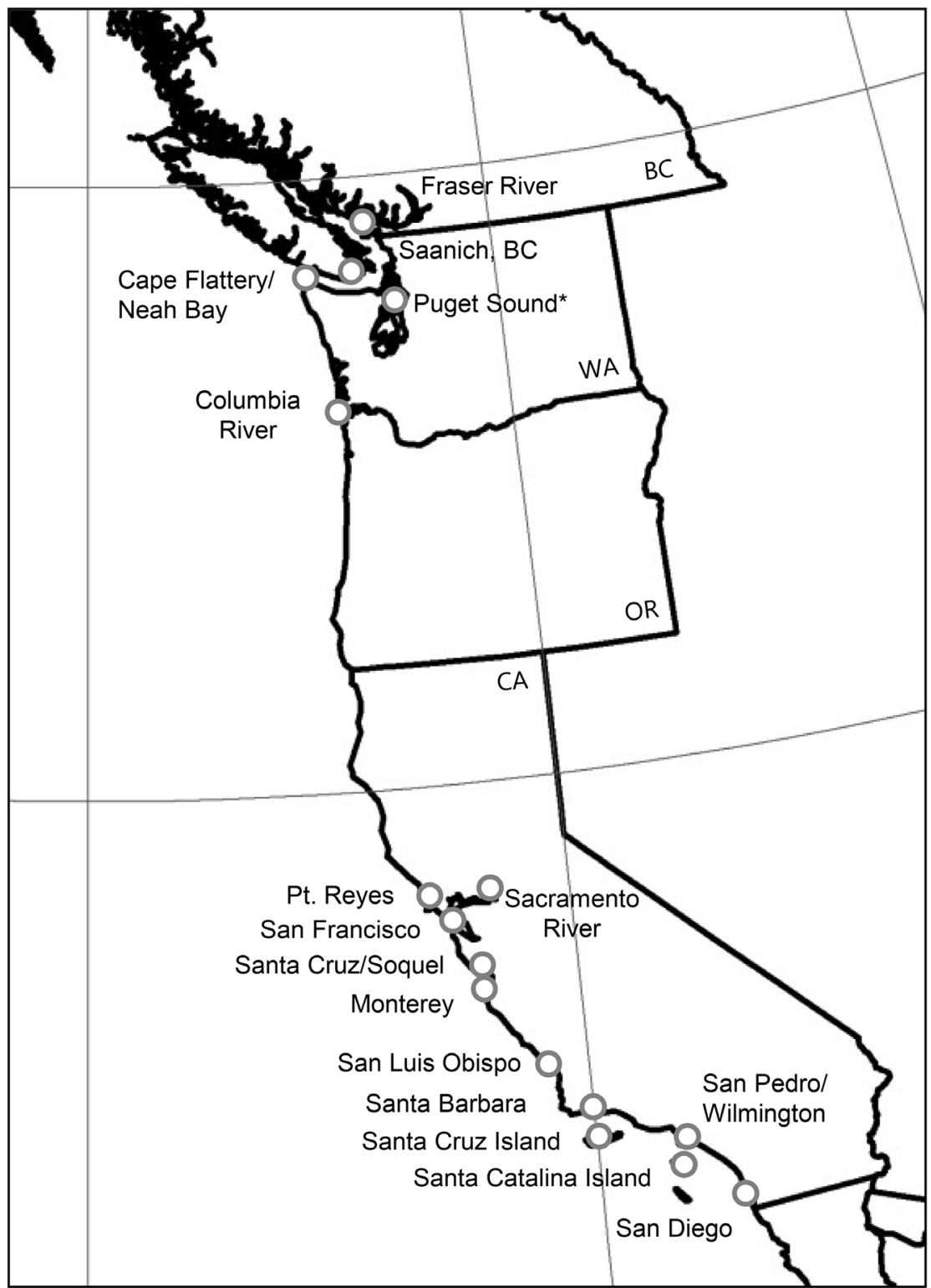

Figure 4.-Locations visited by David Starr Jordan and Charles Henry Gilbert during the 1880 Pacific Coast Expedition from San Diego to the Fraser River. Gray dots indicate ports and locations where samples were collected. *Jordan and Gilbert sampled 7 locations within Puget Sound between Port Townshend and Olympia.

salmon from the Sacramento River; and $O$. mykiss from the San Luis Rey River. ${ }^{18}$ All remaining salmonids in

${ }^{18}$ USNM-26795 is undated but is listed as having been collected by David Starr Jordan in the San Luis [Rey] River near San Diego. Given that Jordan wrote about $S$. irideus in the San Luis Rey River in 1881, it seems likely that this specimen was collected during the 1880 expedition, though curiously it is not listed in Jordan and Gilbert (1880), which catalogs all species obtained on the collection were apparently taken at sea (Table 2; Supplemental Table S3).

Equally important from the perspective of establishing the southern limits of the spawning distributions of $\mathrm{Pa}$ cific salmonids is that fact that Jordan

the expedition and their collection locations. Jordan does, however, mention stopping at Mission San Luis Rey while en route to San Diego (Jordan, 1922). 
Table 2.-Salmonids collected during Jordan and Gilbert's 1880 Pacific Coast Expedition as listed in Jordan and Gilbert (1880), with notes from USNM ichthyology database and collection ledger. $m$ = specimens from marine waters; $f=$ specimens from fresh waters; $u$ - uncertain if marine or freshwater collection.

\begin{tabular}{|c|c|c|c|c|c|c|c|c|c|c|}
\hline No. & Scientific name assigned by Jordan and Gilbert & Accepted scientific name (AFS) & 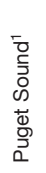 & 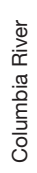 & 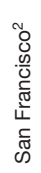 & 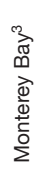 & 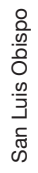 & 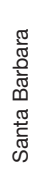 & 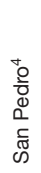 & 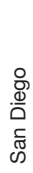 \\
\hline 210 & Salvelinus malma (Walbaum) Jordan \& Gilbert & Salvelinus confluentus/Salvelinus malma ${ }^{5}$ & $\mathrm{~m}$ & $f$ & & & & & & \\
\hline 211 & Salmo purpuratus Pallas & Oncorhynchus clarkii/Oncorhynchus mykiss & $\mathrm{m}$ & $f$ & $u^{6}$ & $u^{6}$ & & & & \\
\hline 212 & Salmo irideus Gibbons & Oncorhynchus mykiss irideus & & & & $\mathrm{m}$ & & & & $f^{7}$ \\
\hline 213 & Salmo gairdneri Richardson & Oncorhynchus mykiss & u & f & u & $\mathrm{u}$ & & & & \\
\hline 214 & Oncorhynchus kennerlyi (Suckley) Jordan & Oncorhynchus nerka & $\mathrm{u}$ & f & & & & & & \\
\hline 215 & Oncorhynchus gorbuscha (Walbaum) Gill \& Jordan & Oncorhynchus gorbuscha & u & $f$ & $f$ & & & & & \\
\hline 216 & Oncorhynchus keta (Walbaum) Gilbert \& Jordan & Oncorhynchus keta & $\mathrm{mf}$ & $\mathrm{f}$ & $\mathrm{mf}$ & & & & & \\
\hline 217 & Oncorhynchus kisutch (Walbaum) Jordan \& Gilbert & Oncorhynchus kisutch & $f$ & f & $\mathrm{mf}$ & & & & & \\
\hline 218 & Oncorhynchus tshawytscha (Walbaum) Jordan \& Gilbert & Oncorhynchus tshawytscha & $\mathrm{mf}$ & $f$ & f & $\mathrm{m}$ & & & & \\
\hline 219 & Oncorhynchus nerka (Walbaum) Gilbert \& Jordan & Oncorhynchus nerka & $f$ & f & & & & & & \\
\hline
\end{tabular}

${ }^{1}$ Puget Sound includes multiple sites in the Sound, as well as Cape Flattery, Neah Bay, and Fraser River.

${ }^{2}$ San Francisco includes Point Reyes and Sacramento River.

${ }^{3}$ Monterey includes Santa Cruz and Soquel.

${ }^{4}$ San Pedro includes Wilmington and Santa Catalina Island.

${ }^{5}$ The distinction between S. confluentus and S. malma had not been recognized, and as the distribution of the two species overlaps in the Puget Sound Region, it is possible that Jordan's samples included either or both species. The specimens from the Columbia River are most likely S. confluentus, as S. malma is not known to occur in the basin.

${ }^{6}$ The diagnostic characteristics (namely, presence of basibranchial teeth) used by Jordan to classify trout species do not reliably discriminate between O. mykiss and O. clarkii. The specimens from San Francisco and Monterey Bay reported as Salmo purpuratus were almost certainly O. mykiss, as the southern-most extent of O. clarkii appears to be the Eel River basin in northern California (Behnke, 2002).

${ }^{7}$ Specimen is in USNM collection (USNM 26795), but San Diego was not listed as collection locality in Jordan and Gilbert (1880) table.

and Gilbert did not make any collections - either freshwater or marine-in the region from Point Reyes, Calif., to Astoria, Oreg., near the mouth of the Columbia River, an expanse of nearly $1,000 \mathrm{~km}$ of coastline (Fig. 4). Jordan (1922:222) wrote in his autobiography that "After a fairly thorough investigation of the marine interests of San Francisco and neighboring waters ${ }^{19}$, we went in May directly to Astoria, the great salmon center of our coast at the mouth of the Columbia." The bypassing of the northern California Coast and virtually all of coastal Oregon is affirmed by the lack of any specimens from this region in the USNM collections associated with the expedition (Supplemental Table S3), as well as in Jordan and Gilbert's detailed table listing of localities for all species collected on the expedition (Jordan and Gilbert, 1880; Supplemental Table S4). ${ }^{20}$

\footnotetext{
${ }^{19}$ In addition to surveying the waters of San Francisco Bay and the lower Sacramento River, Jordan also made marine collections near Point Reyes, about $50 \mathrm{~km}$ north of the Golden Gate.

${ }^{20}$ Jordan and Gilbert (1881a) describes a few non-salmonid species as occurring from Cape Mendocino southward, or in Humboldt Bay; however, these geographic references appear to be obtained from fishermen or other sources. Jordan
}

This table identifies the primary sampling localities as San Diego, San Pedro/Wilmington (including the Channel Islands), Santa Barbara, San Luis Obispo, Monterey, San Francisco (including Pt. Reyes), the Columbia River, and several locations within the Puget Sound and Strait of Juan de Fuca region. Consequently, while the expedition did yield some information on the coastal distribution of Pacific salmonids, the spatial extent of freshwater collections by Jordan and Gilbert was clearly insufficient to rigorously define the freshwater ranges of any salmonid species on the west coast of North America, contrary to what has been implied by others (Kaczynski and Alvarado, 2006). ${ }^{21}$

and Gilbert typically wrote "seen by us at [geographic location]" when they themselves collected specimens on the 1880 expedition. The lack of any USNM collection records from these localities supports this interpretation.

${ }^{21}$ In addition to incorrectly concluding that Jordan's Pacific Coast Expedition involved significant surveys of freshwater systems, Kazcynski and Alvarado (2006) also imply that additional surveys of stream systems were conducted in California in $1889,1892,1904$, and 1908, citing an article by Thompson (1922). Thompson's article, however, makes no references to surveys involving fresh waters. In fact the article is devoted
In addition to the limited sampling of fresh waters and critical spatial gaps in the sampling of the Pacific Coast expedition, the timing of the Pacific Coast expedition was such that it is unlikely that Jordan and Gilbert would have directly encountered any fall-spawning salmon species in streams and rivers. The expedition departed from San Diego in January and did not arrive in Monterey until late March (Jordan, 1922). The party then traveled to San Francisco Bay, where it remained until May. After exploring the area in and around San Francisco Bay, the expedition travelled directly to Astoria, where it remained until early June, before heading north to the Puget Sound region (Jordan, 1922; Pietsch and Dunn, 1997). In California, the migration and spawning season for fall-spawning Pacific salmon species is typically over by early winter, which suggests that whatever information they obtained about the spawning distributions of pink, chum, coho, sockeye, or fall-run Chinook salmon in California was not based on first-hand

to the development of California's marine fisheries and excludes Pacific salmon entirely. 
observations. Jordan and Gilbert routinely spoke with local fishermen and cannery workers during the expedition and, in fact, obtained many specimens either directly from fishermen or by purchasing them at local fish markets (Pietsch and Dunn, 1997). It is thus likely that their perceptions regarding species ranges were influenced by these anecdotal accounts.

In September of 1880, the expedition ended and Jordan returned to Indiana (Jordan, 1922). Less than three months later, he and Gilbert published their tabular list of species from the Pacific Coast (Jordan and Gilbert, 1880), followed within a year by Notes on the Fishes of the Pacific Coast of the United States (Jordan and Gilbert, 1881a), which included species range descriptions for the Pacific salmonids (Table 3). Clearly, information from the expedition shaped these descriptions.

For four of the five Pacific salmon species, the southern extent of the reported distribution is directly traceable to observations made on the 1880 expedition. Jordan and Gilbert's (1881a) statement that coho salmon occur from the "Sacramento River to Puget Sound and northward" likely emanates from the fact that they reported collecting coho salmon in the marine waters near San Francisco (USNM 27222), as well as in the Sacramento River (USNM 2725022). Their description of pink salmon as "occasionally seen in the Columbia and Sacramento, but not sufficiently abundant to constitute a distinct run" likely reflects the reported collection of an adult pink salmon in the Sacramento River (USNM 27249). ${ }^{23}$ Likewise, the conclusion that chum salmon occur as far south as San Francisco ap-

\footnotetext{
${ }^{22}$ This latter record comes from the USNM ledger; it is not present in the USNM electronic database.

${ }^{23}$ This collection record is somewhat puzzling. The specimen is an adult male in reproductive condition, yet Jordan and Gilbert did not arrive in San Francisco until sometime around April, an unlikely time to encounter a mature male in freshwater. Most likely, the specimen was collected and preserved earlier in the year by a third party and presented to Jordan when he arrived in San Francisco.
}

Table 3.-Description of Pacific salmon species ranges given in Jordan and Gilbert (1881). Spellings and capitalization are as found in Jordan and Gilbert. Modern scientific name in square brackets if different from historical name.

\begin{tabular}{|c|c|}
\hline Species (common names) & Range description \\
\hline $\begin{array}{l}\text { Oncorhynchus gorbuscha } \\
\text { (Humpback Salmon; Haddo; Hone; Holia) }\end{array}$ & $\begin{array}{l}\text { Sacramento River northward to the Arctic Sea; abundant in Puget } \\
\text { Sound on alternate years, } 1880 \text { being a year of scarcity. } \\
\text { Occasionally seen in the Columbia and Sacramento, but not } \\
\text { sufficiently abundant to constitute a distinct run. }\end{array}$ \\
\hline $\begin{array}{l}\text { Oncorhynchus keta } \\
\text { (Dog salmon; Quarlsch; Kayko; Le Kai) }\end{array}$ & $\begin{array}{l}\text { San Francisco to Behring's Straits; very abundant in fall when it runs } \\
\text { in all streams, but not to great distance. Not seen by us anywhere in } \\
\text { the spring. }\end{array}$ \\
\hline $\begin{array}{l}\text { Oncorhynchus kisutch } \\
\text { (Coho salmon of Frazer's River; } \\
\text { Silver Salmon; Kisutch; Bielaya Ryba) }\end{array}$ & $\begin{array}{l}\text { Sacramento River to Puget Sound and northward; very abundant in } \\
\text { summer and fall. It is rarely taken in the Columbia in the spring, but } \\
\text { great numbers run up the river in the fall. }\end{array}$ \\
\hline $\begin{array}{l}\text { Oncorhynchus chouicha [tshawytscha] } \\
\text { (Quinnat Salmon; King Salmon; Chouicha; } \\
\text { Chinook Salmon; Spring Salmon; } \\
\text { Columbia River Salmon; Sacramento Salmon; } \\
\text { Winter Salmon; White Salmon). }\end{array}$ & $\begin{array}{l}\text { From Ventura River northward to Behring's Straits, ascending } \\
\text { Sacramento, Rogue's, Klamath, Columbia, and Frazer's Rivers } \\
\text { in spring, as well as the streams of Alaska, Kamtschatka, Japan, } \\
\text { and Northern China; in fall ascending these and probably all other } \\
\text { rivers in greater or less abundance; the young taken in Monterey Bay, } \\
\text { Puget Sound, etc. in summer in considerable numbers. }\end{array}$ \\
\hline $\begin{array}{l}\text { Oncorhynchus nerka } \\
\text { (Blue-back; Sukkeye; Red-Fish; Rascal; } \\
\text { Frazer's River Salmon; Krasnaya Ryba) }\end{array}$ & $\begin{array}{l}\text { From Columbia River to the Aleutian Islands; the principal salmon } \\
\text { of Frazer's River; unknown in Eel River, Rogue River, and in the } \\
\text { Sacramento. In the Columbia River it is much less abundant than the } \\
\text { Quinnat salmon, and its flesh is less firm and paler. }\end{array}$ \\
\hline
\end{tabular}

pears traceable to the collection of specimens near San Francisco (USNM 27220) and in the Sacramento River (USNM 27358). Neither of these latter specimens is listed in the USNM electronic database; however, both appear in the original USNM ledger. Finally, Jordan and Gilbert's (1881a) description of the range of sockeye salmon "from the Columbia River to the Aleutian Islands" aligns with an 1880 collection record from the lower Columbia River (USNM 27303). For all four of these species, the USNM museum records also match the tabular descriptions provided in Jordan and Gilbert (1880) (Table 2).

The lone instance in which Jordan and Gilberts' (1881a) range description for a salmon species does not match evidence gathered during the 1880 expedition is the assertion that the range of Chinook salmon extended "From Ventura River northward to Behring's Straits." This description is puzzling for several reasons. Foremost, Jordan and Gilbert's detailed accounting of collections made during the 1880 expedition reveals no evidence that Chinook salmon (or any other Pacific salmon) were observed or collected any farther south than Monterey Bay (Jordan and Gil- bert 1880:457)(Table 2). Nor do there appear to be any other pre-1880 records of Chinook salmon from waters south of San Francisco Bay in the USNM collection. Hence, the basis for Jordan and Gilbert's assertion that the range of Chinook salmon extended as far south as the Ventura River remains a mystery.

From an ecological perspective, the Ventura River and other coastal watersheds in southern California seem unlikely habitats for Chinook salmon. At the southern end of the Santa Cruz Mountains near Monterey Bay, the coastal mountains transition from coastal redwood forests to chaparral and oak woodland dominated vegetation characteristic of Mediterranean climates. Watersheds of Ventura and neighboring Santa Barbara counties, some $240-420 \mathrm{~km}$ south of Monterey, experience short winters and receive substantially less precipitation than those north of Monterey, usually in infrequent but intense storms. In the larger watersheds of this region (e.g., Santa Maria, Santa Ynez, Ventura, and Santa Clara river basins), rivers flow across broad coastal plains or through alluvial valleys before reaching the $\mathrm{Pa}$ cific Ocean, and these reaches may go dry or have minimal surface flows 
during summer and fall. ${ }^{24}$ Further, for many of these systems, a sandbar forms at the mouth of the river during the dry season, which precludes fish from migrating to and from the ocean. In drought years, these sandbars may not breach until mid-winter or do so intermittently, posing a challenge for Chinook salmon, which must not only enter streams to spawn in winter, but emigrate to the ocean before the sand bar closes again. ${ }^{25}$ These habitat differences and intermittent ocean connectivity make the notion of persistent populations of Chinook salmon in the Ventura River and other Southern California watersheds highly dubious. ${ }^{26}$

Hubbs (1946) believed that Jordan and Gilbert's (1881a) inclusion of the Ventura River in the range of Chinook salmon was based on an observation made by Evermann; however, Hubbs provided no elaboration on why he thought that to be the case. ${ }^{27}$

\footnotetext{
${ }^{24}$ These conditions have been exacerbated by human activities since the 1800's; however, Beller et al. (2011) present evidence that these channels were intermittent even prior to such disturbances. (Beller, E. E., R. M. Gossinger, M. N. Salomon, S. J. Dark, E. D. Stein, B. K. Orr, T. R. Longcore, G. C. Coffman, A. A. Whipple, R. A. Askevold, B. Stanford, and J. R. Beagle. 2011. Historical ecology of the lower Santa Clara River, Ventura River, and Oxnard Plain: an analysis of terrestrial, riverine, and coastal habitats. Rep. prep. for State Coastal Conservancy. A report of SFEI's Historical Ecology Program, SFEI Publication 461, San Francisco Estuary Inst., Oakland, Calif. (Avail. at http://www.sfei.org/documents/ historical-ecology-lower-santa-clara-river-ventura-river-and-oxnard-plain-analysis-terrest).

${ }^{25}$ Some Chinook salmon juveniles exhibit stream-type life histories where they over-summer in stream habitats and migrate either during the following fall (typically to estuaries) or spring. True "stream-type" life history is typically most common in systems with snowmelt-dominated hydrology. Where observed in rain-dominated systems of California and Oregon, yearling smolts generally comprise a small fraction of total smolts produced (e.g., Sparkman, M. D., R. Park, L. Osborn, S. Holt, and M. Griffin. 2016. Lower Redwood Creek juvenile salmonid (smolt) abundance project, 2004-2015 seasons. CDFW Proj. 2a7, Fish. Restoration Grant Program (Proj. No. P1210322). Calif. Dep. Fish Wildl, N. Reg., 85 p.).

${ }^{26}$ Anadromous O. mykiss do inhabit these watersheds, likely because of greater plasticity in migration and spawning timing (NovemberApril), coupled with greater diversity of life histories (e.g., stream-residency, variability in age at smoltification, and iteroparity).

${ }^{27}$ Evermann apparently met Jordan in 1877 at
} Butler University and subsequently moved to
It may be that local fishermen did occasionally catch a stray Chinook salmon in the river, as their ocean distribution can extend to southern California under certain conditions. Alternatively, fishermen may have reported catching "salmon" in the river that were instead steelhead, which were (and still are) present in the river (Busby et al., 1996; Boughton et al., 2006). Such misidentifications were routine in the late 1800's (see discussion below). And lastly, for reasons that will become apparent in the next section, it is also plausible that fishermen reported catching Chinook salmon in the ocean near Ventura, and that Jordan and Gilbert assumed those fish were salmon and had spawned in nearby rivers. ${ }^{28}$ Indeed, Hubbs (1946) noted that all other records of Chinook salmon from southern California (e.g., Croker, 1930, 1936, among others) were based on fish caught at sea between San Pedro and La Jolla. Other early references that assert Chinook occurrence in the Ventura River appear to be restating Jordan's conclusions, rather than indicative of new observations (e.g., Gill, 1883; Collins, 1892). Despite the lack of corroborating evidence of natural occurrence of persistent Chinook salmon populations in fresh waters south of Monterey Bay, both during the 1880 expedition and in the 138 years since, ${ }^{29}$ the assertion made by Jordan that Chinook salmon

Ventura County from 1879 to 1881 (Jennings, 1997). However, Evermann did not begin his formal education with Jordan until 1881, when he returned to Indiana University (http://researcharchive.calacademy.org/research/library/special/ findaids/evermann.html; http://socialarchive.iath. virginia.edu/ark:/99166/w6n301tx).

${ }^{28}$ In discussing the range of Chinook salmon, Jordan and Gilbert (1881b) comment that the Ventura River is the southernmost river in coastal California that is "not muddy and alkaline at its mouth," which suggests they had some information about putative salmon specific to the Ventura River.

${ }^{29}$ There were documented occurrences of Chinook salmon in both the Ventura and Santa Ynez rivers in southern California; however, these were the result of plantings of hatchery fish (CFGC, 1916). In modern times, occasional stray adults have been reported in Big Creek on the Big Sur Coast (T. Williams, NMFS, Southwest Fisheries Science Center, personal commun., Sep., 2017), as well as the lower reaches of streams in Ventura and Orange counties (Alagona et al., 2012) once spawned as far south as the Ventura River has been repeated countless times in textbooks, journal articles, agency reports, and elsewhere (see e.g., Myers et al., 1998; Behnke, 200230; PFMC, 1999; Quinn, 2005; Gustafson et al., 2007).

In total, it is evident that while the Pacific Coast Expedition was a monumental achievement, the limited spatial extent of freshwater sampling (i.e., largely confined to the Sacramento, Columbia, and Fraser rivers), including the large gap in sampling between San Francisco and the Columbia River, coupled with lack of temporal overlap between the expedition and the primary period of migration and spawning by fall-run species greatly limited what was learned about the spawning distributions of Pacific salmon. Equally important, it is evident that Jordan and Gilbert's (1881a) fundamental conceptualization of a species' range was quite distinct from how modern scientists view this question. Whereas current scientists typically define species ranges in terms of those portions of the landscape where biotic and abiotic conditions permit persistent populations of a given species (see above), Jordan and Gilbert's range descriptions simply reported what they believed to be the full geographical extent encompassing all observations of the organism. Moreover, as will be seen in the next section, the poor understanding of Pacific salmon life histories at the time likely led Jordan and Gilbert to believe that the freshwater and marine distributions of salmon were essentially identical.

\section{State of Salmon Life History Knowledge}

Given the taxonomic uncertainty and confusion surrounding Pacific salmon and the rudimentary understanding of species distributions that prevailed in the late 1800 's, it should

\footnotetext{
${ }^{30}$ Interestingly, although Behnke's (2002) narrative makes mention of Chinook salmon extending as far south as the Ventura River, his map depicting the native range of Chinook salmon extends only as far south as the San Francisco Bay area and San Joaquin River basin.
} 
not be surprising that understanding of the life histories of the salmon species was even worse. Particularly relevant to the question of historical ranges is that fact that Jordan was a staunch opponent of what he termed the "parent stream theory," the idea that salmon have an innate ability to home to their natal streams to spawn. Jordan and Gilbert (1881b) wrote,

"It is the prevailing impression that the salmon have some special instinct which leads them to return to spawn in the same spawning grounds where they were originally hatched. We fail to find any evidence of this in the case of Pacific coast salmon, and we do not believe it to be true. It seems more probable that the young salmon, hatched in any river, mostly remain in the ocean within a radius of twenty, thirty or forty miles of its mouth. These, in their movements about in the ocean, may come into contact with the cold waters of their parent rivers, or perhaps any other river, at a considerable distance from the shore. In the case of the quinnat and the blue-back, their "instinct" leads them to ascend these fresh waters, and in a majority of cases these waters will be those in which the fishes in question were originally spawned."

Jordan's belief that Pacific salmon at sea remained in close proximity to their natal rivers and that they did not possess a homing instinct potentially has significant implications when interpreting his early species range descriptions. Namely, it raises the possibility that had Jordan encountered or heard reports of salmon captured at sea, he may have assumed that they originated from a nearby stream or river. Indeed, this provides one plausible explanation for the purported occurrence of Chinook salmon in the Ventura River, though as noted earlier the presence of occasional straying individuals or misidentification of a large O. mykiss in fresh water are plausible explanations as well.
Of course, we now know that Pacific salmon in the ocean may travel hundreds or even thousands of miles from their natal streams. Jordan dogmatically adhered to his view from 1881 until the early 1920 's, repeating it in numerous publications (Jordan and Evermann, 1896, 1922; Jordan, 1888, 1903, 1904b, 1905, 1907a). Ironically, it was Gilbert, his protégé and co-author on the 1881 paper dismissing the home stream theory, who eventually provided the first compelling scientific evidence in favor of it, demonstrating that fish from different populations exhibited unique early growth patterns on their scales (Dunn, 1996).

Jordan was eventually persuaded by Gilbert's careful work, as acknowledged in Jordan and Evermann (1923). Nevertheless, for the majority of his career, Jordan would have assumed any ocean-caught salmon had nearby origins. He and his contemporaries thus would have considered the southern boundary of marine and freshwater spawning ranges of Pacific salmon species to be identical, plus or minus a few tens of miles. The salient lesson is that, without concrete corroborating evidence of freshwater occurrence of Pacific salmon species, we should view the early freshwater spawning range descriptions of Jordan, Gilbert, and others with appropriate caution.

Other aspects of salmon life histories were also poorly understood. For example, Jordan and Gilbert were under the impression that variation in run timing of species such as Chinook salmon was environmentally induced, rather than a trait of a particular lifehistory type. In 1881, they wrote the following:

"High waters on any of these rivers in the spring is always followed by an increased run of salmon. The canners think, and this is probably true, that salmon which would not have run till later, are brought up by the contact with the cold water. The cause of this effect of cold fresh water is not understood. We may call it an instinct of the salmon, which is another way of ex- pressing our ignorance. In general, it seems to be true that in those rivers and in those years when the spring run is greatest, the fall run is least to be depended on." (Jordan and Gilbert, 1881b)

Virtually identical statements were published by Jordan into the 1890's (e.g., Jordan, 1892a, 1894a, 1896), indicating that the question remained unresolved.

Also in dispute among scientists was the question of whether all salmon die after spawning. Suckley (1874) spoke of spawned out Salmo scouleri $(=O$. gorbuscha) lingering in streams until January, February, and March before suddenly disappearing in April, "probably returning by the spring floods to salt water, although the Indians say that but few return to sea." Conversely, in reference to Salmo proteus (also $=O$. gorbuscha), he stated that "according to the natives of our coast, the hunch-back never returns to the sea after spawning, but dies in freshwater." In his description of Salmo canis $(=O$. keta), Suckley (1874) noted that "They [local Native Americans] say that most of the individuals return to the seas after spawning, many more comparatively than do of the $S$. scouleri."

The debate regarding semelparity in Pacific salmon continued into the 1870 's. Hallock (1877), a sportsman, popular writer, and founder of Forest and Stream magazine, implied that Livingston Stone had definitively resolved the question in studies conducted on the McCloud River, quoting an uncited report in which Stone "settles the question finally, and proved beyond a shadow of a doubt, that all of the thousands of Sacramento salmon that spawned in the McCloud, not one in a hundred returned to the sea alive."31 However, Stone (1880) later responded that Hallock (and others ${ }^{32}$ )

\footnotetext{
${ }^{31}$ Although I was unable to find the report to which Hallock referred, there is text in the U.S. Commission on Fish and Fisheries report for 1873-74 and 1874-1875 that is consistent with Hallock's assertion (USFC, 1876: p. xxiii).

${ }^{32}$ Hallock responded specifically to a letter by Horace Dunn, a salmon fishing enthusiast who
} 
had misinterpreted his findings. Specifically, Stone argued that, while he stood behind his findings of semelparity for Chinook salmon in the McCloud River, he also believed that "the Sacramento salmon which spawn near the sea are, many of them, able to return to salt water." In short, Stone apparently believed that the ability of fish to survive spawning was a function of the distance they needed to travel to their spawning streams, presumably because fish with longer migrations did not have sufficient energy reserves or were too battered by their journeys to survive and successfully return to the ocean.

Jordan and Gilbert (1881b) shared Stone's view that some salmon survived to spawn multiple times. In reference to spring-run Chinook salmon in the Columbia and Sacramento rivers, they wrote the following:

"It is questioned whether these large fishes are: (a.) Those which, of the same age, have grown more rapidly; (b.) Those which are older but have, for some reason, failed to spawn; or (c.) Those which have survived one or more spawning seasons. All of these origins may be possible in individual cases; we are, however, of the opinion that the majority of these large fish are those which have hitherto run in the fall and so may have survived the spawning season previous."

Jordan (1884a) perpetuated the belief that salmon could spawn more than once, quoting the following description of sockeye salmon written by Captain Charles Bendire:

"The only thing as yet which I can't understand is, how do they get rid of the hooked nose and hump after going back to salt water? They surely can't all die after spawning, as sometimes one that weighs as much as ten pounds is caught, and this fish is certainly

(erroneously) argued that "a very large portion of the [Chinook] run return to sea again." older than a five-pounder; and it would not be presuming too much to assert that a Salmon of that size must have made more than one trip to the sea. While in the lake they do not appear to eat anything, and the stomachs of several which I examined were entirely empty. I cannot understand how they get rid of their long hooked nose and hump."

Four years later, Jordan (1888) republished his 1881 descriptions, again asserting that large spring-run "quinnat" salmon in the Columbia and Sacramento rivers likely survived spawning from the previous year. The belief of Jordan and others of this era that Pacific salmon could be repeat spawners may have contributed to published accounts of salmon "returning to the sea in spring" following spawning (e.g., CFC, 1872; Hallock, 1877), though misidentification of steelhead kelts as salmon was likely also a contributing factor.

Even less well understood during this era were the juvenile life stages of Pacific salmonids. In their writings from 1881 and 1894, Jordan and Gilbert rarely discuss the early life history of salmon or steelhead, and what little is written tends to be vague. Regarding salmon, Jordan and Gilbert (1881b) wrote that "The manner of spawning is probably similar for all the species, but we have no data except for any but the quinnat....The young hatch in about sixty days, and most of them return to the ocean during the high water of spring," the latter sentence being repeated in subsequent publications (Jordan, 1888, 1892a, 1894a, 1896). Although one cannot be completely certain, Jordan and Gilbert's language suggests that they believed the majority young salmon went to sea in their first year of life, regardless of species. Hence, they were apparently unaware of life history types where young spend a year or more in fresh waters.

Cloudsley Rutter (1903), a former student of Jordan's who had, by the early 1900's, achieved considerable stature as a fishery biologist (Jennings, 2014), believed that the period of freshwater residence was dictated primarily by the distance a juvenile fish must travel to reach the ocean, rather than being a trait of a particular species or life history type:

"As soon as the yolk-sac has been absorbed, the fish is large enough to swim and eat, and is known as a fry. When this stage is reached, the young of the Pacific salmons begin their migration to salt water. They float down-stream backward, for ease in breathing and catching food....The age at which young Pacific salmon reach the ocean depends, of course, very much on the distance they have to travel. Those that hatch in the head-waters of the Columbia are over fifteen hundred miles from the ocean, and, as they fight the current more strongly with age, are probably nearly a year en route; while those that hatch in Olema creek, near San Francisco, may reach Tomales Bay in a day's travel."

Rutter's description implies that the downstream movement of salmon smolts was primarily a passive process, rather than active directional migration. That there were significant differences in the typical age and timing of outmigration among species or life history types went largely unrecognized. In fact, it was not until the work of Chamberlain (1907) in Alaska that these life history differences began to be fully appreciated. In sections that follow, we will see some examples of where this poor understanding of juvenile life histories contributed to misidentification of species and where those misidentifications contributed to species freshwater range descriptions in California that are either inaccurate or, at best, highly dubious.

\section{What's in a Name?}

Although questions about the freshwater ranges of various Pacific salmon were not definitively answered by the 1880 Pacific Coast Expedition, Jordan and Gilbert did succeed in resolving the long-running confusion re- 
garding the number of Pacific salmon species in western North America. Jordan and Gilbert (1881a) contained descriptions of the five Pacific salmon species known today, as well as a table of meristic traits of each species including average counts of gill rakers, branchiostegal rays, anal fin rays, pyloric caeca, and scales in longitudinal series. ${ }^{33}$ With one exception, the average values of various meristic traits given by Jordan and Gilbert fall within the currently accepted ranges for each species. ${ }^{34}$ Hence, Jordan and Gilbert (1881a) clearly set the table for a better understanding of the distributions of these species along the California Coast.

Yet, despite this significant advance, progress on this front was slow in coming. Exploration of the fish faunas of California's coastal watersheds remained limited for the next 15 years. Scientific publications from the 1880's and early 1890's added but few new collection localities for Pacific salmon in California (Supplemental Table S1; Evermann and Clark, 1931), and most descriptions of species ranges from this era (e.g., Eigenmann, 1890; Jordan, 1894a) tend simply to repeat the range descriptions published in Jordan and Gilbert (1881a).

Further, while Jordan and Gilbert (1881a) clarified the formal taxonomy of Pacific salmon, it is evident that confusion surrounding common names of Pacific salmon and trout continued unabated for decades in both scientific and popular literature. In writings of the 1800 's, the term "salmon" itself is highly ambiguous, as it was commonly used to describe any large, ocean-run salmonid. Many newspaper accounts from the 1800's refer to "salmon" returning to coastal rivers when, based on the timing of these observations, these fish were in all likelihood steel-

\footnotetext{
${ }^{33}$ Gilbert's journal from the expedition contains a handwritten table of meristic traits that matches that published in Jordan and Gilbert (1881a). This table was apparently completed while the expedition was in Puget Sound, near its end.

${ }^{34}$ Jordan and Gilbert listed coho salmon as averaging 10 gill rakers on the upper arch. The range is now given as 6 to 9 (Scott and Crossman, 1973; McPhail and Lindsey, 1970).
}

head (e.g., Anonymous 1885a, 1885b, 1885c, 1886). Even Jordan occasionally slipped into this casual usage. When describing the fisheries of Carmel, $\mathrm{Ca}$ lif., Jordan (1887) wrote the following:

\begin{abstract}
"There is no regular fishing done at Carmelo (sic). In the river of that name, a great many trout are taken and sold in Monterey at 12 1/2 cents a pound. In the spring salmon ascend the river and are taken by the farmers. In the summer the water in the river is low and a bar is formed across its mouth, causing many young salmon to become landlocked. These are easily caught by the farmers and whalers at Carmelo (sic)"
\end{abstract}

The springtime ascent of these supposed "salmon" leaves little doubt that the fish to which Jordan refers were steelhead, as the rain-dominated hydrology of the Carmel River would not have allowed access to spring-run Chinook salmon. Whether Jordan (1887) intentionally used the term "salmon" to describe steelhead or was simply adopting the terminology of local fishermen is unclear, but the latter explanation would seem the more likely, as I can find no other writings where he did not discriminate between salmon and steelhead.

The term "salmon trout" lends to similar confusion. In general, salmon trout was applied to anadromous forms of $O$. mykiss, O.clarkii, and even Salvelinus malma (Jordan and Gilbert, 1881a; Jordan and Evermann, 1896), as well as lake-dwelling interior populations of cutthroat trout $(O$. clarkii henshawi and $O$. clarkii utah) with no access to the sea (e.g., Fremont, 1856). However, references to "salmon trout" in the popular literature and newspapers of this era should be interpreted with caution, as the term may have been misapplied, both accidentally and purposefully.

California fish and game laws were such that it was illegal to fish for "salmon" in streams during certain summer and winter months, and for "trout" during the winter (Anonymous, 1885d). Reports of hundreds of "trout" being caught in local streams during the summer almost certainly included some juvenile salmon, and those of "salmon" being captured during the spring are almost assuredly steelhead. Wrote one Santa Cruz newspaper (Anonymous, 1890):

"The State Board of Fish Commissioners has decided to forward to the authorities at Washington one of the fish commonly known as "salmon trout" and find out whether it is a salmon or trout. This fish has been taken from the water in large quantities at all seasons of the year and the law has been evaded by the fishermen swearing that the fish were young salmon in the closed trout season and full-grown trout in the closed salmon season."

Hence anglers (wittingly or not) were routinely breaking the law, and the newspapers may have been loath to acknowledge wrongdoing by local citizens. Jordan himself was on occasion shipped specimens for species identification in order to determine if they had been captured in violation of fishing regulations (Anonymous, 1885e).

Perhaps no other common name has generated more confusion than the term "dog salmon." Although in modern times, "dog salmon" has generally been reserved for $O$. keta, throughout the 1880's and well into the 1900's, the term was routinely applied by scientists and fishermen to the males of all Pacific salmon species during the fall spawning season (Jordan and Gilbert, 1881b), no doubt due to the elongation of the jaws and development of large canine-like front teeth that occurs as males approach reproductive maturity. In his description of $O$. keta, Jordan (1884a) wrote the following:

"This species, during the period of its run in the fall, generally goes by the name of "Dog salmon," under which name the males of the Silver Salmon [O. kisutch], and even the Quinnat [O. tshawytscha], are often confounded with it." 
This same paper also lists "Dog Salmon" as a common name for $O$. gorbuscha, and in a second paper published the same year, Jordan (1884b) lists "Dog Salmon" as a common name for $O$. nerka (but curiously, not for the other four Pacific salmon species). Thus, between those two publications, Jordan noted that "dog salmon" had been applied to all five species of Pacific salmon.

Other scientists of the era added to the confusion. William N. Lockington, a well-known zoologist and curator of the California Academy of Sciences museum from 1875-1881, switched the common names of $O$. keta and $O$. kisutch, attributing the names "Silverside Salmon" and "Cohoe salmon" to O. keta, and "Dog Salmon" to O. kisutch (Lockington, 1880). Two years later, Lockington (1882) partially corrected his mistake, assigning the common name "silver salmon" to $O$. kisutch, but listing O. gorbuscha as the "dog salmon."

Rutter (1902) describes experiments in which Chinook salmon were introduced into Lagunitas Creek in Marin County (then known as Paper-mill Creek) to determine if fish returned to their natal stream to spawn. Lagunitas Creek was selected by Rutter specifically because it was believed not to support Chinook salmon. Wrote Rutter (1902), "Paper-mill Creek is not suitable for Quinnat salmon, being entirely too small, but it is frequented by Dog salmon and Steelheads." Although there have been occasional reports of chum salmon in Lagunitas Creek over the years, the "Dog salmon" to which Rutter referred were almost certainly coho salmon, as this species has persistently occupied the stream for more than a century (Eigenmann, 1890). ${ }^{35}$ Thus, even among leaders in the scientific community, we find inconsis-

\footnotetext{
${ }^{35}$ Eigenmann (1890) reported that juvenile coho salmon were collected from Lagunitas Creek by Mr. Chas. Ohm in March 1890. Additionally, juveniles collected from the stream by Snyder and his assistants in 1909 currently reside in the U.S. National Museum collection (USNM 75327). These specimens, initially cataloged as Salmo iridea, were only recently determined through genetic analysis to be coho salmon. See Spence et al. (2011) for details.
}

tencies in use of the term "dog salmon" into the 1900's. In fact, even 50 years later, Shapovalov and Taft (1954) in their classic study of Waddell Creek still felt compelled to offer the following clarification:

"One popular misconception that has existed among the various parts of the Pacific Coast is that the hook-nosed salmon, called 'dog salmon' by local residents form a distinct species. Such fish are simply males whose snouts have become hooked and elongated during the spawning season. This phenomenon takes place to a greater or lesser extent in all of the species of Pacific salmons and to some extent in steelhead. A distinct species of salmon, the chum salmon (Oncorhynchus keta), is sometimes also known as dog salmon, but occurs comparatively infrequently in California. Common names applied to the silver salmon are jack salmon (applied seasonally to young males), dog salmon, or hookbill (applied to males with hooked snouts and red sides), coho, and silversides."

Often times, common names were the product of regional usage. Use of the term "silver salmon" is illustrative. Although now most commonly applied to coho salmon, O. kisutch, silver salmon was applied to other species as well. For example, Gibbons (1876) described what he believed to be a new species of salmonid he named Salmo mendocinensis $(=O$. mykiss iride$u s$ ), noting that "When first caught, the females are of a bright silver color; hence, some call them 'silver salmon." He goes on to state that the spawning season for this species commenced "usually in the latter part of March...", consistent with Evermann and Clark's (1931) interpretation that these were steelhead. Likewise, Wakeman (1870: in CFC, 1872) reported "salmon and silver salmon" from 2 to 30 pounds being taken by fishermen in Pescadero and San Gregorio creeks during the months October to March, a window that certainly includes steelhead. A San Francisco-based newspaper (Anonymous, 1889) reporting on a meeting of a sportsmen's club stated the following:

"A member moved to invite the Fish Commissioner to the club meeting. 'My reason,' he said, 'is that they can give us some valuable information on the different kinds of fish. Now, I have been fishing for years, but for the life of me I do not know what a salmon trout actually is. Some call it a salmon trout, some call it a silver salmon, and some call it a steelheaded salmon.",

The quote indicates that some local fishermen referred to steelhead as "silver salmon." The terms "silvers" or "silver salmon" were also historically applied to chum salmon, O. keta, in the Yukon River (Gilbert, 1922); sockeye salmon, O. nerka, in the Columbia (Bendire, 1881); and spring-run Chinook, O. tshawytscha, in the Columbia (Murphy, 1879), Klamath (Snyder, 1931), and Battle Creek (Sacramento River) watersheds (Anonymous, 1899). Jordan (1891) pointed out that the term "silver salmon" was "carelessly" applied by fishermen to juveniles of all salmon species.

An excellent illustration of the confusion in salmonid nomenclature surrounds the activities of a small county-owned hatchery in the Santa Cruz Mountains during the early 1900's. In 1906, a local newspaper reported that Hatchery Manager Frank Shebley planned to import "silver salmon" from Baker Lake in the Washington Cascades and that this would "give us another valuable game fish," implying that the species was not found in local waters (Anonymous, 1905). However, just a few months later, another local paper quotes Superintendent Shebley saying it would be a "good idea to get eggs from dog salmon which run up Scotts Creek [a nearby stream] and hatch out a quantity. The dog salmon come up the creek in the fall, after waiting in the lagoon for the fall 
rains to come down and raise the water" (Anonymous, 1906). In all likelihood, the local "dog salmon" that Shebley referred to were $O$. kisutch and not $O$. keta, as evidenced by the fact that the article comments on the high quality of "dog salmon" as a food fish, stating that "dog salmon are the richest fish that swim the rivers. They have more oil, and more and tastier flesh than any other salmon."

$O$. keta have long been recognized as the least desirable food fish of the five Pacific salmon species, a fact recognized even in Jordan's earliest writings (see e.g., Jordan and Gilbert, 1881a). I suspect that Shebley was simply unaware that the "silver salmon" he intended to bring down from Washington and the fish known locally as "dog salmon" were the same species, O. kisutch. ${ }^{36}$ As will be seen momentarily, the ambiguous use of "dog salmon" appears to have played a key role in some early species identifications that tangibly influenced Jordan's range descriptions of both coho and chum salmon.

Another nomenclatural inconsistency and potential source of ambiguity is the term "quinnat salmon." Quinnat salmon is generally taken by modern scientists to be a synonym for Chinook salmon, and, in fact, Jordan's earliest writings on Pacific salmon assigned the scientific name "Oncorhynchus quinnat" or "Salmo quinnat" to what is now recognized as $O$. tshawytscha (Jordan, 1878a, 1878b, 1884b). However, in the 19th century,

\footnotetext{
${ }^{36}$ Other evidence supports the interpretation that the "dog salmon" Shebley referred to were not $O$. keta. An 1887 news article notes the discovery of a "Piscatorial Curiosity" in the San Lorenzo River, which upon examination of an expert was determined to be O. keta (Anonymous, 1887). The expert noted that "This fish is a stranger to Santa Cruz waters, none of the kind to my knowledge ever being seen here before." Nearly thirty years later, Scofield (1916) again documented occurrence of three O. keta adults in the San Lorenzo River, stating that "The dog salmon has been reported from the Sacramento River also, but never before from a point as far south as the San Lorenzo River." The fact that these observations of $O$. keta in the Santa Cruz Mountain were viewed as rare, even unprecedented events, argues against Shebley's Scott Creek "dog salmon" being $O$. keta, particularly since Shebley believed them abundant enough to supply the hatchery with a ready source of eggs.
}

quinnat salmon was used by Jordan and others not only in specific reference to $O$. tshawytscha, but also as a general name for all five of the Pacific salmon species. This is evidenced in the following quote from Jordan (1892a):

"They [the Pacific Coast salmon] have therefore been placed in another genus known as Oncorhynchus. For the lack of any other common name they are always spoken of as and will always be canned, as long as the canning industry lasts, under the name of Salmon. The Chinook name, Quinnat, was early applied to them, and if we feel the need of some other name to distinguish them from real salmon [Atlantic salmon, Salmo salar] we may call the Pacific Coast salmon Quinnat, or Quinnat Salmon. These species all live in the ocean, ascend the rivers in spring and summer, spawn in fresh water in the fall, the young, as soon as they are able to swim, floating tail foremost down river and growing rapidly as soon as they reach the ocean and the peculiar ocean food. There are five species of these Quinnats, which will be described farther on [emphasis added]."

In another paper, Jordan (1894a:129) wrote "all the so-called salmon of the Pacific Coast, all the Quinnats or species of Oncorhynchus, have an increased number of rays in the anal fin, from fourteen to twenty, not counting the stubs or rudiments in front of the first ray." These examples illustrate that the potential exists to misinterpret early references to "Quinnat salmon" as specific to Chinook salmon when, in fact, it may be a generic reference to Pacific salmon as a group.

A few additional common names have the potential to cause confusion in the historical literature. The term "white salmon" was used as a common name for $O$. chouicha $(=O$. tshawytscha; Jordan and Gilbert, 1881a), as well as $O$. kisutch in the Columbia
River region (Jordan, 1884a). Similarly, Gilbert (1922) reported that the name "chinook" was applied to $O$. kisutch in the Yukon Basin.

Lewis and Clark described a fish they called the "White Salmon Trout" from the Columbia River and its tributaries, which subsequent authors interpreted to be coho salmon (Coues, 1893; Burroughs, 1961; Cutright, 1969); however, more critical analysis of the timing of these observations (March and April), as well as meristic characteristics, indicates these were most likely steelhead (Trotter and Bisson, 1988; Butler, 2004). ${ }^{37}$

Since the 1880's, "blue-back" has been used to describe sockeye salmon (Jordan, 1880); however, the term has also been applied to both steelhead and coastal cutthroat trout. This confusion may have led Jordan and Evermann (1896) to write that sockeye salmon once occurred in the Klamath River (Snyder, 1931). And finally, the terms "hookbill" or "hook-nosed" salmon were used for pink salmon (Suckley, 1874; Kerry, 1874), coho salmon (Shapovalov and Taft, 1954), and Chinook salmon (Snyder, 1931).

In summary, the use of various nondefinitive common names continued for decades, despite the fact that Jordan and Gilbert (1881a) had accurately described the five Pacific salmon species and their diagnostic characteristics. ${ }^{38}$ This often makes it difficult to interpret writings from the late 1800 's. Accounts from the popular literature and newspaper articles are particularly dubious, but, as will be seen in the next section, this confusion was often evident in the scientific literature as well.

\footnotetext{
${ }^{37}$ The naming of the White Salmon River in Washington is traceable to Lewis and Clark's "white salmon trout." For a thorough discussion, see McMillan, B. 2017. Lewis and Clark's white salmon trout: coho salmon or steelhead? 200 years of getting it wrong. Part III: Fort Clatsop. The Conservation Angler (avail. at https:// theconservationangler.wordpress.com/category/ essays-by-bill-mcmillan/).

${ }^{38}$ It was not until the late 20 th century that the taxonomic status of steelhead was settled (Stearley and Smith, 1993).
} 
Table 4.-Sampling localities and salmonid records from the 1895 Carmel River Expedition from the California Academy of Sciences collection database.

\begin{tabular}{|c|c|c|c|c|c|c|}
\hline $\begin{array}{l}\text { CAS } \\
\text { cat. no. }\end{array}$ & $\begin{array}{l}\text { Collection } \\
\text { date }\end{array}$ & Collection location ${ }^{1}$ & Collectors & $\begin{array}{l}\text { Stanford } \\
\text { ledger ID }\end{array}$ & $\begin{array}{l}\text { Revised } \\
\text { species ID }\end{array}$ & Disposition \\
\hline SU 4679 & not given & Carmel River (at mouth) & Scofield \& Rutter & Salmo irideus & O. mykiss irideus & discarded \\
\hline SU 4672 & not given & Carmel River & Rutter \& Pierson & Salmo irideus & O. mykiss irideus & discarded \\
\hline SU 4675 & not given & Salinas² River (Soledad) & Rutter \& Scofield & Salmo irideus & O. mykiss irideus & extant \\
\hline SU 4680 & not given & Soquel Creek & Scofield \& Seale & Salmo irideus & O. mykiss irideus & discarded \\
\hline SU 4670 & not given & San Lorenzo River ${ }^{3}$ & Rutter \& Pierson & Salmo gairdneri irideus & O. mykiss irideus & extant \\
\hline SU 4673 & not given & Wilder Creek & Scofield \& Seale & Salmo gairdneri irideus & O. mykiss irideus & extant \\
\hline SU 4802 & not given & Liddell Creek & Rutter \& Scofield & Salmo irideus & O. mykiss irideus & transferred \\
\hline SU 4799 & not given & Liddell Creek & Rutter \& Scofield & Salmo irideus & O. mykiss irideus & extant \\
\hline SU 4783 & 6/6/1895 & Laguna Creek ${ }^{4}$ & Rutter \& Scofield & Salmo irideus & O. mykiss irideus & extant \\
\hline SU 4798 & not given & San Vicente Creek ${ }^{5}$ & Rutter \& Scofield & Salmo irideus & O. mykiss irideus & with 4665 \\
\hline SU 4665 & $6 / 6 / 1895$ & San Vicente Creek ${ }^{5}$ & Rutter \& Scofield & Salmo irideus & O. mykiss irideus & extant \\
\hline SU 4685 & not given & San Vicente Creek ${ }^{6}$ & Rutter \& Scofield & Oncorhynchus keta & O. kisutch & extant \\
\hline SU 4674 & not given & Scott Creek & Rutter \& Seale & Salmo irideus & O. mykiss irideus & extant \\
\hline SU 4797 & 6/5/1895 & Scott Creek & Rutter \& Seale & Oncorhynchus tschawytscha & O. kisutch & extant \\
\hline SU 4756 & not given & Waddell Creek & & Salmo irideus & O. mykiss irideus & discarded \\
\hline SU 4671 & not given & Waddell Creek & Rutter, Seale, Scofield & Salmo irideus & O. mykiss irideus & transferred to 4796 \\
\hline SU 4796 & not given & Waddell Creek & Rutter \& Scofield & Salmo irideus & O. mykiss irideus & extant \\
\hline SU 4667 & $6 / 5 / 1895$ & Waddell Creek & Rutter \& Scofield & Oncorhynchus keta & O. kisutch & extant \\
\hline SU 4666 & not given & Gazos Creek ${ }^{8}$ & Rutter \& Pierson & Salmo irideus & O. mykiss irideus & extant \\
\hline SU 4686 & not given & Gazos Creek ${ }^{8}$ & Rutter \& Pierson & Oncorhynchus keta & O. kisutch & extant \\
\hline SU 4668 & not given & Pescadero Creek (Harrison) & Rutter \& Scofield & Salmo irideus & O. mykiss irideus & extant \\
\hline SU 4669 & not given & San Gregorio Creek ${ }^{9}$ & Scofield \& party & Salmo irideus & O. mykiss irideus & extant \\
\hline
\end{tabular}

${ }^{1}$ Modern spellings are used. Alternative spellings found in Stanford ledger are footnoted.

${ }^{2}$ Misspelled as Salinal River

${ }^{3}$ Listed as San Lorenzo Creek

${ }^{4}$ Misspelled as Lagoon Creek in ledger and Lagoona on labe

${ }^{5}$ Misspelled as San Macento Creek

Misspelled as San Vicinto Creek

${ }^{7}$ One specimen in the jar has been tentatively identified as O. tshawytscha.

${ }^{8}$ Misspelled as Gassus Creek

${ }^{8}$ No creek name given, but locality listed as San Gregorio, La Honda

\section{5-1910: Systematic Exploration Begins}

More systematic exploration of California's coastal watersheds did not begin until several years after Jordan arrived at the newly founded Stanford University in 1891 and assumed the position of University President (Evermann and Clark, 1931). In his first five years at Stanford, Jordan spent much of his time handling the administrative demands of running the university, including averting financial collapse of the institution following the death of its founder Leland Stanford in 1893 (Jordan, 1922). Any free time Jordan had for scientific work during the early 1890 's was devoted largely to preparation of the four-volume treatise The Fishes of North and Middle America with Barton Warren Evermann. This book gave descriptions of some 3,127 species of fishes found north of the Isthmus of Panama. The first of four volumes was published in 1896, and it was only during the latter stages of its preparation that Jordan resumed field explorations (Jordan, 1922:524).

Jordan brought Gilbert with him from Indiana, appointing him Chair of the Zoology Department (Hubbs, 1964). Snyder, then an undergraduate, likewise followed Jordan from Indiana to Stanford, completing his Bachelor of Arts degree in 1897 and his Master of Arts degree in 1899, with Gilbert serving as his major professor (Brittain and Jennings, 2008). Both Gilbert and Snyder played key roles in the exploration of California's coastal waters, as did others under their direction, including Cloudsley Rutter, Norman Scofield, Alvin Seale, and Charles Pierson.

Jordan and others at Stanford resumed field work in zoology in late 1894 (Jordan, 1922:526). Over the next two decades, the Stanford faculty and staff led many influential investigations into the fish faunas of Mexico, South America, Hawaii, Japan, Russia, and other faraway destinations (Böhlke, 1953); however, it is the local explorations of California and Oregon that are germane to the question of $\mathrm{Pa}$ cific salmon distributions.

Two expeditions in coastal California are particularly noteworthy: the Carmel River Expedition of 1895, and the Northern California/Oregon Expedition of 1897 and 1899. These sur- veys constituted the first systematic sampling of fish faunas in coastal watersheds of California and Oregon, and as such, were the first scientific collections with the potential to elucidate the freshwater spawning ranges of various salmonid species. However, readers should recognize that these surveys were hardly exhaustive. Collection records indicate that surveys most often took place at one or two locations within a watershed, and that survey sites on consecutive days were often 10 miles or more apart. Given that the mode of transportation was probably horseback, the actual sampling time at each location was likely fairly short. More importantly, despite the credentials of the expedition leaders, the misidentification of salmonid fishes on these surveys appears to have occurred, and this likely contributed substantially to confusion regarding the freshwater distribution of certain species of salmon.

\section{The Carmel River Expedition (1895)}

The 1895 Carmel River expedition was conducted by Rutter, Scofield, Seale, and Pierson, in June 1895. The 
foursome sampled streams in watersheds from the Carmel River in Monterey County, north to San Gregorio Creek in San Mateo County, roughly a $140 \mathrm{~km}$ stretch of coastline (Table 4). The expedition involved the collection of fishes from freshwater and possibly lagoon habitats in at least 15 coastal streams. Importantly, the region covered by this expedition included streams of the Santa Cruz Mountains, which may very well have marked the southern limits of the historical spawning distributions of both coho and Chinook salmon. Specimens obtained during this expedition were incorporated into the Stanford ichthyological collection, and many still reside at the California Academy of Sciences (CAS), which took possession of the Stanford collection in 1969. ${ }^{39}$ These provide a striking example of how the correct identification of salmon species, especially juveniles, continued to be elusive even well after Jordan and Gilbert (1881a) published descriptions of the diagnostic characteristics of these species.

Based on the Stanford museum ledger and collection database, the Carmel River expedition reported collecting Salmo irideus (=O. mykiss iride$u s$ ) from 13 of the streams and rivers sampled in the Central Coast region ${ }^{40}$ (Table 4). The original Stanford ledger entries indicate that, in addition to " $S$. irideus," two other salmonid species were collected. These include specimens initially identified as $O$. keta from Waddell, Gazos, and San Vicente creeks and specimens identified as $O$. tshawytscha from Scott Creek. However, all of these putative $O$. keta and $O$. tshawytscha specimens have subsequently been determined to be $O$. kisutch (Adams et al., 2007, and Spence et al., 2011 provide details), with the possible exception of one specimen from San Vicente Creek, which

\footnotetext{
${ }^{39}$ See http://www.calacademy.org/scientists/ichthyology-about.

${ }^{40}$ Specimens from four of these localities have since been discarded from the CAS collection; however, I have personally examined specimens from 7 of the remaining 9 localities and have confirmed that they are $O$. mykiss.
}

was originally identified as $O$. keta, but may be $O$. tshawytscha. ${ }^{41}$ All of these redeterminations were apparently made while the specimens were still in the possession of Stanford University, as indicated by labels that are still present in the sample jars housed at the CAS. ${ }^{42}$

These Carmel Expedition collections are noteworthy in that they represent the first collection of juvenile coho salmon from the Santa Cruz Mountain region, which lies to the south of San Francisco, previously listed by Jordan and Gilbert (1881a) as the southern limit of the species' known distribution. That juvenile coho salmon were observed in four different watersheds provides strong evidence that the species regularly occupied streams in the region and that this was not an isolated case of straying. Yet because the initial species identifications were incorrect, the observations were not immediately recognized as an extension of the published range of coho salmon. Rather, the misidentification of coho salmon as chum salmon likely explains changes in the range description of the latter species in the writings of Jordan (see below).

\section{The Oregon and Northern California Coast Expedition (1897-1899)}

The second important investigation of coastal watersheds in the northern California and Oregon was led by Gilbert and Snyder during the summers of 1897 and 1899. Although Snyder's

\footnotetext{
${ }^{41}$ The CAS database record for SU 4685 identifies the specimens as $O$. kisutch; however, the "Specimen remarks" column indicates that "one spec. is a chinook." This determination was made by CAS staff (D. Catania, CAS, personal commun., Nov., 2004), though given the small size of San Vicente Creek, the redetermination may be questionable. Unfortunately, stomachs from all of the 1895 specimens were removed for dietary analysis; thus, the most useful meristic characteristic for discriminating between coho and Chinook salmon - numbers of pyloric caeca - cannot be determined. The redeterminations of most specimens originally identified as $O$. keta as $O$. kisutch is consistent with the time of collection (June), which is after most southern chum populations would have emigrated to the ocean.

${ }^{42}$ The SU 4667 and SU 4797 jars both have Stanford University labels identifying Oncorhynchus kisutch as the species.
}

(1907) account of the expedition does not provide details of the route, this can be reconstructed to a large degree from records in the CAS and USNM ichthyological collections. The 1897 expedition began in Napa County in late May, moved coastward to the Russian and Gualala rivers (Sonoma Co.) in June, and then proceeded northward as far as the Smith River near the Oregon border.

The expedition then turned inland, visiting Cottonwood Creek and Shasta River in the upper Klamath Basin in late $\mathrm{July}^{43}$ (Table 5). Overall, this first segment of the Northern CaliforniaOregon Expedition covered approximately $445 \mathrm{~km}$ of the northern California Coast, including all of the major coastal basins (e.g., Russian, Gualala, Garcia, Navarro, Russian, Albion, Noyo, Ten Mile, Mattole, Bear, Eel, Mad, Klamath, and Smith rivers) and several smaller basins as well. The expedition returned to Stanford in September 1897, and the study resumed in late July 1899, this time with Snyder leading a group of three other Stanford students. ${ }^{44}$ This extension of the survey included interior basins of southern Oregon, the Willamette Basin, as well as coastal watersheds as far north as the Nehalem River (Supplemental Table S5).

Snyder (1907) published an extensive table detailing the species of fish collected at each sampling location. Regrettably, Snyder purposely omitted salmon and trout species from this table, though he did not offer a reason for doing so. However, in the body of the paper, he included narratives of all species encountered, including three salmon species, as well as both steelhead and cutthroat trout. In these narratives, we find strong evidence that Gilbert and Snyder misidentified juvenile salmonids during these surveys, even though accurate descriptions of characters used to discriminate among

\footnotetext{
${ }^{43}$ Collections attributed to the 1897 expedition were also made in southern Oregon; however, these collections were actually made by Frank Cramer and Keinosuke Otaki (Snyder, 1907).

${ }^{44}$ Snyder was either finishing or had just finished his master's degree.
} 
Table 5. - Sampling localities and salmonid records from the California portion of the 1897/1899 Northern California/Oregon Expedition led by Gilbert and Snyder, as determined from the California Academy of Sciences (CAS) and U.S. National Museum (USNM) collection database records.

\begin{tabular}{|c|c|c|c|c|c|}
\hline Date & Location & Watershed & CAS(SU) $1 /$ USNM Collection records & Salmonids reported & Collector \\
\hline $5 / 181897$ & Walker Cr. & Walker Cr. & USNM 75406 & & Snyder \\
\hline $5 / 26 / 1897$ & Conn Cr./Napa R. & Napa R. & SU 60339, 15970/USNM 58318, 58314, 59827 & O. mykiss gairdneri ${ }^{2}$ & Gilbert \\
\hline $5 / 27 / 1897$ & Putah Cr. (near Monticello) & Sacramento R. & SU 37851, 23966 & & Gilbert et al. \\
\hline $5 / 28 / 1897$ & Berryessa Cr. & Sacramento R. & USNM 58145, 58123 & & Gilbert \\
\hline $5 / 29 / 1897$ & Aetna Springs (Putah Cr.) & Sacramento R. & SU 15975 & & Gilbert et al. \\
\hline $5 / 30 / 1897$ & Napa Cr. (Calistoga) & Napa R. & SU 24642 & & Gilbert \\
\hline $5 / 31 / 1897$ & Napa Cr. (Calistoga) & Napa R. & SU 24282, 54910 & O. mykiss gairdneri & Gilbert et al. \\
\hline $6 / 1 / 1897$ & Knights Valley $\mathrm{Cr}^{3}$ (near Kellog) & Russian R. & USNM 62304 & & Gilbert \\
\hline $6 / 2 / 1897$ & Dry Cr. (near Healdsburg) & Russian R. & SU 37013, 66735, 66736, 22479/USNM 58139 & & Gilbert et al. \\
\hline 6/3/1897 & Russian R. (near Healdsburg) & Russian R. & SU 28768,37014 & & Gilbert \\
\hline 6/8/1897 & Gualala R. (at jct. of Wheatfield Fork) & Gualala R. & SU 14903 & & Gilbert et al. \\
\hline 6/8/1897 & Gualala R. (jc.t of Gualala and N. Fk) & Gualala R. & USNM 58328 & & Gilbert \\
\hline $6 / 10 / 1897$ & Garcia R. (5 mi. above mouth) & Garcia R. & SU 37977/USNM 62441 & O. mykiss iridea & Gilbert \\
\hline $6 / 12 / 1897$ & Garcia R. (1.5 mi. above mouth) & Garcia R. & SU $24111 /$ USNM 58379 & & Gilbert et al. \\
\hline $6 / 13 / 1897$ & Navarro R. (4 mi. above mouth) & Navarro R. & SU 14902, 59766, 54835/USNM 62298 & O. mykiss gairdneri & Gilbert et al. \\
\hline $6 / 14 / 1897$ & Navarro R. (near Philo) & Navarro R. & SU 22488/USNM 58238, 74477 & & Gilbert et al./Snyder \\
\hline 6/17/1897 & Russian R. (at Ukiah) & Russian R. & SU 15976 & & Gilbert et al. \\
\hline $6 / 22 / 1897$ & Albion R. (2 mi. below Comptsche) & Albion R. & SU 58573, 38016 & & Gilbert et al. \\
\hline $6 / 24 / 1897$ & Noyo R. & Noyo R. & SU $38011, \mathbf{5 4 8 6 3 ,} \mathbf{5 4 8 7 0 ^ { 4 }}$ & O. tshawytscha, O. kisutch & Gilbert et al. \\
\hline 6/25/1897 & Ten Mile R. & Ten Mile R. & SU 37745,20138 & & Gilbert et al. \\
\hline $6 / 26 / 1897$ & Cottoneva $\mathrm{Cr}^{5}$ (2 mi. above Rockport) & Cottaneva Cr. & SU 54805 & O. mykiss gairdneri & Gilbert \\
\hline $6 / 27 / 1897$ & Usal Cr. & Usal Cr. & SU 62102, 59858, 59830, 59855, 60049/USNM 62299 & Oncorhynchus spp., Salmo spp. ${ }^{6}$ & C.H. Gilbert \\
\hline $6 / 30 / 1897$ & South Fk. Eel R. (at Garberville) & Eel $\mathrm{R}$. & SU 24661/USNM 58277, 58163 & & Gilbert \\
\hline 7/1/1897 & South Fk. Eel R. (at Myers Flat) & Eel $\mathrm{R}$. & SU $54909 /$ USNM 75333 & O. mykiss gairdneri & Gilbert \\
\hline 7/3/1897 & Van Duzen R. ${ }^{7}$ & Eel $\mathrm{R}$. & SU 60045 & O. mykiss gairdneri & Gilbert \\
\hline 7/5/1897 & Mattole R. (at Petrolia) & Mattole R. & SU 37993, 60046 & Salmo spp. ${ }^{8}$ & Gilbert \\
\hline 7/6/1897 & Bear R. (at Capetown) & Bear R. & SU 54810/USNM 58188 & O. mykiss gairdneri & Gilbert \\
\hline 7/7/1897 & Mad R. (4 mi. above mouth) & Mad R. & SU 9861, 37047, 54811/USNM 126870, 61579 & O. mykiss gairdneri & Gilbert et al. \\
\hline 7/8/1897 & Maple Cr. & Maple Cr. & SU 24114 & & Gilbert \\
\hline 7/8/1897 & Little R. & Little R. & SU 5980 & & Gilbert et al. \\
\hline 7/9/1897 & Redwood Cr. (at Orick) & Redwood Cr. & SU 67289, 37988, 26012 & O. mykiss iridea & Snyder \& Gilbert et al. \\
\hline 7/10/1897 & Klamath R. (at mouth) & Klamath R. & USNM 58081 & & Gilbert \\
\hline $7 / 12 / 1897$ & Klamath R. (at mouth) & Klamath R. & SU $37021,37799,60073^{9}$ & Salmo spp. ${ }^{8}$ & Gilbert et al. \\
\hline 7/12/1897 & Hunter Cr. & Klamath R. & SU 26011, CAS 225431 & O. mykiss iridea & Snyder \\
\hline 7/14/1897 & Smith R. (near mouth) & Smith R. & SU 60379/USNM 62301 & Oncorhynchus spp. & C.H. Gilbert \\
\hline $7 / 16 / 1897$ & Smith R. (at Gasquet) & Smith R. & SU 41882 & O. mykiss iridea & C.H. Gilbert et al. \\
\hline $7 / 23 / 1897$ & Cottonwood Cr. & Klamath R. & SU 59847, 37798, 54907 & O. mykiss gairdneri & C.H. Gilbert et al. \\
\hline $7 / 24 / 1897$ & Shasta R. & Klamath R. & SU $60191,31852,59691, \mathbf{5 4 8 0 9 ,} \mathbf{5 4 8 4 4}$ & O. mykiss gairdneri, O. ts & C.H. Gilbert \\
\hline
\end{tabular}

${ }^{1}$ Collections from the CAS database that were acquired from Stanford University retain their SU record numbers. Specimen numbers in bold are salmonids reported for the locality. ${ }^{2}$ All specimens identified in CAS and USNM database as O. mykiss gairdneri are likely O. mykiss irideus, as defined by Behnke, 2002.

${ }^{2}$ All specimens identified in CAS and USNM database as O. mykiss
${ }^{3}$ Currently known as Redwood Creek, tributary to Maacama Creek.

${ }^{3}$ Currently known as Redwood Creek, tributary to Maacama Creek.

${ }^{4}$ CAS database lists collection date for SU 54863 and 54870 as 6/24/1900; however, as Cottus aleuticus were collected at this locality on 6/24/1897 and there are no records of additional collections by Gilbert in 1900 anywhere in this region, I suspect that the 1900 date in the Stanford ledger is in error.

5Locality listed as Cottonwood Creek; however, Cottoneva Creek flows through Rockport and lies between Ten Mile River and Usal Creek, which were sampled on the preceding and subsequent days.

${ }^{6}$ Two salmonids were apparently collected from Usal Creek, but no species' determinations were made.

${ }^{7}$ Locality listed in Stanford ledger as Van Duzin Creek.

${ }^{8}$ No species determination made.

${ }^{9}$ Collection date listed in ledger as 7/12/1899; however, given other collections at this locality on this date in 1897 and lack of any 1899 specimens from the region, I assume the 1899 date is in error.

species had been published nearly two decades earlier (Jordan and Gilbert, 1881a). Specifically, in his description of Oncorhynchus keta, Snyder (1907) wrote the following:

"Occurs in all except the smallest streams between the Sacramento and Columbia rivers. The young of this salmon were apparently more abundant than those of any other."

The timing of the surveys makes this claim highly dubious, since they took place from mid-June to September. Chum salmon migrate to sea almost immediately after emergence from the gravel-typically late winter or early spring —-with peak emigration typically occurring in March and April and only rarely extending into June (Johnson et al., 1997). Hence, it is implausible that juvenile chum salmon were not only present but more abundant than any other salmon during the expedition.

Further support for this interpretation is found in Snyder's narrative for $O$. kisutch, in which he lists Redwood Creek (near Orick) as the only California locality where this species was found. Here again, it seems highly improbable that surveys conducted at more than two dozen sites in coastal watersheds of Mendocino, Humboldt, and Del Norte counties - the heart of the coastal redwood zone where coho salmon reach their peak abundance in the state-would have failed to produce coho salmon juveniles.

The clinching evidence in support of this interpretation of these records can be found in two subsequent publications. Five years after Snyder's (1907) description of the expedition was published, Gilbert (1912) openly acknowledged that he and his contemporaries had commonly misidentified juvenile coho salmon as chum salmon in the past. This is evident in the following description of "dog salmon" (O. keta):

"Less is known of the life history of the dog salmon than any of the species thus far considered. Our knowledge of the young is en- 
tirely due to Chamberlain [1907], who secured them on their seaward migration as fry, some with remnants of the yolk still attached. They were not associated with larger individuals which could be considered yearlings. As stated by Chamberlain, 'records of the occurrence of large individuals in streams have not been authenticated, and, so far as is known, all leave fresh water as soon as they are able to swim.' Records of yearling dog salmon have been made by the writer [Gilbert] and by others in the streams of Washington, Oregon, and California, but all such have been founded on incorrect identification of the coho yearlings."

Here, Gilbert explicitly credits the misidentification of juvenile coho salmon as chum salmon to the poor understanding of juvenile life histories that existed during that time. Twenty-four years later, Snyder (1931) tacitly admitted his 1907 error, writing that "Humpback and dog salmon are not common enough anywhere in the State [California] to be of commercial importance; in fact, they are so rarely seen as to be unknown to any but the most observant fisherman."

These admissions reinforce the need to exercise considerable caution when interpreting collection records and writings related to the distributions of both coho and chum salmon prior to 1912. Yet, despite the fact that both Snyder and Gilbert both eventually acknowledged their errors, the misidentification influenced Jordan's subsequent writings (see below) and has contributed to a perception that chum salmon were once substantially more abundant in California that has been perpetuated in the modern literature (see e.g., Johnson et al., 2012). ${ }^{45}$

\footnotetext{
${ }^{45}$ Moyle et al. (1995) cite Jordan and Gilbert's (1881a) statement that chum salmon were reported to occur in "all streams from San Francisco to [the] Bering Straits" (Moyle, P. B., R. M. Yoshiyama, J. E. Williams, and E. D. Wikramanayake. 1995. Fish species of special concern in California, second ed. Final rep. for contr. 2128IF prep. for Calif. Dep. Fish Game, Inland Fish. Div., Ran-
}

One perplexing aspect of the 1897 expedition is scarcity of specimens of O. kisutch in the CAS museum collection, especially given Snyder's statement that (misidentified) O. keta were the most abundant salmonid in coastal streams. Only one coho salmon specimen (SU 54870) from this expedition currently resides in the CAS and USNM collections, and its date of collection is equivocal (see Table 5 footnote). One can only speculate as to the fate of other coho salmon specimens and why they were never recorded in the Stanford ledger. Other specimens from this expedition were not catalogued in the Stanford ledger until 1961-62, so perhaps these jars were lost or transferred elsewhere.

Interestingly, in 1919 Snyder and two students (Bonnot and Hays) replicated the 1897 survey of northern California coast streams, visiting many of survey locations on nearly the exact same day of year. CAS specimens from the 1919 expedition include coho salmon from Ten Mile River (SU 54775), South Fork Eel River at Garberville and Myers Ranch (SU 54845, 54864), Mad River (SU 60068), Hunter Creek (SU 23613), Klamath River (SU 54783), Turwar Creek (tributary to Klamath River; SU54771), and Rowdy Creek (tributary to Smith River; SU 54776). Likewise, they include specimens of Chinook salmon from South Fork Eel River (SU 54854, 23614), Van Duzen River (SU 59806, 54855), Mad River (SU 59660), Klamath River (SU 54917; CAS 210057), and Rowdy Creek (SU 54774). Given that 1) both coho and Chinook were common in these rivers during the 1919 collections, and 2) Snyder (1907) reported Chinook salmon as being present during the 1897 surveys in the Eel, Mad, and Klamath rivers, I am inclined to

cho Cordova, Calif., 272 p.); however, in a subsequent report, Moyle et al. (2015) acknowledge that the current status of chum salmon in California is equivocal, in part because of the poor understanding of historical occurrence (Moyle, P. B., R. M. Quinones, J. V. Katz, and J. Weaver. 2015. Fish species of special concern in California, third ed. Rep. prep. for Calif. Dep. Fish Wild., Sacramento, Calif., 842 p. (avail. at www. wildlife.ca.gov/Conservation/SSC/Fishes)). believe that many juvenile salmon samples, including the coho samples Snyder believed to be $O$. keta, were never cataloged in the Stanford ledger and have since been lost.

In summary, the Northern California/Oregon expedition led by Snyder and Gilbert should have yielded greater specificity regarding the distribution of various salmon species in California and Oregon. However, the misidentification of coho salmon as chum salmon, as well as the apparent failure to catalog collection localities for coho and Chinook salmon, greatly diminished the ability of these surveys to inform species freshwater range determinations.

\section{Other Surveys}

In addition to the above surveys, the Stanford Zoology Department was also involved with other more localized surveys in coastal watersheds of central and south-central California that are germane to the discussion of Pacific salmon freshwater ranges. Jordan himself, apparently with assistance from a local resident, surveyed three streams in coastal San Luis Obispo County, including San Luis Creek (=San Luis Obispo Creek) near the town of Avila, Corral de Piedra Creek (a tributary of Pismo Creek), and Arroyo Grande Creek (Jordan, 1894b). Interestingly, Jordan's surveys produced no salmonids of any kind in any of these three streams. ${ }^{46}$

However, with regard to Arroyo Grande Creek, Jordan stated the following:

"In this stream and in the others, trout are occasionally taken and sometimes salmon enter them from the sea. Lopez Creek, a mountain tributary of Arroyo Grande, is the best-known trout stream in San Luis Obispo County. It is said by anglers that the brook trout exist in the mountains and the salmon trout come up from the

\footnotetext{
${ }^{46}$ Unfortunately, Jordan's paper does not indicate the time of year that the surveys were conducted, which would influence the likelihood of encountering certain species.
} 


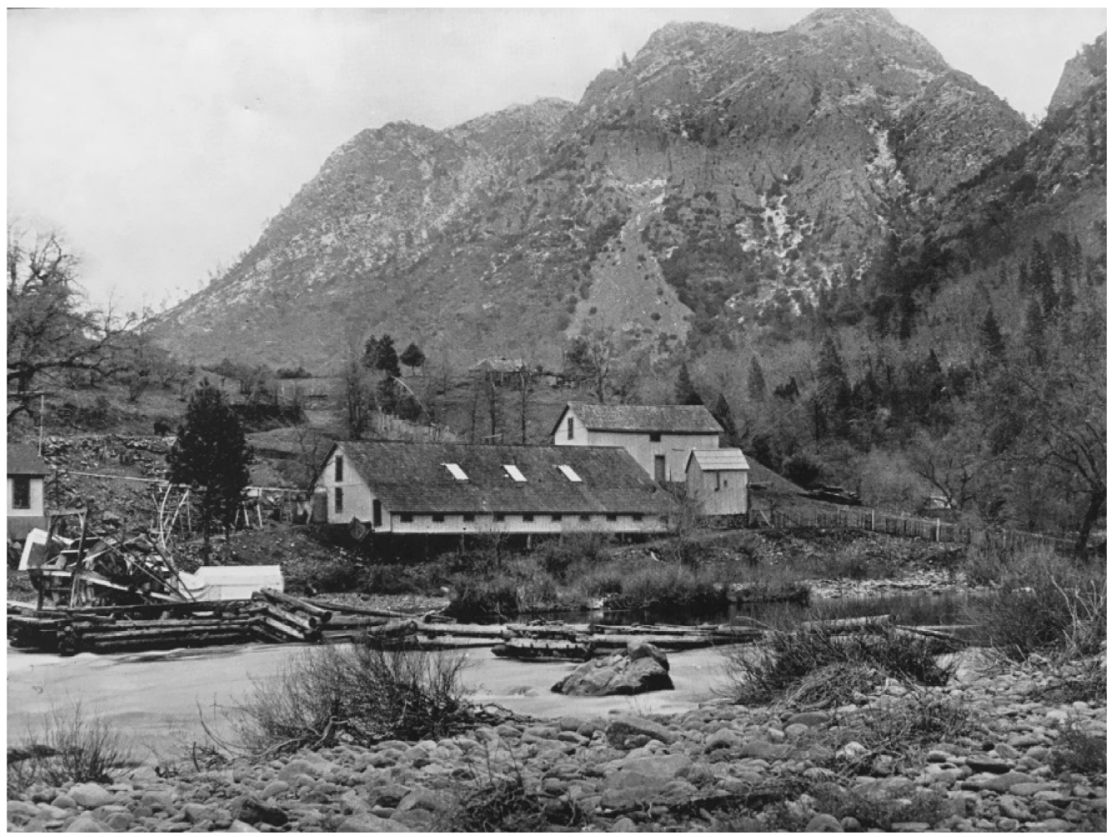

Figure 5.-Baird Hatchery along the McCloud River taken between 1890 and 1897. Figure from Stone (1897).

sea and 'promiscuously mix with it.' This seems another way of saying that the brook trout (irideus) and the salmon trout (gairdneri) are but forms of the same fish. The individuals which run to the sea grow larger and are more silvery in color than those which remain in the brooks."

Jordan concludes his narrative with a "list of the fishes of the streams of San Luis Obispo County so far as recorded," which includes three salmonids: Salmo mykiss gairdneri, Salmo mykiss irideus, and Oncorhynchus tschawytscha. Given that no salmonids were actually observed or collected during his surveys, it appears Jordan relied on other information - quite possibly accounts from the local resident that assisted him-to conclude that Chinook salmon and the resident and anadromous forms of $O$. mykiss occurred in San Luis Obispo County streams.

The observation of resident and anadromous forms of $O$. mykiss steelhead raises no eyebrows, as steelhead did and still do occupy coastal streams to both the north and south (Boughton et al., 2006). Yet the assertion of Chinook salmon seems considerably more dubious, for reasons similar to those outlined earlier regarding the Ventura River-namely, these are watersheds dominated by grassland, chaparral, and oak woodlands, with relatively dry climates and intermittent connectivity between the freshwater and marine environments.

Swift et al. (1993) expressed similar doubt about the veracity of this report. Despite the apparent lack of direct evidence of occurrence, Evermann and Clark (1931) and others that have followed (e.g., PFMC, 1999:A-51; Gustafson et al., 2007) have cited Jordan's (1894b) paper as evidence of Chinook salmon in creeks of San Luis Obispo

In addition to the San Luis Obispo area surveys, Stanford faculty and staff also conducted limited surveys in coastal watersheds of the Central California Coast. In October of 1896, Gilbert and Snyder led a three-day survey of streams in the Pajaro River system, sampling Uvas and Llagas creeks (Santa Clara County), along with sites County. on the lower mainstem of the Pajaro River (Santa Cruz/Monterey counties). O. mykiss was the only salmonid species collected on this survey (USNM 75320). The following October, a 4-day survey sampled the Salinas River and one tributary (Arroyo Seco) in Monterey County, as well as a site in the San Lorenzo River basin near the town of Felton. Again, O. mykiss is the only salmonid species represented in the collections, being found in both the San Lorenzo River and Arroyo Seco (USNM 75331, 75323), although as will be discussed in a subsequent section, given the land-use disturbances that had occurred prior to 1906, this should not be construed as evidence that other salmonid species were never present. ${ }^{47}$

\section{Early Artificial Propagation and Outplanting of Salmon in California}

In evaluating early historical records of occurrence of various Pacific salmon in California, it is important to acknowledge the possibility that some early observations might be the result of plantings of hatchery-reared fish into waters outside of their historical range. Artificial propagation of salmonids by private interests in the state pre-dates 1870 (Leitritz, 1970), and the first government-operated salmon hatchery was built by the U.S. Fish Commission on the McCloud River in 1872 (Fig. 5). One might thus presume that stocking of salmon species outside of their accepted historical range in California occurred early on. However, the distribution of salmon from these early hatchery activities is well documented and indicates that, prior to 1905 , releases of hatchery salmon likely had a negligible influence on the perceived freshwater ranges of salmon species within California.

\footnotetext{
${ }^{47}$ Snyder also conducted surveys of Monterey Bay tributaries during 1909, reporting the occurrence of Chinook and coho salmon in the San Lorenzo River, and Chinook salmon in the Pajaro River (Snyder, 1913). However, these observations occurred during a period when both species were being reared and released from Brookdale Hatchery into Monterey Bay tributaries (Cobb, 1911). Thus, the usefulness of these observations in establishing natural historical presence is limited.
} 

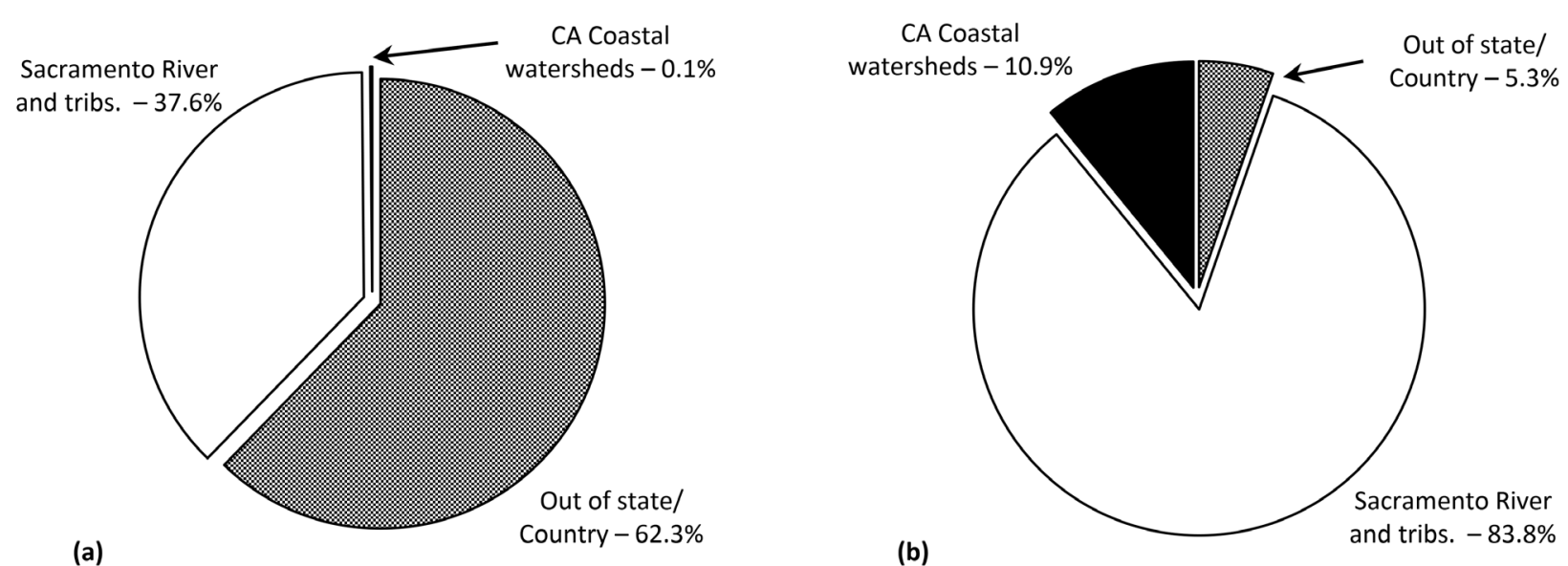

Figure 6.-Distribution of Chinook salmon eggs and fry from Baird Hatchery during the periods (a) 1872-1883 and (b) 1888-1905.

In this section, I review the published information on the propagation and distribution of the five Pacific salmon species in California in the late 1800's and early 1900's, which demonstrates both that early propagation efforts focused almost exclusively on Chinook salmon, and that the vast majority of salmon eggs produced by early California hatcheries were either shipped out of state (or country) or released back into local waters. Only after 1905, with the establishment of more state-operated salmon hatching and rearing facilities, as well as improved transportation, did more widespread out-of-basin plantings within California begin to occur.

Establishment of the Baird Hatchery on the McCloud River in 1872 was a landmark event, representing the first salmon hatchery in the western United States (USFC, 1874; Lichatowich, 1999). Prior to 1872 , a few small privately owned hatcheries had been operated in California; however, these hatcheries primarily reared either fish imported from the U.S. east coast (e.g., eastern brook trout, Salvelinus fontinalis; landlocked Atlantic salmon, Salmo salar; and lake whitefish, Coregonus clupeaformis), or local cutthroat trout (O. clarkii henshawi) from Lake Tahoe and Truckee River basin (Leitritz, 1970). There is no evidence that any of these early private facilities attempted to propagate Pacific salmon.

The Baird Hatchery, built and operated under the direction of Livingston Stone, was located on the McCloud River a few kilometers upstream of its confluence with the Pit River, a tributary of the upper Sacramento River in Shasta County. In its first years of operation, the primary purpose of the hatchery was to produce Chinook salmon eggs to be shipped to the eastern United States and beyond to Europe and New Zealand (Cobb, 1911). Indeed, Baird (1874) and others brimmed with optimism that, because of their ability to tolerate comparatively warm waters, salmon from the west coast would thrive in waters along the east coast well south of the range of other eastern salmonids. ${ }^{48}$

Between 1872 and 1883, the Baird Hatchery produced roughly 64 million Chinook salmon eggs. About 62\% of these were shipped out of California to other states or countries (Fig. $6 \mathrm{a}$; Clark, 1929). Of the remaining $38 \%$, that vast majority $(98 \%)$ were either turned over to the California State

\footnotetext{
${ }^{48}$ Livingston Stone, in a letter to the California Fish Commission (Stone, 1875), struck a slightly more cautious tone, implying that even if the majority of experimental introductions failed, a single successful introduction would "pay over and over again for all that the failures cost."
}

Fish Commission for release into the upper Sacramento River and its tributaries or retained at the Baird Hatchery for release back into the McCloud River. Hence, within-state releases of Chinook salmon in California during this early period were largely confined to the Sacramento River basin, not far from the Baird facility.

The only documented exceptions were the transfer of a combined 550,000 eggs to the San Francisco Sports Club in 1876 and 1877 (presumably for release in or near San Francisco Bay; Clark, 1929), and the 1881 release of about 150,500 fry into various waters including the Russian River basin (30,000); Donner Lake and nearby streams $(20,000)^{49}$; Pescadero and San Gregorio creeks in San Mateo County (15,000 each); Santa Cruz County $(15,000)$; the Salinas and Pajaro rivers in northern Monterey County $(15,000)$, and the San Francisco Bay area $\left(40,500^{50}\right)(\mathrm{CFC}, 1882)$. Collectively, releases within California but outside of the Sacramento River Basin and San Francisco Bay made up a tiny

\footnotetext{
${ }^{49}$ The Truckee River watershed in which Donner Lake resides drains to the east side of the Sierra and not to the Pacific Ocean.

${ }^{50}$ An unknown number of fish from the Bay Area release total was released in Grass Valley, Calif., part of the Sacramento River watershed.
} 
fraction $(<0.1 \%)$ of the total Chinook salmon hatchery production.

In late 1883, activities at the Baird Hatchery were suspended when the number of returning adults declined precipitously. This decline was attributed to construction of the railroad up the Sacramento Valley from Redding northward. Heavy blasting by the railroad crews apparently deterred salmon from entering the upper Sacramento River. Additionally, thousands more salmon were intentionally destroyed by the 3,000-6,000 railroad laborers ${ }^{51}$ who used blasting powder to kill fish for food (Stone, 1885). While many fish were eaten by the workers, many more likely died due to the highly destructive method of capture (Shebley, 1922; Leitritz, 1970). The Baird Hatchery resumed operation in 1888 shortly after the northward rail line from Redding, Calif., to Ashland, Oreg., was completed.

By this time, it was clear that attempts to establish Chinook salmon runs in eastern waters flowing into the Atlantic Ocean and Gulf of Mexico had failed entirely (McDonald, 1892:xxxv). As a consequence, optimism about spreading Chinook salmon to other parts of the world faded, and the primary purpose of the federally owned facility shifted toward supplying eggs for the newly established and state-operated Sisson Hatchery (now known as Mt. Shasta Hatchery). From here, Chinook salmon began to be distributed more widely within California.

Two new federal facilities were established on Battle Creek (1895) and Mill Creek (1903), which substantially increased egg production. Between 1888 and 1905, almost 480 million Chinook salmon eggs and fry were produced at these three facilities, an average of more than 26 million per year (Clark, 1929). The shift in priorities is evident in the fish distribution records (Fig. 6b). Approximately $84 \%$ of these fish were released back into the upper Sacramento, McCloud,

\footnotetext{
${ }^{51}$ Shebley (1922) reported the number of laborers as 9,000 .
}

Battle Creek, and Mill Creek watersheds.

Nearly 50 million fish (about 10\% of the total) were transferred into the Eel River basin between 1897 and 1905 , representing the first significant out-of-basin, within-state transfers of Chinook salmon in California. Additionally, between 1896 and 1898 , about 1.75 million fry were released into Lagunitas Creek as part of experiments to introduce Chinook salmon into the watershed and determine if fish returned to their "home stream" to spawn $^{52}$ (Rutter, 1902). Only $5 \%$ of the salmon were shipped outside of California.

In summary, although the numbers of Chinook salmon produced at Baird, Sisson, Mill, and Battle Creek hatcheries were substantial, the overwhelming majority of hatchery fish were either transferred out of state or released back into the Sacramento River and its tributaries. The only major out-ofbasin transfers of Sacramento River salmon to coastal watersheds were to the Eel River, which already supported native populations of Chinook salmon.

I have found no evidence that fish were released in California south of Monterey Bay prior to 1905. Consequently, the likelihood that hatchery plantings played a significant role in early descriptions of the freshwater range of Chinook salmon seems low. One might argue that the plantings to Pescadero, San Gregorio, and Santa Cruz and northern Monterey Counties may have been outside of the historical spawning distribution of Chinook salmon. However, the number of fry released $(45,000$ total) was small, and survival of fry is generally very low (Flagg et al., 1995). Furthermore, given that hundreds of thousands (if not more) of Chinook salmon from Central Valley rivers reared in Monterey Bay each year, it seems highly likely that strays routinely entered systems

\footnotetext{
${ }^{52}$ Although adult Chinook salmon did return to the stream, Rutter still rejected the idea that this reflected a homing tendency, instead concluding that these fish never left Tomales Bay and returned to Lagunitas Creek simply because it was the nearest freshwater source.
}

like the San Lorenzo River, Pescadero Creek, and perhaps the Salinas River in years when rainfall was early and sufficient to breach sand bars allowing fish to enter. Thus, the numerically minor plantings of Chinook salmon fry into streams between the Golden Gate and Monterey Bay overlaps areas where there was likely at least sporadic natural occurrence of Chinook salmon in coastal watersheds.

The early history of coho salmon propagation in California is considerably simpler. Prior to 1889 , there is no evidence that artificial propagation of coho salmon took place in California. In that year, the U.S. Fish Commission completed construction of a new hatchery facility at Fort Gaston in the Hoopa Valley along the Trinity River (Humboldt Co.). In its first year of operation, the hatchery hatched approximately 100,000 Chinook salmon eggs that had been transferred from the Baird Hatchery and released the resulting fry $(\sim 30,000)$ into the Trinity River (USFC, 1893).

The following year, traps were constructed on both the Trinity River and Redwood Creek, a coastal watershed only 13 miles overland from Fort Gaston where an auxiliary station was established. U.S. Fish Commission records indicate that "collecting of the eggs of the quinnat and steelhead salmon was begun in November, 1889, and continued three months," the fry of which were released locally into nearby Supply Creek, which provided water for the Fort Gaston hatchery. At Redwood Creek, about 30,000 "salmon" eggs were collected, and the resulting 25,000 fry were released one month later into Minor Creek, a tributary of the creek (USFC, 1893). Given that the term "quinnat" salmon was sometimes applied generally to west coast salmon species, and that the fish collected in Redwood Creek were referred to only as "salmon," one cannot be $100 \%$ certain that coho salmon were not part of these collections. But all progeny were listed as "quinnat salmon" in the summary of distribution tables, and as all hatchery-reared fish were released locally, this distinc- 
tion is immaterial to the question of whether these outplantings influenced the historical distributions of California's salmon.

Over the next several years, salmon continued to be collected from both the Trinity River at Fort Gaston and Redwood Creek, with apparent exchange of individuals among these basins. In 1893, a new station was established near Korbel along the Mad River. The annual U.S. Fish Commission Report for 1894 (Bean, 1896), contains the first explicit mention of "Silver salmon" being captured and propagated in California, with all 280,000 fry being released into the Mad River. ${ }^{53}$ Over the next three years, an additional 1.77 million coho fry and yearlings were reared and released, but none of these releases occurred outside of the Trinity River, Redwood Creek, or Mad River basins (Ravenel, 1896, 1898).

In 1898 , few salmon and no steelhead reached the traps on the Trinity River, so no collection of eggs was made at Fort Gaston. Returning Chinook and "nerka" salmon (but curiously no coho salmon) were apparently collected in Redwood Creek and the resulting fry released locally. Korbel Station was not operated that year. Due to the difficult access to the Fort Gaston, Redwood Creek, and Korbel stations, which had to be supplied and serviced entirely with pack mules, the stations were abandoned at the close of the year (Ravenel, 1899). In sum, although these three federal facilities were the first in California to propagate coho salmon, there are no records to indicate that any of these fish were ever transplanted outside of the immediate vicinity of these stations.

Following closure of those stations, there were no federal or staterun hatcheries in California that produced coho salmon until the 1910-11, season, when the state opened Klamathon Egg Collecting Station, collect-

\footnotetext{
${ }^{53}$ The origin of these fish is unclear. The text reported capturing "silverside salmon" on the Trinity River, but did not indicate if any coho salmon were collected at the Redwood Creek or Korbel facilities. ${ }^{\circ}$
}

ing "silver salmon" eggs and transporting them to the Sisson Hatchery in the Sacramento River basin. About 1.4 million fry were produced, half of which were released into the Klamath River and half into the Sacramento River. According to the California Fish and Game Commission (CFGC, 1913), the collections at Klamathon marked "the first effort made in this state to increase the run of silver salmon." More accurately, this marked the first state-run hatchery operations, as coho salmon had been propagated at the federally owned facilities discussed above from 1894 to 1897, and the County of Santa Cruz's Brookdale Hatchery had reared coho salmon imported from Baker Lake, Wash., and released them into the San Lorenzo River between 1906 and 1910 (Spence et al., 2011).

Records of propagation or transplanting of pink, chum, and sockeye salmon between 1870 and 1905 are rare to nonexistent. In fall of 1891 , two female and one male pink salmon were collected and propagated at Baird Station, but all fry were released back into the McCloud River (USFC, 1894). Similarly, the record of "nerka" salmon being collected, propagated, and released in Redwood Creek in 1898 appears to be the only record of sockeye salmon being propagated in California in the 1800's. I have found no evidence to indicate that chum salmon were ever bred or transplanted into California waters in the 1800's.

In summary, there is little evidence to suggest that, in the period 1870 1905 , observations of salmon resulting from planting of fish outside of their historical range would have appreciably influenced the range descriptions published by Jordan and others. After this period, the situation changed significantly, as out-of-basin transfers became more commonplace. For example, between 1905 and 1911, approximately 4.6 million Chinook salmon eggs were transferred to Brookdale Hatchery in the Santa Cruz Mountains (Santa Cruz Co.), with the resulting fry likely released into the San Lorenzo River and perhaps other lo- cal streams (Clark, 1929). Additionally, records indicate that between 1915 and 1919, 150,000 Chinook salmon fry were released into the Santa Ynez River and other Santa Barbara County streams, and another 125,000 were released into the Ventura River (Cobb, 1921). However, these plantings occurred well after Jordan's initial descriptions of species ranges were written in the 1880's.

\section{The State of California's Rivers and Streams in the Late 19th Century}

When reading the historical salmon literature, one may be inclined to assume that habitat conditions for salmon during the late 1800's were far better than at present and that, therefore, these early accounts provide a better indication of historical freshwater distribution than more recent information. While this generalization may hold true in some locations, it would be far from correct to assume that California's watersheds within the accepted historical range of anadromous salmonids were in pristine condition. The discovery of gold at Sutter's Mill in 1848 triggered a massive influx of settlers to California. Between 1850 and 1900, California's population increased more than fifteen-fold, from under 100,000 to nearly 1.5 million people, nearly half which took up residence in the counties immediately surrounding San Francisco Bay (CSDC, 2012). This tremendous increase in population prompted many human industries that dramatically affected salmonid habitats in many coastal California watersheds well before the first scientific exploration of these watersheds had occurred and the taxonomy of the various salmon species was resolved.

The principal land-use activities that degraded salmonid habitats in California during the 19th century varied with region. Logging unquestionably had severe and widespread impacts on California's coastal populations of Pacific salmon, particularly in coastal mountains from the Oregon border south to northern Monterey County with exten- 


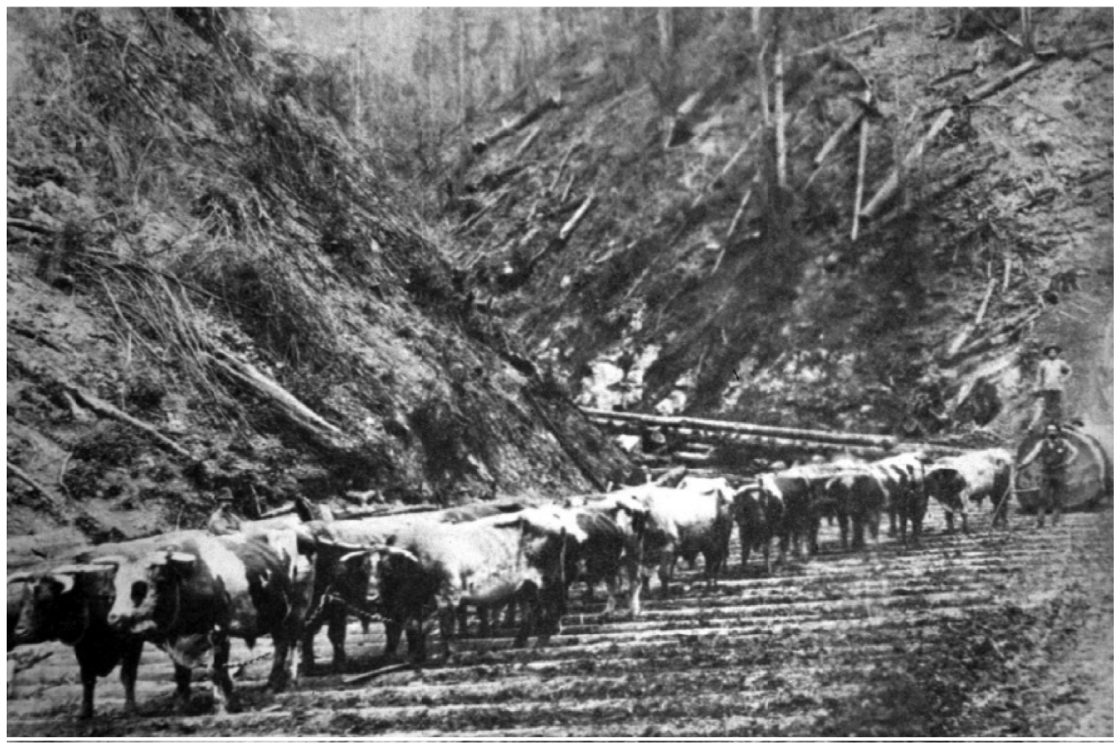

Figure 7.- Oxen hauling logs on a "corduroy road" in Mendocino County, ca. 1851. Photo courtesy of the Held-Poage Memorial Home and Mendocino Historical Society, Ukiah, California, from the Robert Lee Collection.

sive stands of such commercially harvestable conifers as coast redwoods, Sequoia sempervirens; Douglas fir, Pseudotsuga menzeisii; Sitka spruce, Picea sitchensis; and pine, Pinus spp. Hydraulic mining for gold had its greatest impact on rivers and streams draining the west slope of the Sierra Nevada from the Feather River in Plumas County south to the Merced River in Mariposa County, though large-scale mining also occurred in the upper Klamath and Trinity River basins. The chaparral and grassland dominated regions of central and southern coastal California were subjected to grazing by domestic cattle and sheep even before the gold rush, but the intensity of grazing increased many-fold in the 1850 's in response to the goldfueled increase in California's human population. Accompanying these activities were dam building, water diversions, agricultural land conversion, release of pollutants, and many other activities that further affected salmon and their habitats.

An exhaustive treatment of the many human alterations to the habitats of anadromous fishes that took place in California during the 1800's is beyond the scope of this paper. Nevertheless, it is instructive to consider a few specific examples in detail to illustrate the enormous effects that logging, mining, grazing, and other land and water uses likely had on salmon populations well before the 1900's. These examples demonstrate that the baseline of salmon productivity and possibly distribution had very likely already undergone a substantial shift before Jordan and others began writing about salmon distributions in California.

\section{Impacts of Early Logging}

Although logging took place in the 1800 's up and down the northern and central California coasts, the history of logging in the Santa Cruz Mountains is especially germane since it encompasses the region that likely represents the southern extent of the historical distribution of persistent reproducing populations of coho salmon (Spence et al., 2011) and possibly Chinook salmon as well. Prior to the 1840's, logging in Santa Cruz County occurred on a limited basis using "pit and whipsaw" methods in which a large pit was dug beneath a fallen tree, and planks were sawn off by a team of two sawyers, one standing atop the $\log$ and another less fortu- nate one standing in the pit below (Stanger, 1963). The pace of logging was slow and the spatial extent limited. In 1842, the first water-powered sawmill in the Santa Cruz Mountains was built along the San Lorenzo River near its confluence with Zayante Creek (Poli, 1956). ${ }^{54}$ Following the discovery of gold in 1848 at Sutter's Mill, California's population expanded rapidly and with it the demand for lumber, shingles, fence posts, railroad ties, and a variety of other wood products, all of which were produced from redwoods (Carranco, 1982). Water-powered mills thus began to proliferate throughout the Santa Cruz Mountain region. By 1860 , more than 10 million board feet of timber were being cut annually in Santa Cruz County (Payne, 1978).

The typical practice was for fallers to clear cut an area within a mile or two of an existing mill site. Frequently, the area was burned to remove understory vegetation, which facilitated skidding of $\log s$ to the mill site. Trees were bucked into shorter lengths and often dragged over so-called "corduroy roads" by teams of oxen or horses to the mill site (Fig. 7). Corduroy roads were skid trails constructed by placing small diameter logs (typically $8-10$ inches) at close intervals perpendicular to the direction of the roads. These roads were greased with beef tallow to facilitate the sliding of logs to the mill (Payne, 1978). Often times, corduroy roads were built directly atop a stream channel. Skidding logs was among the more arduous and labor-intensive practices. Thus, when the local supply of logs ran out, it was more cost-effective to dismantle and relocate the mill than to skid logs greater distances. Consequently, new mill sites were continually being established penetrating further into the more remote regions of a basin (Stanger, 1967).

\footnotetext{
${ }^{54}$ The sawmill, owned by Isaac Graham, is often purported to be the first power-operated sawmill in California; however, apparently Cooper's sawmill along Mark West Creek in Sonoma County predates the Graham mill by 8 years, having been built in 1834 (California State Parks, 2017).
} 
The pace of logging accelerated in the 1870 's with the advent of steampowered mills equipped with circular saws, coupled with the steam donkey, a mechanical steam-powered winch that was capable of dragging logs thousands of feet to mill sites (Payne, 1978). The reduced dependence on water for power meant that milling could occur year-round, not just seasonally as had been the case in years prior. Additionally, transportation of logs to mill sites and lumber to ports was facilitated by the construction of narrowgauge rail lines, sometimes on impressively steep terrain. With these new tools available, logging in the Santa Cruz Mountains reached its peak, and by 1884 , annual harvest had increased to approximately $\sim 34$ million board feet in the Big Basin and San Lorenzo Valley areas alone (California State Parks, 2011). This rapid rate of harvest quickly depleted the timber supply in the Santa Cruz Mountains, and by the early 1900's many mills had closed. Over the 55-yr period from 1850 to 1905, no fewer than 340 different mill sites had been used in the Santa Cruz Mountains, and no sizeable watershed had been spared (Fig. 8).

The impacts of these intensive logging activities on salmon habitats in the region were enormous. The longlasting impacts of logging practices on salmonid habitats are well documented (Meehan, 1991; Spence et al., 1995). Loss of large wood and sources of wood recruitment, increases in stream temperatures from canopy removal, and accelerated erosion and sedimentation in streams were undoubtedly pervasive. In addition, early logging practices included construction of mill ponds, often with dams that precluded fish passage (CFC, 1892). These sometimes stood in place for many years at some of the larger, more permanent mill sites, blocking access to spawning areas.

Furthermore, up until the late 1880 's, it was standard practice for mill operators to dump sawdust and refuse wood directly into the streams. Decomposition of this material undoubtedly affected dissolved oxy-

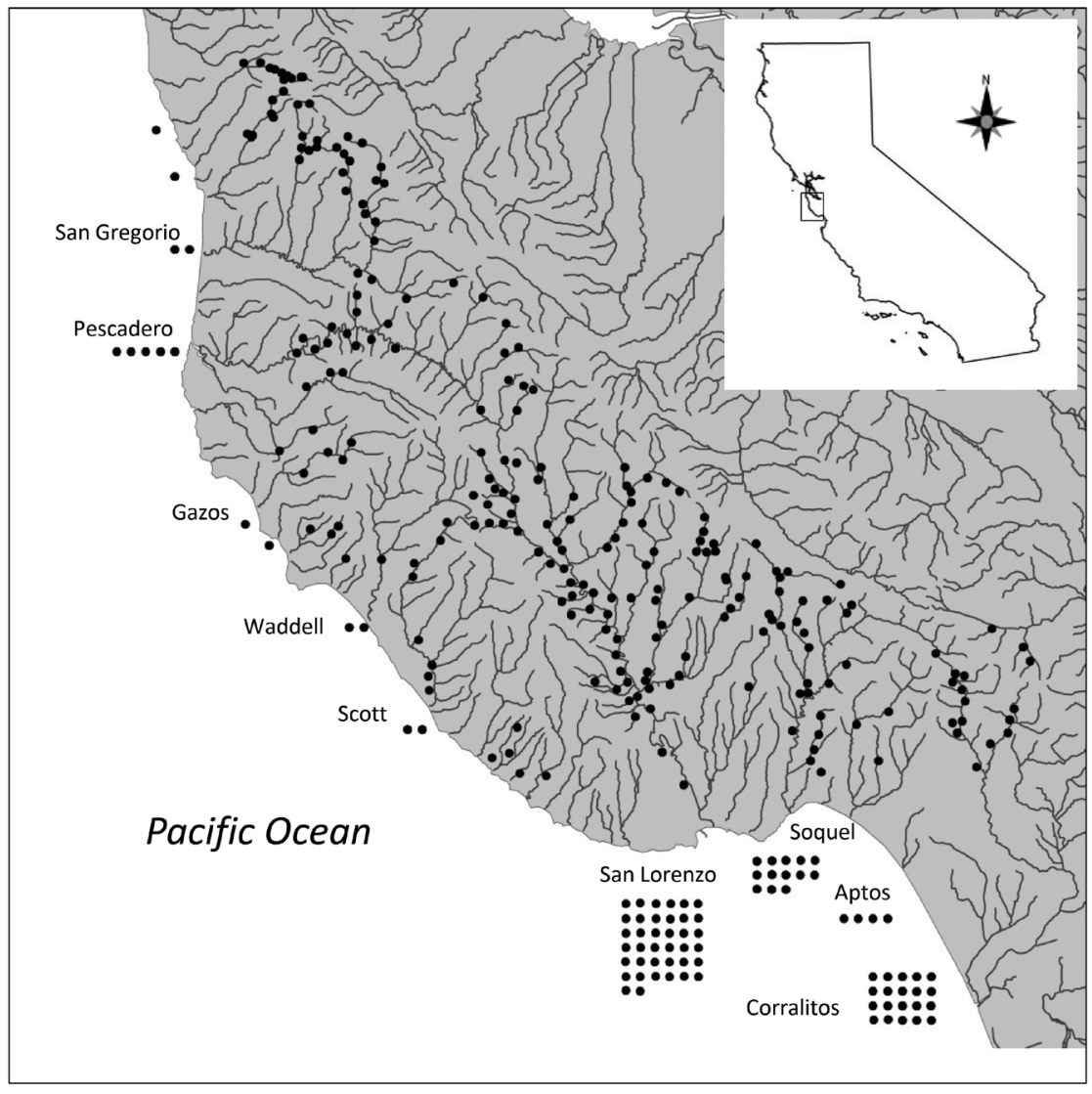

Figure 8.- Locations of sawmills and shingle mills in the Santa Cruz Mountains between 1840 and 1905. Circles adjacent to stream mouths indicate additional mills known to have been present in the watershed but that could not be reliably placed on the map. Based on data from Rood (1975) and Stanger (1967).

gen levels, to the detriment of salmon and other aquatic life. In 1871, one local Santa Cruz newspaper indicates that dumping sawdust into streams had "become universal...until our pure limpid streams were discolored, and the water became in some instances black as tar - a moving mass of turgid filth." The article elaborates on how mill ponds downstream of dumping sites frequently filled up with sawdust, describing one situation on Soquel Creek where an impoundment 175 yards long by 20 yards wide was filled to a depth of two to four feet. They described the process of cleaning out the dam as follows (Anonymous, 1871):

“...a more intolerable nuisance we have seldom seen anywhere; the saw-dust was steaming in the hot sun, with concentrated mephitic gases emitting all the stinks and smells so famed, in Cologne, besides the innumerable stenches locally incident to decayed vegetation and rotten saw-dust, so that the workmen could hardly endure it....We are thus particular in describing what we saw, to give the exact truth of the matter, as it appeared, and to correct...a former expressed impression that placing saw-dust in running brooks was only injurious to the fish-brook trout and salmon-so plentiful in all the streams in this country."

Several years later, the Santa Cruz Sentinel (Anonymous, 1877) again decried the dumping of sawdust into local streams as follows: 

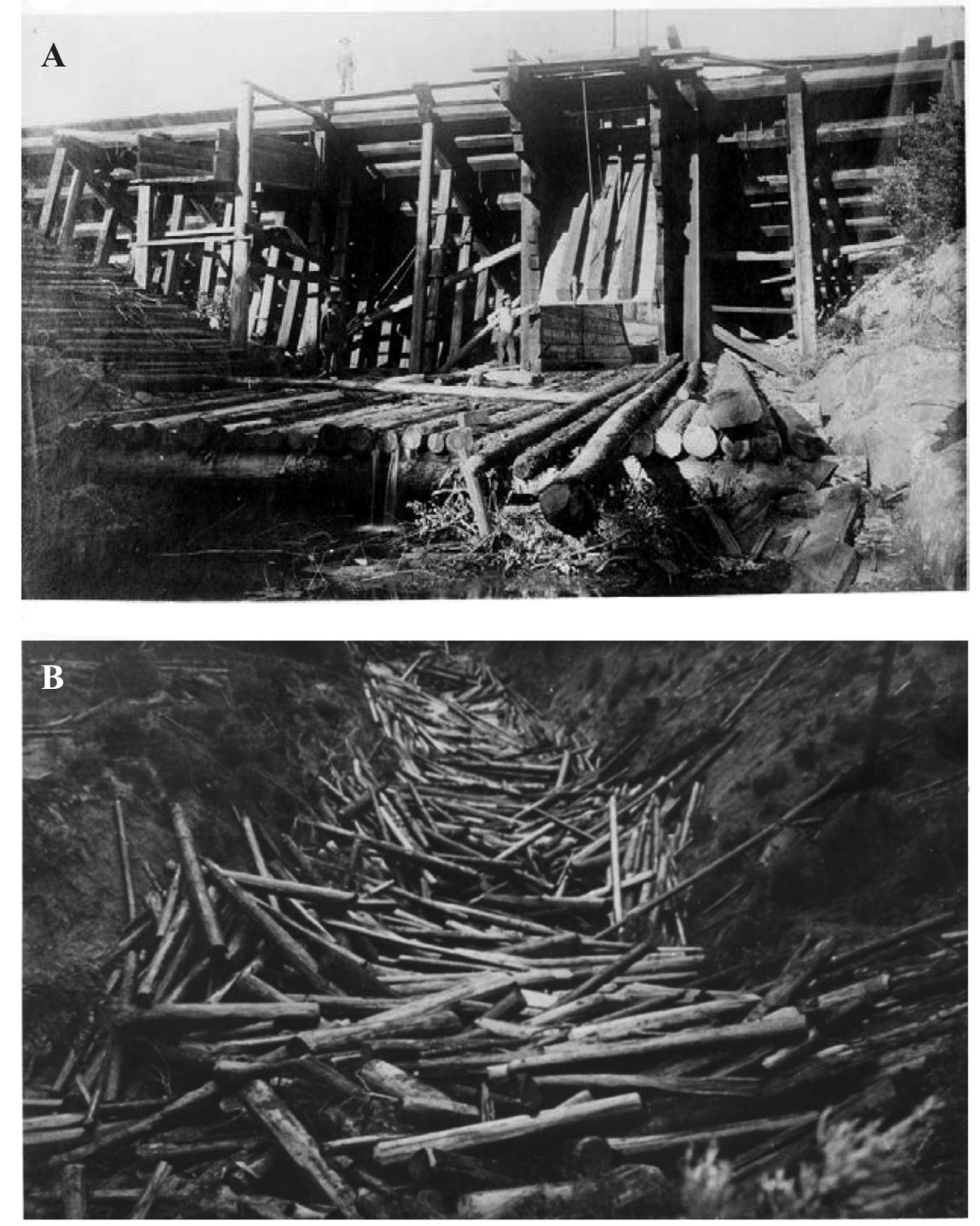

Figure 9.- - (a) Crib dam under construction on the Navarro River, Mendocino County, date unknown, and (b) log jam on Big River, ca. 1924. Photos provided courtesy of the Held-Poage Memorial Home and Mendocino Historical Society, Ukiah, California, from the Robert Lee Collection.

"We have always maintained that lumberman dumping their refuse timber and saw-dust into the San Lorenzo River and its tributaries were committing a nuisance. They are destroying the fish and poisoning the water for human use. A dumb brute has too much sense to drink from the water fresh and inky black from a saw-dust pile. We fear that this fact has something to do with the prolonged existence of diptheria and other fe- actment of a state law that banned the practice of dumping sawdust in streams and required mill owners to burn or otherwise discard their refuse away from water (California State Legislature, 1889).

In Mendocino, Humboldt, and Del Norte counties, the logging history parallels that of the Santa Cruz Mountains, both in time and with respect to logging methods. The first sawmills were built in the early 1850 's. In these counties, however, there were fewer roads for hauling wood; thus, the timber companies relied primarily on the rivers themselves to transport logs from remote areas down to river mouths, where they could be milled and the lumber taken to markets in San Francisco and elsewhere. Riverine transport was accomplished through the use of splash and crib dams (Fig. 9a), particularly destructive practices that were largely avoided in the Santa Cruz Mountains because of the early availability of rail transport.

Splash and crib damming involved constructing a dam across the stream for the purpose raising water levels, splash dams being temporary and crib dams being larger and semi-permanent (Jackson, 1991). Logs were rolled into the stream either above or below the dam (Fig. 9b). Then, during storm events, either flood gates were opened or the dam was demolished with explosives, releasing the water, logs, and remnants of the dam (Carranco, 1982). As described by Jackson (1991), when the dam broke, "all Hell broke loose. The water, the former jammed logs, and last but not least the dam, all went down the river. When the dam went, all evidence of its existence was removed." Another witness described a "wall of logs, trash, rocks and other debris that towered nearly 20 feet high," noting that it was odd to see the "dust flying as the logs in the drive sheared off sharp points on the stream banks." When the torrent of logs eventually came to a halt, a new dam was built and the process repeated until logs reached the river mouths, where they were collected on large booms.

Needless these to say, these so- 
called "log drives" had immediate and devastating impacts on any fish rearing in the stream or eggs deposited within the gravel. Even more importantly, the long-term result of these splashdam activities was that river channels were often widened and heavily scoured, leaving little of the structural complexity and other critical habitat elements (e.g., spawning gravels, cover, velocity refuge) needed by salmon (Sedell et al., 1991).

\section{Impacts of Hydraulic Mining}

In terms of habitat damage, few human activities could rival the devastating impacts of hydraulic mining for gold. At hydraulic mine sites, high-pressure jets of water were directed at stream banks, terraces, and hillsides to dislodge rock and move sediment through sluice boxes, from which gold was retrieved (Fig. 10). Through this process, massive amounts of sediment were thereby flushed into streams and rivers. Gilbert (1917) estimated that between 1849 and 1909, more than 684 million cubic yards of gravel, sand, silt, and other mining debris moved through the Yuba River system alone. When mining was complete, a barren wasteland of tailings was left within and along the stream channel. Downstream of the mining sites, river channels filled with massive deposits of debris, sometimes many tens of feet in depth (Gilbert, 1917). To supply the hydraulic mines with water, numerous dams were built higher in the mountains and water was diverted through extensive networks of ditches and flumes, sometimes totaling hundreds of miles (Kelley, 1954, 1989).

Salmon populations that suffered the greatest damage were found in the foothill region of the western Sierra Nevada from Merced County in the south to Plumas County in the north. Six years after its founding, the California Fish Commission (CFC 1877:5) wrote the following:

"In eighteen hundred and fifty the salmon resorted in vast numbers to the Feather, Yuba, Ameri-

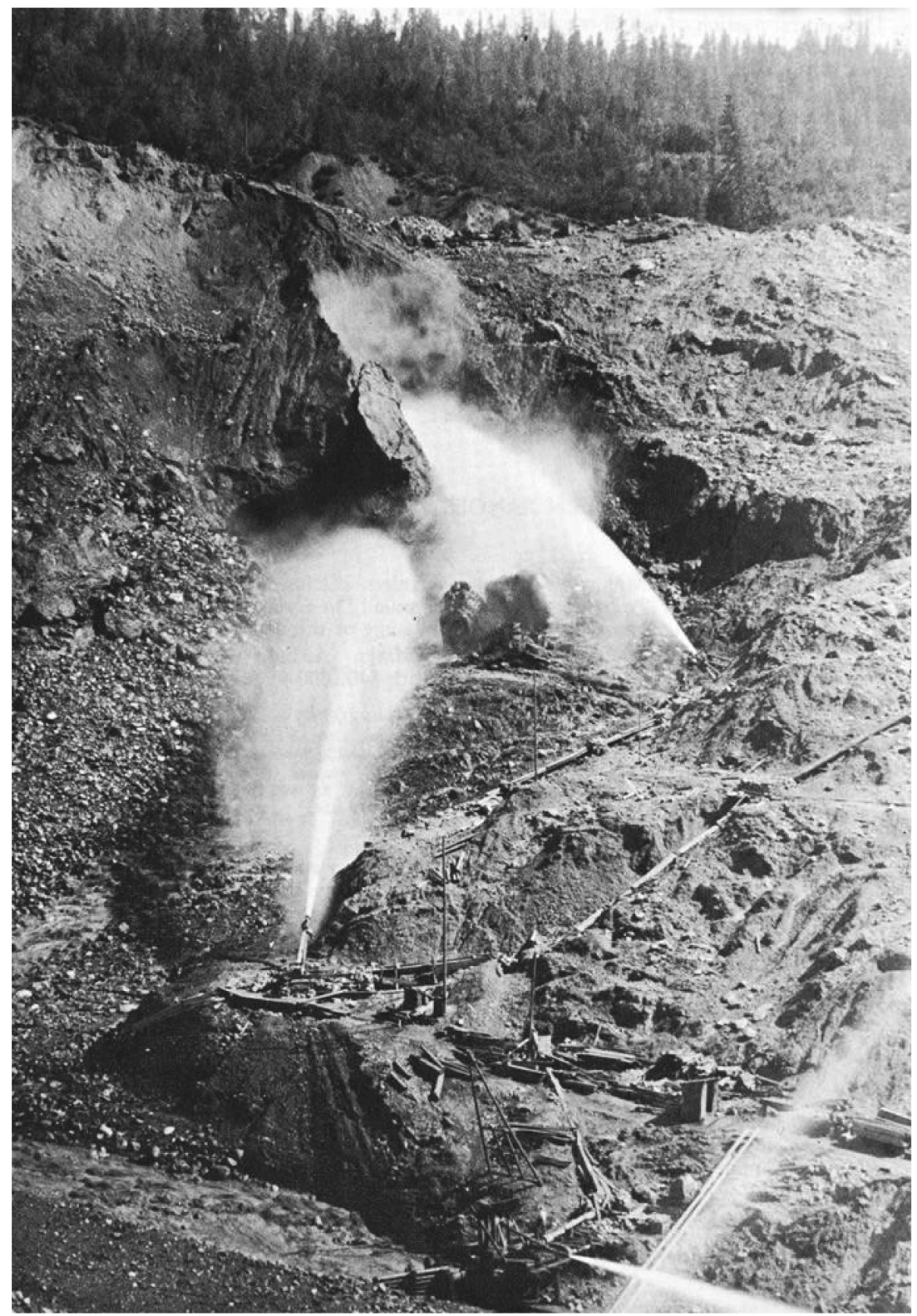

Figure 10.- Hydraulic mining at the La Grange Mine (1851-1918) near Junction City in the Trinity River basin. Photo taken ca. 1914. From Clark 1970.

can, Mokelumne, and Tuolumne Rivers for the purpose of spawning, and many places, such as Salmon Falls, on the American, were named from the abundance of these fish....At the present time no salmon enter these streams. It would be safe to estimate that one-half the streams in this State to which salmon formerly resorted for spawning, have, for this purpose, been destroyed by mining. As mining is the more important industry, of course, for this evil there is no remedy, other than by artificial means to increase the supply in those tributaries that are still the resort of these fish." 
A few years later, the CFC (1880:3) added further detail:

"The numbers of salmon that could have been taken in this river [Sacramento], before the greater part of their spawning beds had been destroyed by sediment from the gold mines, can never be known. It is the testimony of all the pioneer miners that every tributary of the Sacramento, at the commencement of mining, was, in the season, filled with this fish, hurrying and struggling as if to reach the very sources of these rivers. A few salmon continued to enter the Feather, Yuba, Bear, and American Rivers until the floods of the Winter 1860-1, which covered the gravel bottoms of those streams with mining sediment, and thereby destroyed their spawning grounds."

Although the damage to fisheries was extreme, it was the aggradation of sediments and debris on farmlands that eventually led to the end of hydraulic mining in the Mother Lode Region (Sumner and Smith, 1940). The accumulated debris buried valuable agricultural lands, clogged irrigation ditches and shipping channels, and contributed to flooding of towns downstream of the mines. Rulings handed down in both state (People $\mathrm{v}$ Gold Run Ditch and Mining Co. ${ }^{55}$ ) and federal courts (Woodruff $\mathrm{v}$ North Bloomfield ${ }^{56}$ in 1884 effectively halted large-scale hydraulic mining (Sumner and Smith, 1940; Kelley, 1989). ${ }^{57}$ The Sawyer Decision in the North Bloomfield case, though it did not prohibit hydraulic mining outright, did prohibit the discharge of mining debris into the Yuba River (Mitchell, 1994). Federal legislation, known as the Cami-

\footnotetext{
${ }^{55}$ People vs. The Gold Run Ditch and Mining Co., et al., 66 Cal. 138, 151, 4 P. 1152 (1884)

${ }^{56}$ Woodruff vs. North Bloomfield Mining Co., 18 F 753 (1884).

${ }^{57}$ Illegal hydraulic mining continued to occur for some time after the injunction, as ordinary miners continued to use mining facilities abandoned by the larger corporations (Kelley, 1989), but generally at a much smaller scale.
}

netti Act of 1893, affirmed the right to use hydraulic techniques; however, the Act likewise prohibited release of mining debris and established a "California Debris Commission" to oversee dam structures designed to contain mining wastes. Ultimately, the costs of building debris dams and other containment structures proved prohibitive, and most hydraulic mining operations ceased by 1900 (Mitchell, 1994; Kelley, 1989; Krause et al., 2010). ${ }^{58}$

Although hydraulic mining activity was centered in the foothills of western Sierra Nevada, it was not confined solely to this region. Hydraulic mining and associated channel dredging was particularly intense in tributaries to the Klamath River, including the Trinity, Salmon, Scott, and Shasta rivers (Alpers et al., 2005). Because the Klamath-Trinity mountains were outside of the Central Valley, they were exempt from the Caminetti Act; thus, hydraulic mining continued into the 1950's in this region (Krause et al., 2010).

According to state records for the year 1898, 307 hydraulic mines were operated in Trinity County alone, including the two largest hydraulic mines in the world at that time, the La Grange mine near Junction City and the Union Hill mine near Douglas City (Bailey, 2008). The Salmon River in the middle portion of the Klamath basin was similarly hard hit, with an estimated 15 million cubic yards of material washed off of riparian hillsides between 1870 and 1950 (Elder et al., 2002). Many large tailing piles still exist today that continue to limit riparian function. Liquid mercury was added to troughs in the sluice in order to enhance recovery of gold, which bonded to the heavy mercury to form gold-mercury amalgam (Alpers et al., 2005). Thus, the impacts of hydraulic mining included not only massive al-

\footnotetext{
${ }^{58} \mathrm{Hydraulic}$ mining saw a brief resurgence after passage of the Caminetti Act; however, a major storm in January of 1896 extensively damaged water supply systems and caused the failure of many debris dams, sending a new wave of sediments down the Sierra rivers (Kelley, 1989). Many mine owners subsequently abandoned or sold their water rights.
}

teration of physical habitats, but chemical contamination as well.

\section{Impacts of Grazing}

Livestock were first brought into California in 1769 by Spanish missionaries (Burcham, 1957). Between 1769 and 1833, the Spanish established 21 missions in the coastal region from San Diego to Sonoma along the famed El Camino Real in what was then called Alta California. To encourage settlement around the missions and associated pueblos and presidios, the Spanish government issued land grants that permitted settlement and granted grazing rights on surrounding lands. The crown retained ownership of the lands; thus, the grants effectively amounted to free leases. However, when Mexico gained its independence from Spain in 1821, it moved to establish rules for petitioning for land grants in an effort to break the land monopoly of the missions and give title of the lands to settlers (Burcham, 1957; Cleland, 1964).

In the years of Spanish and Mexican rule, livestock were reared primarily for local subsistence, as well as for the production of hides, tallow, and wool, all non-perishable products that could be exported. However, with the massive influx of settlers to California following the end of the Mexican-American war and the discovery of gold, the demand for food products (beef and mutton) skyrocketed, as did the value of livestock (Cleland, 1964). Cattle that sold for $\$ 4$ per head in the late 1840's could fetch $\$ 75$ in the growing urban centers by the 1850 's (Larson-Praplan, 2016). Though comprehensive estimates of the total numbers of livestock are not available for this era, estimates from the U.S. Census Bureau indicate that between 1850 and 1860 , the number of beef cattle in California increased nearly four-fold and the number of sheep increased 62fold (Burcham, 1957:143). The Census Bureau counts underestimate the total number of livestock on California lands during this era as they counted only livestock on farms and excluded those animals grazed on the open 
range. Regardless, the numbers of cattle, sheep, and feral horses clearly numbered in the millions.

Impacts from this extensive grazing on fish habitats during the 1800's are poorly documented, though modern understanding of grazing impacts indicates that alteration of streams and rivers was likely substantial (Platts, 1991, and Spence et al., 1995, provide reviews of grazing impacts). The ranchos of the Spanish and Mexican era were invariably situated around permanent water sources. Livestock often congregate in riparian areas as these provide water, shade, and more succulent vegetation; thus, riparian vegetation is frequently reduced or eliminated by grazing and trampling. The loss of riparian canopy increases the amount of solar radiation reaching the stream channel, resulting in warmer stream temperatures. Further, the loss of root structure from riparian vegetation reduces the frequency of undercut banks and decreases channel complexity, often resulting in widening and shallowing of the channel.

In upland areas, removal of vegetation and soil compaction by livestock leads to decreased infiltration of rainfall into soils and more rapid routing of surface runoff to stream channels, leading to flashier stream flows. When coupled with loss of riparian vegetation, the roots of which stabilize streambanks, this increased stream energy typically leads to increased erosion and downcutting of stream channels, which can separate them from the adjacent floodplain. Collectively, these processes can lead to substantially altered hydrologic regimes. Reduced subsurface and floodplain storage of water during the winter months means that once perennial streams may become intermittent or ephemeral during the dry months (Elmore, 1992).

The impacts of grazing on riverine habitats along California's central and southern coasts are important to recognize, particularly in the absence of credible evidence suggesting that any populations of any Pacific salmon species persisted in these watersheds. If such habitats were ever conducive to occupancy by Pacific salmon, they were likely marginal to begin with given the Mediterranean climate, intermittent connectivity with the ocean, and temperatures near the upper limits of tolerability for species like coho salmon that spend a year or more in fresh water. Consequently, even modest changes in hydrology (and hence ocean connectivity) and temperature regimes would likely have rendered them unsuitable for salmon. Though populations of $O$. mykiss have been able to persist in these watersheds, it is almost certainly because of their greater life history diversity, including the ability to complete their life cycle entirely in fresh water. For this species, headwater tributaries with perennial flow offer refugia where populations can persist during prolonged droughts when access to and from the sea is intermittent.

\section{Other Developmental Activities}

In addition to logging, mining, and grazing, all of which had broad regional impacts, other industries likely created additional impacts to salmon habitats in coastal and inland watersheds prior to the turn of the century though on a more local basis. Again activities in the Santa Cruz Mountain region are illustrative. Beginning in the 1840's, a number of tanneries were established in the area, making use of the bark of tanoak trees, Notholithocarpus densiflorus, that grow in these mountains. Three of these were located in the lower San Lorenzo River, a fourth in Scotts Valley a few kilometers inland, and a fifth in the nearby town of Soquel (Lehmann, 2000). By the late 1870's, there were ten tanneries in operation, which collectively provided roughly half of the saddle leather produced in California (Gendron and Domhoff, 2009).

Impacts of the tanning industry on local streams and rivers are poorly documented but were likely substantial. Large quantities of bark were required for tanning, and by late in the century, tanoak trees had been severely depleted (Jepsen, 1911; Lehmann, 2000), requiring tanneries to look to more northerly counties for tanbark supplies (Bowcutt, 2015). Although the impacts of tree removal were relatively minor compared to logging of the redwoods, they nevertheless added to the cumulative impact of land-clearing activities. Perhaps the greatest impact of tanneries to aquatic ecosystems was the discharge of tannery wastes into local streams, which was common practice. In 1885, one of Santa Cruz's most prominent businessmen, Frederick A. Hihn, wrote an editorial in a local newspaper lobbying for development of a sewage system through downtown Santa Cruz that would empty into the bay. Responding to claims from opponents that the sewer line would pollute local bathing beaches, he wrote the following (Hihn, 1885):

"Compare this with the foul water of the lagoon which empties into the bay near the railroad wharf, and into which the filth of a tannery is being discharged, or compare it with the water of the San Lorenzo River, into which a tannery and other factories drain, and which for years has actually received, and is now receiving, a large part of the sewage of our city, either directly or by percolation, and still the lower part of this same river is a favorite bathing place."

In addition to the tanning industry, the Santa Cruz Mountains were also home to the California Powder Works, established in 1861 as the first and largest black powder manufacturing company west of the Mississippi River (Brown, 2008). Operated until 1914, the plant was located on the San Lorenzo River about $6 \mathrm{~km}$ upstream of its mouth. To provide power to the plant, a diversion dam was constructed 4 river $\mathrm{km}$ upstream, which routed water through a flume and tunnel cut through a steep mountain spur to the Powder Works facilities. During periods of low flow, the diversion dam had the capacity to divert all of the San Lorenzo River water into the flume, resulting in dewatering of sev- 
eral kilometers of stream. In response, the State Fish Commission eventually negotiated for the owner to install three fish ladders in the flume to facilitate passage of fish around the dewatered reach (CFC, 1892). This did not occur until 1891, thirty years after the flume was built.

Finally, a number of paper mills were in operation in the Santa Cruz Mountain region prior to the turn of the century. The San Lorenzo Paper Mill, which operated intermittently between 1861 and 1872, was located on the San Lorenzo River not far downstream from the Powder Works site. To provide water to power the mill, the owners constructed a $5.2 \mathrm{~m}$ high by $54.9 \mathrm{~m}$ wide channel-spanning dam across the San Lorenzo River, as well as a $1 \mathrm{~km}$ flume to carry water to the mill site (Koch, 1973). The dam formed a lake that backed water up onto the Powder Works property, to the dismay of the Powder Works owner. Eventually, the two owners resolved the issue by constructing a flume between the Powder Works and the paper mill, which allowed the paper mill owner to tear down the dam. Nevertheless, for the years it stood, it almost certainly blocked passage to the majority of spawning habitat for what were likely the largest populations of coho salmon and steelhead in the Santa Cruz Mountain region.

Effluent from the paper mill was almost certainly dumped into the river, as was common practice. The South Coast Paper Mill (1879-1924), located on Soquel Creek near the town of Soquel, discharged highly acidic effluent that killed fish ${ }^{59}$ and created what a local newspaper described as an "unbearable nuisance to residents of the neighborhood" (Anonymous, 1885f). To remedy the situation, the mill owners financed construction of a $2.4 \mathrm{~km}$ flume that carried mill waste around the town of Capitola and dumped it

\footnotetext{
${ }^{59}$ Johnston, P. D. 1973. Aptos and the mid-Santa Cruz County area from the 1890s through World War II. Interviewed and edited by Elizabeth Spedding Calciano. University of California Santa Cruz Library. (avail. at http://library.ucsc. edu/reg-hist/johnston).
}

directly into the ocean. Water quality problems persisted, however, as claims were later brought against the mill owners for allowing "lime water, cocculus indicus, factory refuse, and substances deleterious to fish" to run into Soquel Creek (Anonymous, 1897).

The Corralitos Paper and Board Mill (1880-1902) on Corralitos Creek (Koch, 1973) likewise polluted the stream with its effluent. Local residents battled the mill owner for several years, eventually resulting in an indictment of the owner for "fouling the creek" with waste from his paper mill. The Santa Cruz Surf (Anonymous, 1888) reported that "The witnesses all agreed that there were fish in the stream before the mill was built and that there are none there now."

Such cases were not unique to the Santa Cruz region. For example, the San Francisco Call newspaper (Anonymous, 1892) decried the "flagrant violation of the fish laws" by Taylor Paper Mill on the eponymously named Papermill Creek (now known as Lagunitas Creek) in Marin County, stating that the "slaughter of fish from the poisoned refuse of the mill was enormous." The paper described the scene as follows:

\begin{abstract}
"Every season and almost every month, the trout seek to pass the mill on their way up the stream. And every season and almost every month hundreds and thousands of the trout die in the attempt. They are killed by the lime and acid cast into the crystal stream with the refuse from Taylor's Paper-mill, and their dead carcasses strew the shores for miles below the mill. Since 1850 this thing has been going on."
\end{abstract}

This collection of examples, though it represents only a small fraction of the myriad human-caused changes that were underway in coastal watersheds in California during the 1800's, highlights the fact that coastal watersheds in California were far from pristine when scientists first began undertaking studies of salmonids and other aquat- ic fauna. In addition to the widespread physical impacts of logging, mining, and grazing, streams and rivers were commonly dammed or straightened for a variety of purposes and served as dumping grounds for all manner of refuse and waste, from sawdust to tannery and paper mill effluent, not to mention raw sewage.

Except for the occasional mention of impacts from these industries on fisheries in local newspapers and reports from local game wardens published in the State Fish Commission's biennial reports, the documentation of damage is limited. Nevertheless, all of these impacts had been ongoing for several decades prior to Jordan and Gilbert's (1881a) resolution of Pacific salmon taxonomy or the first attempts to characterize the fish faunas of these coastal watersheds. Knowledge of these impacts should serve as a sharp reminder of the aphorism "the absence of evidence is not evidence of absence" when evaluating historical evidence for Pacific salmon occurrence in specific regions or watersheds.

\section{Evolution of the Writings of Jordan, Gilbert, and Evermann}

In light of the historical context provided above, it is instructive to review what Jordan and his collaborators (chiefly Gilbert and Evermann) wrote about the distribution of Pacific salmon species during the period between 1881 and the early 1900's. During this time, Jordan and colleagues published many papers and books that included descriptions of the five west coast salmon species and their putative freshwater ranges (e.g., Jordan and Gilbert, 1881a,b; Jordan and Gilbert, 1882; Jordan, 1888; Jordan, 1892a; Jordan, 1894a; Jordan and Evermann, 1896; Jordan and Evermann, 1902; Jordan, 1904a; Jordan and Evermann, 1904; Jordan, 1905; Jordan, 1907a; and Jordan, 1907b).

In the latter publications, the species descriptions are taken nearly verbatim from Jordan's previous publications, as many were updates to previously published books or reports prepared for the California State Fish 
and Game Commission. Nevertheless, following these writings through time, one can observe subtle but significant changes in species range descriptions that reflect both new information that Jordan had gathered - not all of which was necessarily accurate - as well as his evolving perceptions of the ranges of these species.

I begin with Chinook salmon. As mentioned earlier, following their 1880 Pacific Coast expedition, Jordan and Gilbert (1881a) wrote that Chinook salmon were found "From Ventura River northward to Behring's Straits..." despite the fact that they did not actually record collecting Chinook salmon anywhere south of Monterey Bay. References to Chinook salmon in the Ventura River remained in Jordan's writings through publication of Jordan and Evermann's (1896) monumental work The Fishes of North and Middle America. ${ }^{60}$

However, in Jordan and Evermann's (1902) American Food and Game Fishes, we find evidence that Jordan had perhaps begun to doubt his previous assertion that Chinook salmon ranged as far south as the Ventura River. In their general description of Pacific salmon, Jordan and Evermann note that "Concerning the habits and distribution of the salmon we quote (with such modification as later observations necessitate) the following, based upon investigation made by Jordan, Evermann, and Gilbert." This acknowledgment is followed by a paragraph taken more or less verbatim from previous papers (Jordan, 1888, 1892a, 1894a), which includes the statement that "Only the quinnat or king salmon has been noticed south of San Francisco. Its range has been traced as far as Ventura River."

Yet later, in a section of the book devoted solely to Chinook salmon, the species' range is described as follows: "It is found on both coasts of the Pacific, from Monterey Bay, California and

\footnotetext{
${ }^{60}$ The full title of this book was The Fishes of North and Middle America: A Descriptive Catalogue of the Species of Fish-like Vertebrates Found in the Waters of North America, North of the Isthmus of Panama.
}

China north to Bering Straits." This new language had not appeared in any previous Jordan publications and begs the question: if Jordan and Evermann had definitive evidence of the occurrence of Chinook salmon in the Ventura River from the 1880 expedition, as well as in San Luis Obispo County, as asserted in Jordan (1894b), then why were the authors now describing the southern end of the range as Monterey Bay, which lies nearly $425 \mathrm{~km}$ to the north? Bear in mind that, at the time this book was written, Jordan still actively opposed the "home stream theory" and assumed that salmon did not migrate more than a few tens of miles from their natal streams (Jordan, 1903). Thus, if he and Evermann had firsthand knowledge of occurrence south of Monterey Bay (i.e., in the Ventura River or in San Luis Obispo County), then it seems peculiar that they would have changed their range description.

Jordan and Evermann continued to publish these seemingly disparate range descriptions in subsequent editions of American Food and Game Fishes (Jordan and Evermann, 1904, 1908, 1922). But in the final version of Check List of the Fishes and Fishlike Vertebrates of North and Middle America North of the Northern Boundary of Venezuela and Colombia (Jordan et al., 1930), the range of Chinook salmon is listed simply as "Alaska, Oregon, and California, southward to Monterey, and to northern China." We cannot know with complete certainty if Jordan had come to disbelieve whatever information led to his original Ventura River and San Luis Obispo descriptions, but it would certainly seem so, especially in the absence of any subsequent information to confirm spawning populations of Chinook salmon in these regions.

The writings of Jordan and his collaborators related to coho and chum salmon contain examples where new but incorrect information appears to have influenced their range descriptions. In the earliest of these writings, Jordan and Gilbert (1881b) note that "the silver salmon [predominates] in Puget Sound" and "in most of the small streams along the coast." This description is repeated nearly verbatim in subsequent writings through 1896 (e.g., Jordan, 1888, 1892a, 1894a; and Jordan and Evermann, 1896).

Then, quite abruptly, Jordan and Evermann (1902) in American Food and Game Fishes revised their description, writing instead that it is the dog salmon, not the silver salmon, that predominates "in most of the streams along the coast." Recall that during Gilbert and Snyder's 1897 and 1899 survey of Northern California and Southern Oregon coastal streams, they mistook yearling coho salmon for chum salmon. I suspect that Jordan and Evermann accepted Gilbert and Snyder's initial and erroneous conclusion that chum salmon were the most abundant salmon captured during these expeditions (Snyder, 1907) and so revised their narrative. Curiously, subsequent editions of American Food and Game Fishes (Jordan and Evermann, 1904, 1908, 1922) retained this language, while Jordan's (1904a) report to the California Fish and Game Commission reverted back to silver salmon as being "in most streams along the coast." In the latter case, this may have resulted from Jordan simply recycling language from his previous reports to the California Fish and Game Commission (Jordan, 1888, 1892a, 1894a).

A second example of where a species misidentification appears to have influenced Jordan's range description emanates from the Carmel River Expedition. As noted earlier, fish collected from four Santa Cruz Mountain streams in 1895 on the Carmel River Expedition were initially identified as chum salmon but were later determined to be coho salmon. In most of his earliest writings, Jordan stated that "Only the quinnat [or king salmon] has been noticed south of San Francisco" (e.g., Jordan and Gilbert, 1881b; Jordan, 1888, 1892a, 1894a; Jordan and Evermann, 1896, 1902).

Yet, in 1904 and afterwards, Jordan changed this language to "Only the quinnat and dog salmon have been noticed south of San Francisco" (Jordan, 1904a, 1905, 1907a), though other 
Jordan publications retained the original language (e.g., Jordan and Evermann, 1908, 1914, 1922). Here, I suspect that Jordan modified this verbiage to accommodate the apparent new, but incorrect, identification of chum salmon from four Santa Cruz Mountain streams collected during the Carmel River Expedition. Had the coho salmon from these streams been correctly identified from the outset, it seems likely that subsequent confusion about whether coho salmon were native to Santa Cruz Mountain streams would never have occurred (see Spence et al., 2011).

Additional uncertainty in the distribution of coho salmon is evident through time in Jordan's writings. In Jordan (1884a), he wrote that "The Silver Salmon enters all the rivers from the Sacramento to Kamtchatka [sic]." Similarly, in two subsequent reports prepared for the State Fish Commission (Jordan, 1888, 1892a) he stated that they are found "in most streams along the coast." Yet in Jordan (1894a:131), following a description of coho salmon identical to the previous two publications, one finds the puzzling statement that "This species [Silver salmon] is not common south of the Columbia, but is sometimes taken in California."

The implication that coho salmon were not abundant in Oregon or northern California is surprising, considering that by the late 1880 's canneries on the Nehalem, Nestucca, Siuslaw, Umpqua, and Rogue Rivers, as well as Tillamook, Yaquina, Alsea, and Coos Bays in coastal Oregon were processing between 1.5 and 2.5 million coho salmon annually (Meengs and Lackey, 2005). Jordan returned to his statement that coho salmon were "in most streams along the coast" in subsequent writings. Nevertheless, this momentary vacillation suggests lingering uncertainty about the distribution, identity, and abundance of various species.

The progression of writings on sockeye salmon demonstrates shifts in understanding through time regarding occurrence. In Jordan's earliest writings (Jordan and Gilbert, 1881b) he remarked that "All the species have been seen by us in the Columbia and in Frazer's River; all but the blue-back [sockeye] in waters tributary to Puget Sound," and in subsequent papers (Jordan, 1892a) he expanded the statement to "all but the blue-back in waters in the Sacramento and in waters tributary to Puget Sound." In each of these descriptions he indicated that it is the silver salmon that predominates in Puget Sound. Ten years later, however, Jordan and Evermann (1902) indicated that all five species, including sockeye, have been seen in waters tributary to Puget Sound, and in all subsequent writings he indicated that both "red and silver salmon" predominate in Puget Sound (Jordan, 1904a, 1905, 1907a). Through time, it is apparent that Jordan received new information on both the distribution and abundance of sockeye salmon in the Puget Sound region.

Jordan and Evermann (1896) described the range of sockeye salmon as from "Klamath and Rogue rivers northward to Kamchatka and Japan," representing Jordan's first mention of sockeye salmon in either California or Oregon waters. As noted earlier, Snyder (1931) found "nothing to substantiate" the assertion of sockeye in the Klamath River and questioned whether these observations might be based on collection of sea-run $O$. mykiss and $O$. clarkii, which local fishermen referred to as "blue-backs." On the other hand, Cobb (1921) reported that 20 sockeye salmon were taken from the Klamath River in the autumn of 1915. All editions of American Food and Game Fishes contain a general description of Pacific salmon ranges that states "all but the blueback" occurs in the Sacramento (Jordan and Evermann, 19021923); however, in species-specific descriptions within these books, they acknowledge that the sockeye salmon "has occasionally been reported from the Sacramento and Klamath rivers, but is not at all common south of the Columbia." It appears by this time that they viewed sockeye salmon as occasional visitors to California. Jordan's periodic reports to the California Fish
Commission written during this same period state that the "blueback is not found in the Sacramento" and do not mention the occasional appearances (Jordan, 1904a, 1907b).

Only Jordan's descriptions of pink salmon distribution remained fairly consistent through time. Jordan and Gilbert apparently acquired a pink salmon collected from the Sacramento River while on their 1880 Pacific Coast Expedition (Jordan and Gilbert, 1880)(Table 2), so from the beginning Jordan describes their range as from the "Sacramento northward to the Arctic Sea," though they qualify this by stating that it is "Occasionally seen in the Columbia and Sacramento, but not sufficiently abundant to constitute a distinct run" (Jordan and Gilbert, 1881a). In later writings, Jordan notes that pink salmon in the Sacramento River are referred to as "Lost salmon" (Jordan and Evermann, 1896) and that it is "rarely seen in California" (Jordan, 1907b), further suggesting he did not believe them to occur in the state on a regular basis.

\section{Conclusions}

The evolution in the writings of Jordan and colleagues regarding the freshwater distribution of Pacific salmon serves as an important reminder that, when seeking to determine historical ranges of species, holding up any individual reference as definitive evidence of occurrence is both risky and inappropriate. The fluidity-and in some cases, apparent inaccuracy or inconsistency — of Jordan's Pacific salmon range descriptions over the years is not surprising given the limited extent of exploration and the primitive state of knowledge related to Pacific salmon that prevailed in the 1880 's. Thus, this conclusion should in no way be construed as diminishing the credibility or accomplishments of some of our most revered ichthyologists. The inaccuracies and uncertainties merely reflect the natural and sometimes non-linear progression of understanding in a scientific discipline that was in its earliest stages.

Jordan, Gilbert, Snyder, and other 
19th century scientists were pioneers in every sense of the word. Consequently, criticism should not be directed toward the fact that they occasionally got some things wrong. Rather, if criticism is to be levied, it is with those of us who, in standing on the broad shoulders of these ichthyological luminaries, have relied wholly on their conclusions without stopping to fully consider the nature of the scientific foundation upon which they stood.

Resolving the historical ranges of the five Pacific salmon species in western North America remains a challenging endeavor, and the writings of pioneering ichthyologists constitute only one source of information. Museum records may provide definitive evidence supporting occurrence in particular locations; however, even these records must be used with caution, as specimens contained in museum collections may be misidentified and thus species determinations should be validated through genetic or morphomet$\mathrm{ric} / \mathrm{meristic}$ analysis (see footnote 35 for example).

In some cases, it may be possible to extract important information from 19th century popular literature or newspaper accounts, though my experience has been that this information is seldom definitive due to vagaries in taxonomy and nomenclature that existed at the time. Despite this caveat, such writings may contain clues in ancillary information such as the timing of migration or size of individuals that may be useful in discriminating among species. Overlap in these characteristics often precludes definitive conclusions regarding species, but it may allow exclusion of some species and help establish the likelihood of others.

Use of ethnographic and archaeological information may also prove informative, though both have their limitations. As noted by Alagona et al. (2012), Native American cultures sometimes had different names for "trout" and "salmon," but it is unclear if salmon referred to actual salmon or simply sea-run O. mykiss. Likewise, Gobalet et al. (2004) have highlight- ed difficulties discriminating among salmonid species using fish bones, as well as the fact that middens often contain little evidence of salmonids, even in areas where they were known to be abundant. In short, credible assessment of historical occurrence in a particular watershed requires integrating many different sources of information, rather than reliance on any single information type (see Yoshiyama et al., 2001; Alagona et al., 2012; and Hamilton et al., 2017 for excellent examples of integrated analysis of salmon and steelhead occurrence in California river systems).

An unfortunate reality is that, even if all relevant evidence is gathered, it simply may not be possible to reconstruct the historical distributions of certain salmonid species in some areas. This is in part because species were likely extirpated from many watersheds by human activities before anyone had recorded their presence. For example, although pink and chum salmon have been periodically observed in California streams throughout the last 150 years, there is little compelling evidence to suggest that persistent reproducing populations of either species occurred in the state. This does not mean that they did not, as many of the low-gradient habitats that would have been the most likely spawning areas for these fish would have been severely impacted by logging, splash damming, mining, and other human developments in the 1800 's. But building the case for their occurrence based on traceable historical evidence simply may not be possible.

In these instances, we must be willing to accept that the question is unanswerable and resist the temptation to place undue weight on the accounts of our scientific predecessors, however esteemed they may be, simply because it is the only information available to us. Further, given the highly migratory nature of the Pacific salmon, and salmonids generally, a fixed freshwater spawning range for the species over geologic periods of time, or in response to shorter climatic changes, should not be expected, further compounding questions of the reproductive range of these species.

Perhaps the last word on the challenges of defining species ranges should go to David Starr Jordan, who wrote in A Classification of Fishes (Jordan, 1923), "I may repeat a warning as old as science itself: that we must not expect a degree of accuracy which the subject in question does not permit."

\section{Acknowledgments}

I would like to express my sincere gratitude to Kit Johnston, librarian at the NMFS Southwest Fisheries Science Center, Fisheries Ecology Division, who acquired dozens of obscure historical references in support of this research. Additionally, I thank Dave Catania, curator of the California Academy of Sciences Ichthyological Collection, who provided much valuable information and granted access to museum specimens collected by Jordan, Gilbert, and Snyder. I gratefully acknowledge Dave Rundio and Tommy Williams, NMFS Southwest Fisheries Science Center, with both of whom I had numerous helpful discussions regarding the organization and content of this manuscript. Finally, I thank Mark Capelli, NMFS West Coast Region, and two anonymous reviewers for their thorough and thoughtful reviews of earlier drafts of this manuscript.

\section{Literature Cited}

Adams, P. B., L. W. Botsford, K. W. Gobalet, R. A. Leidy, D. R. McEwan, P. B. Moyle, J. J. Smith, J. G. Williams, and R. M. Yoshiyama. 2007. Coho salmon are native south of San Francisco Bay: a reexamination of North American coho salmon's southern range limit. Fisheries 32(9):441-451 (doi: https://doi. org/10.1577/1548-8446(2007)32[441:CSAN SO]2.0.CO;2).

Alagona, P. S., S. D. Cooper, M. Capelli, M. Stoecker, and P. Beedle. 2012. A history of steelhead and rainbow trout (Oncorhynchus mykiss) in the Santa Ynez River watershed, Santa Barbara County, California. Bull. So. Calif. Acad. Sci. 111(3):163-222.

Alpers, C. N., M. P. Hunerlach, J. T. May, and R. L. Hothem. 2005. Mercury contamination from historical gold mining in California. Publ. U.S. Geol. Surv. 61, 7 p.

Anonymous. 1871. Saw dust in running streams. Santa Cruz Sentinel 6(49):2 [20 May]. 1877. The saw-dust nuisance. Santa Cruz Sentinel 23(22):2 [3 Nov.]. 
. 1880. The revision of the Salmonidae. Forest Stream 15(7):130. (Editor's note preceding an article by D. S. Jordan.).

1885a. "James Bolton caught forty-eight salmon..." Santa Cruz Sentinel 1(298):3 [3 Apr.]

1885b. "Salmon have been quite

plentiful in the Pescadero creek..." Santa Cruz Sentinel 1(300):1 [5 Apr.].

$1885 \mathrm{c}$. "F. Voron and J. Notley returned Wednesday from a fishing expedition to Waddell's creek. They caught seven salmon and one hundred and fifty trout...." Santa Cruz Sentinel 1(304):3 [10 Apr.].

1885d. The game law. Santa Cruz

Sentinel 2(105):7 [19 Aug.].

1885 e. A high authority says trout

and salmon trout are the same thing. Daily Morning Astorian 23(69):3 [21 Mar.]. (With excerpts of letter from D. S. Jordan.).

1885f. Soquel siftings. Santa Cruz

Daily Surf 3(133):3 [12 Oct.]. 1886. "Salmon are beginning to make their appearance..." Santa Cruz Sentinel 4(147):5 [6 Apr.] 1887. A piscatorial curiosity. Santa Cruz Sentinel 8(10):3 [26 Oct.]. 1888. The paper mill case. Santa Cruz Surf 10(24):5 [29 May]. 1889. Anti-preserve men. Daily

Alta Calif. 81(94):8 [2 Oct.]. 1890. "The State Board of Fish Commissioners..." Santa Cruz Sentinel 12(69):2 [7 Jan.]

1892. Fish killed by poison. San Francisco Morning Call 72(86):7 [25 Aug.]. 1897. Defiling the stream. Santa Cruz Surf 28(145):4 [22 Dec.]. 1899. "It is said that the upper waters of Battle Creek... are teeming with silver salmon..." Red Bluff News 39:3 [21 July]. 1905. Our county fish hatchery. Mountain Echo (Santa Cruz) 10(8):2 [16 Dec.].

1906. New additions to Supt. Shebley's family: dog salmon may be propagated at the hatchery-half-million king and quinaiutt [sic] salmon fry ready. Evening Sentinel (Santa Cruz) 10(234):1 [7 Mar.]

Bailey, J. 2008. The other California gold: Trinity County placer mining, 1848-1962. U.S. Bur. Reclam., Denver, Colo., 103 p. (online at http://odp.trrp.net/DataPort/doc.php?id=387).

Baird, S. F. 1874. Part II. C. Multiplication of fish in general. In Rep. Comm. 1872-1873, p. xxxi-xcli. U.S. Comm. Fish Fish. Wash, D.C.

Bean, T. H. 1880. Check-list of duplicates of North American fishes distributed by the Smithsonian Institution in behalf of the United States National Museum, 1877-1880. Proc. U.S. Natl. Mus. 3:75-116.

1896. Report on the propagation and distribution of food fishes. In Rep. Comm. for the year ending June 30, 1894, p. 20-80. U.S. Comm. Fish Fish., Wash., D.C.

Behnke, R. J. 2002. Trout and salmon of North America. Free Press, N.Y., 359 p.

Beidleman, R. G. 2006. California's frontier naturalists. Univ. Calif. Press, Berkeley, 484 p.

Bellinger, M. R., M. A. Banks, S. J. Bates, E. D. Crandall, J. C. Garza, G. Sylvia, and P. W. Lawson. 2015. Geo-references, abundance calibrated ocean distribution of Chinook salmon (Oncorhynchus tshawytscha) stocks across the west coast of North Amer- ica. PLoS ONE 10(7):e0131276 (doi: https:// doi.org/10.1371/journal.pone.0131276).

Bendire, C. 1881. Notes on Salmonidae of the upper Columbia. Proc. U.S. Natl. Mus. 4:81-87 (doi: https://doi.org/10.5479/ si.00963801.4-196.81)

Böhlke, J. 1953. A catalogue of the type specimens of recent fishes in the Natural History Museum of Stanford University. Stanford Ichthyol. Bull. 5:1-168.

Boughton, D. A. 2000. The dispersal system of a butterfly: a test of source-sink theory suggests the intermediate-scale hypothesis. Am. Nat. 156(2):131-144 (doi: https://doi. org/10.1086/303380)

P. B. Adams, E. Anderson, C. Fusaro, E. Keller, E. Kelley, L. Lentsch, J. Nielsen, K. Perry, H. Regan, J. Smith, C. Swift, L. Thompson, and F. Watson. 2006. Steelhead of the south-central/southern California coast: population characterization for recovery planning. U.S. Dep. Commer., NOAA Tech. Memo. NMFS-SWFSC-394, $116 \mathrm{p}$.

Bowcutt, F. 2015. The tanoak tree: an environmental history of a Pacific Coast hardwood. Univ. Wash. Press, Seattle, 240 p.

Brewer, W. H. 1974. Up and down California in 1860-1864: the journal of William H. Brewer, 3rd ed. (F. P. Farquhar, Editor.) Univ. Calif. Press, Berkeley, $583 \mathrm{p}$.

Brittain, M. R., and M. R. Jennings. 2008. Stanford University's John Otterbein Snyder: student, collaborator, and colleague of David Starr Jordan and Charles Henry Gilbert. Mar. Fish. Rev. 70(1):24-29.

Brown, B. 2008. The California Powder Works and San Lorenzo Paper Mill: self-guided tour. Paradise Park Masonic Club, Santa Cruz, Calif. (excerpts avail. at http://www.santacruzpl. org/history/articles/511/).

Brown, J. H., G. C. Stevens, and D. M. Kaufman. 1996. The geographic range: size, shape, boundaries, and internal structure. Annu. Rev. Ecol. Systematics 27(1996):597623 (doi: https://doi.org/10.1146/annurev. ecolsys.27.1.597)

Burcham, L. T. 1957. California range land: an historico-ecological study of the range resource of California. Div. Forestry, Calif. Dep. Nat. Resour., Sacramento, Calif., 261 p.

Burroughs, R. D. 1961. The natural history of the Lewis and Clark Expedition. Mich. State Univ. Press, East Lansing, 340 p.

Busby, P. J., T. C. Wainwright, G. J. Bryant, L. J. Lierheimer, R. S. Waples, F. W. Waknitz, and I. V. Lagomarsino. 1996. Status review of west coast steelhead from Washington, Idaho, Oregon, and California. U.S. Dep. Commer., NOAA Tech. Memo. NMFS-NWFSC-27, 261

Butler, V. L. 2004. Where have all the native fish gone? The fate of fish that Lewis and Clark encountered on the lower Columbia River. Oreg. Hist. Quar. 105(3):438-463.

California State Legislature. 1889. Chapter LXV. An Act to amend an Act entitled "An Act to establish a Penal Code," approved February 14,1872 , relating to the depositing of sawdust in the waters of this state [approved March 4, 1889], p. 61-62. Twenty-eighth session of the State Legislature, Sacramento.

California State Parks. 2011. Big Basin Redwoods State Park. Calif. State Parks, Sacramento (accessed 2 Nov. 2017 at https://www.
parks.ca.gov/pages/540/files/BigBasinRedwoodsFinalWebLayout101816.pdf).

2017. Cooper's sawmill: historical landmark. Calif. State Parks Off. Hist. Preservation (accessed 2 Nov. 2017 at http://ohp. parks.ca.gov/ListedResources/Detail/835).

Carranco, L. 1982. Redwood lumber industry. Golden West Books, San Marino, Calif., 218 p.

CFC. 1872. Report of the Commissioners of Fisheries of the State of California for the years 1870 and 1871, 24 p. Calif. Fish Comm., Sacramento.

1877. Report of the Commissioners of Fisheries of the State of California for the years 1876 and 1877, 30 p. Calif. Fish Comm., Sacramento.

1880. Report of the Commissioners of Fisheries of the State of California for the year 1880,70 p. Calif. Fish Comm., Sacramento.

1882. Report of the Commissioners of Fisheries of the State of California for the years 1881 and 1882, 23 p. Calif. Fish Comm., Sacramento.

1892. Biennial report of the State Board of Fish Commissioners of the State of California for the years 1891 and 1892, 65 p. Calif. Fish Comm., Sacramento.

CFGC. 1913. Fish and Game Commission twenty-second biennial report for the years 1910 1912. Calif. Fish Game Comm. 80 p.

1916. Fish and Game Commission twenty-fourth biennial report for the years 1914-1916. Calif. Fish Game Comm. 248 p.

Chamberlain, F. M. 1907. Some observations on salmon and trout in Alaska. In Rep. Comm. Fish. for the fiscal year 1906 and special papers. U.S. Bur. Fish. Doc. 627, 112 p, Wash. D.C.

Clark, G. H. 1929. Sacramento-San Joaquin salmon (Oncorhynchus tschawytscha) fishery of California. Calif. Div. Fish Game, Fish Bull. 17, $73 \mathrm{p}$

Clark, W. B. 1970. Gold districts of California. Calif. Div. Mines Geol., Bull. 193, 186 p.

Cleland, R. G. 1964. The cattle on a thousand hills. Southern California 1850-1880. Second ed., second print. Huntington Lib., San Marino, Calif., 365 p.

Cobb, J. N. 1911. The salmon fisheries of the Pacific Coast. In Rep. Comm. Fish. for the fiscal year 1910 and special papers. U.S. Bur. Fish. Doc. 751, 179 p., Wash., D.C. 1921. Pacific salmon fisheries. Appendix I to Rep. U.S. Comm. Fish. for 1921. U.S. Bur. Fish. Doc. $902 ., 268$ p., Wash., D.C.

Collins, J. W. 1892. Report on the fisheries of the Pacific Coast of the United States. In Rep. Comm. Fish Fish. for 1888, p. 3-269. U.S Comm. Fish Fish. Wash., D.C.

Costanso, M. 1911. The Portola expedition of 1769-1770, diary of Miguel Costanso (transl. and edited by M. B. Carpio and F. J. Teggart). Univ. Calif. Press, Berkeley, 167 p.

Coues, E. (Editor). History of the expedition under the command of Lewis and Clark, to the sources of the Missouri River, thence across the Rocky Mountains and down the Columbia River to the Pacific Ocean performed during the years 1804-5-6 by order of the government of the United States, Vol. 3, p. 8211298. Francis P. Harper, N.Y.

Crespi, J. 2001. A description of distant roads original journals of the first expedition into California, 1769-1770 (transl. and edited by 
A. K. Brown). San Diego State Univ. Press., $848 \mathrm{p}$.

Croker, R. S. 1930. Unusual fish at San Pedro, California. Calif. Fish Game 16(1):77.

1936. King salmon in southern California. Calif. Fish Game 22(4):323.

CSDC. 2012. Historical census populations of California, counties, and incorporated Cities, 1850-2010. Demographic Res. Unit, Calif. Dep. Finance, Calif. State Data Cent. (accessed 2 Nov. 2017 at http://www.dof.ca.gov/ Reports/Demographic Reports/).

Cutright, P. R. 1969. Lewis and Clark: pioneering naturalists. Univ. Nebraska Press, Lincoln, $506 \mathrm{p}$.

Dall, W. H. 1915. Spencer Fullerton Baird: a biography including selections from his correspondence with Audubon, Agassiz, Dana, and others. J. P. Lippincott Co., Phila. Lond., 462 p.

Dunn, J. R. 1996. Charles Henry Gilbert (18591928): an early fishery biologist and his contributions to knowledge of Pacific salmon (Oncorhynchus spp.). Rev. Fish. Sci. 4(2):133-184 (doi: https://doi.org/10.1080/10 641269609388583)

Eigenmann, C. H. 1890. The food fishes of the California fresh waters. In Biennial report of the State Board of Fish Commissioners of the State of California for the years 1888-1890, p. 53-65. Calif. Fish Comm., Sacramento.

Elder, D., B. Olson, A. Olson, J. Villeponteaux, and P. Brucker. 2002. Salmon River subbasin restoration strategy: steps to recovery and conservation of aquatic resources. Rep. prep. for Klamath River Basin Fisheries Restoration Task Force (Interagency Agreement 1448-11333-98-H019). U.S. Fish Wildlife Serv. Office, Yreka, Calif., $52 \mathrm{p}$.

Elmore, W. 1992. Riparian responses to grazing practices. In R. J. Naiman (Editor), Watershed management: balancing sustainability and environmental change, p. 442-457. Springer-Verlag, N.Y.

Ettlinger, E., G. Andrew, P. Doughty, and V. Rogers. 2015. Adult salmonid monitoring in the Lagunitas Creek watershed-2014-2015. Rep. to Calif. Dep. Fish Wildl., Fish. Restoration Grant Program, Grant \#P1130417, 23 p. Marin Municipal Water District, Corte Madera, Calif.

Evermann, B. W. 1930. David Starr Jordan, the man. Copeia 1930(4):93-106 (doi: https:// doi.org/10.2307/1436463).

and H. W. Clark. 1931. A distribu-

tional list of the species of freshwater fishes known to occur in California. Calif. Div. Fish Game, Fish Bull. 35, 67 p.

Fages, P. 1937. A historical, political, and natural description of California (transl. by H. I. Priestly). Univ. Calif. Press, Berkeley, 83 p.

Flagg, T. A., F. W. Waknitz, D. J. Maynard, G. B. Milner, and C. V. W. Mahnken. 1995. Impacts of hatcheries on native coho salmon populations in the lower Columbia River. Am. Fish. Soc. Symposium 15:366-357.

Ford, C. 1966. Where the sea breaks its back: the epic story of a pioneer naturalist and the discovery of Alaska. Little, Brown and Company, Boston, $206 \mathrm{p}$.

Fremont, J. C. 1856. The exploring expedition to the Rocky Mountains, Oregon and California. Miller, Ortin \& Mulligan, N.Y., 456 p.

Gendron, R., and G. W. Domhoff. 2009. The leftmost city: power and progressive poli- tics in Santa Cruz. Westview Press, Boulder, Colo., $256 \mathrm{p}$.

Gibbons, W. P. 1854. Description of four new species of viviparous fish, read before the California Academy of Natural Sciences, Monday evening, 15 May 1854. Daily Placer Times and Transcript (San Franc.), 18 May, p. 2.

1855. Untitled description of a new species of trout (Salmo iridea), in record of 19 March 1855 meeting. Proc. Calif. Acad. Nat. Sci. 1:36-37.

1876. Description of a new species of trout from Mendocino County. Proc. Calif. Acad. Sci. Ser. 1(VI):142-144.

Gibson, J. R. 2013. California through Russian eyes 1806-1848. Early California Commentaries, vol. 2. Arthur H. Clark Co., Norman, $492 \mathrm{p}$

Gilbert, C. H. 1912. Age at maturity of the Pacific coast salmon of the genus Oncorhynchus. U.S. Bur. Fish. Bull. 32:1-22. 1922. The salmon of the Yukon River. U.S. Bur. Fish. Bull. 38:317-332.

Gilbert, K. G. 1917. Hydraulic mining debris in the Sierra Nevada. U.S. Geol. Surv. Prof. Pap. $105,154 \mathrm{p}$.

Gill, T. 1883. An account of progress in zoology in the year 1881. Smithsonian Rep. for 1881, Wash., D.C., $90 \mathrm{p}$

Gobalet, K. W., P. D. Schulz, P. D. Wake, and N. Siefkin. 2004. Archaeological perspectives on Native American fisheries of California, with emphasis on steelhead and salmon. Trans. Am. Fish. Soc. 133(4):801-833.

Goetzmann, W. H. 1993. Exploration and empire. The explorer and the scientist in the winning of the West. Hist. Book Club, N.Y., $656 \mathrm{p}$.

Gustafson, R. G., R. S. Waples, J. M. Myers, L. A. Weitkamp, G. J. Bryant, O. W. Johnson, and J. J. Hard. 2007. Pacific salmon extinctions: quantifying lost and remaining diversity. Cons. Biol. 21(4):1009-1020 (doi: https:// doi.org/10.1111/j.1523-1739.2007.00693.x).

Hallock, C. 1877. The sportsman's gazetteer and general guide. Forest Stream Publ. Co., N.Y., $688 \mathrm{p}$.

Hamilton, J. B., D. W. Rondorf, W. R. Tinniswood, R. J. Leary, T. Mayer, C. Gavette, and L. A. Casal. 2017. The persistence and characteristics of Chinook salmon migrations to the upper Klamath River prior to exclusion by dams. Oreg. Hist. Q. 117(3):327-377.

Hihn, F.A. 1885. Pacific Avenue sewer. Santa Cruz Sentinel 4(8): 5 [22 Oct.]

Holt, R. D. 1996. Adaptive evolution in sourcesink environments: direct and indirect effects of density-dependence on niche evolution. Oikos 75(2):182-192 (doi: https://doi. org/10.2307/3546242).

Hubbs, C. L. 1946. Wandering of pink salmon and other salmonid fishes into southern California. Calif. Fish Game 32(2):81-86. 1964. History of ichthyology in the United States after 1850. Copeia 1964(1):4260 (doi: https:doi.org/10.2307/1440831)

Jackson, D. D., and M. L. Spence (Editors) 1970. The expeditions of John Charles Fremont, vol. 1. Univ. Illi. Press, Urbana, 854 p. Jackson, W. F. 1991. Big River was dammed. FMMC Books, Mendocino, Calif., 165 p.

Jackson, J. R., and W. C. Kimler. 1999. Taxonomy and the personal equation: the historical fates of Charles Girard and Louis Agassiz. J.
Hist. Biol. 32(3):509-555 (doi: https://doi org/10.1023/A:1004784904703)

Jennings, M. R. 1997. Barton Warren Evermann (1853-1932) and his contribution to North American ichthyology. In T. W. Pietsch and W. D. Anderson, Jr. (Editors). Collection building in ichthyology and herpetology, $\mathrm{p}$. 291-310. Am. Soc. Ichthyol. Herpetol., Spec. Publ. 3, Lawrence, Kan.

2014. Cloudsley Louis Rutter (1867-1903): pioneer salmon biologist and resident naturalist, fisheries steamer Albatross. Mar. Fish. Rev. 76(4):1-27 (doi: https:// doi.org/10.7755/MFR.76.4.1).

Jepsen, W. L. 1911. Tanbark oak and the tanning industry. In California tanbark oak, p. 5-23. U.S. For. Serv. Bull. 75.

Johnson, O., W. S. Grant, R. G. Kope, K. Neely, F. W. Waknitz, and R. S. Waples. 1997. Status review of chum salmon from Washington, Oregon, and California. U.S. Dep. Commer. NOAA Tech. Memo. NMFS-NWFSC-32, 280 p. 2012. Why did the chum cross the road? Genetics and life history of chum salmon in the southern portion of their range. N. Pac. Anad. Fish Comm. Tech. Rep. 8:135-137.

Jordan, D. S. 1878a. A catalogue of the fishes of the fresh waters of North America. Extracted from U.S. Geol. Geogr. Surv. Bull. 4(2):407442 .

1878b. Notes on a collection of fishes from Clackamas River, Oregon. Proc. U.S. Natl. Mus. 1:69-85 (doi: https://doi. org/10.5479/si.00963801.20.69).

1880. The revision of the Salmonidae. Forest Stream 15(7):130.

1884a. The salmons of the Pacific. In G. B. Goode (Editor), The fisheries and fishery industries of the United States; Section I, Natural history of useful aquatic animals, p. 474-479. U.S. Comm. Fish Fish. Wash., D.C

1884b. Manual of the vertebrates of the northern United States including the district east of the Mississippi River, and north of North Carolina and Tennessee, exclusive of marine species. Fourth ed. Jansen, McClurg \& Co., Chicago, 406 p.

1887. The fisheries of the Pacific

Coast. In G. B. Goode (Editor), The fisheries and fishing industries of the United States. Section II, Geographic review for the year 1880, p. 591-630. U.S. Comm. Fish Fish. Wash., D.C.

1888. The salmon family. In Science sketches, p. 35-82. McClurg \& Co. Chicago.

1891. Steelhead or salmon trout: a lean, spent fish, that should be rejected by canners. San Francisco Morning Cal 70(161): 12 [excerpts from a communication from David Starr Jordan to the Call; 15 Nov.] 1892a. Salmon and trout of the Pacific Coast. In Biennial report of the State Board of Fish Commissioners of the State of California for the years 1891-1892, p. 44-58. Calif. Board Fish. Comm., Sacramento.

$1892 \mathrm{~b}$. History of zoological explorations of the Pacific Coast. Calif. Fish Game 17(2):156-158.

1894a. Salmon and trout of the $\mathrm{Pa}$ cific Coast. In Thirteenth biennial report of the State Board of Fish Commissioners of the State of California, for the years 1893-1894, 
p. 125-141. Calif. Board Fish. Comm., Sacramento.

1894b. Notes on the fresh-water fishes of San Luis Obispo, County. Bull. U.S. Fish Comm. 14:141-142.

1896. The salmon family. In Science sketches (new, enl. ed.), p. 35-82. A.C. McClurg \& Co., Chicago.

1903. The parent-stream theory of the return of salmon. Pop. Sci. Mon. 64:4852 .

1904a. Pacific species of salmon and trout. In Eighteenth biennial report of the State Board of Fish Commissioners of the State of California for the years 1903-1904, p. 75-97. Calif. Board Fish Comm., Sacramento.

1904b. The parent-stream theory of the return of salmon. In Eighteenth biennial report of the State Board of Fish Commissioners of the State of California for the years 1903-1904, p. 98-102. Calif. Board Fish Comm., Sacramento.

1905. A guide to the study of fishes. Vol II. Henry Holt and Co., N.Y., 599 p. N.Y., 789 p. 1907a. Fishes. Henry Holt and Co,

1907b. The trout and salmon of the Pacific Coast. In Nineteenth biennial report of the State Board of Fish Commissioners of the State of California for the years 19051906, p. 77-92. Calif. Board Fish Comm., Sacramento.

1922. The days of a man, volume one: being memories of a naturalist, teacher, and minor prophet of democracy, 1851-1899, vol. I. World Book Co., Yonkers-on-Hudson, N.Y., 710 p.

1923. A classification of fishes including families and genera as far as known. Stanford Univ. Publ., Univ. Ser., Biol. Sci. 3(2): 77-243.

and B. W. Evermann. 1896. The fishes of North and Middle America. A descriptive catalogue of the species of fishlike vertebrates found in the waters of North America, north of the Isthmus of Panama. Part I. Bull. U.S. Natl. Mus., No. 47, 954 p. Gov. Print. Off., Wash., D.C.

$$
\text { and }
$$

1904-1923.

American food and game fishes. A popular account of all the species found in America north of the equator, with keys for ready identification, life histories and methods of capture. Doubleday, Page \& Co., N.Y., 572 p. (Note: book was reissued many times between 1902 and 1923).

and and H. W. Clark.

1930. Check list of the fishes and fishlike vertebrates of North and Middle America north of the northern boundary of Venezuela and Columbia. In Rep. U.S. Comm. Fish. for the fiscal year 1928, Part II, p. 1-670. U.S. Bur. Fish. Wash., D.C

and C. H. Gilbert. 1880. List of the fishes of the Pacific Coast of the United States, with a table showing the distribution of the species. Proc. U.S. Natl. Mus. 3:452-458 (doi: https://doi.org/10.5479/ si.00963801.3-173.452). and

1881a. Notes on the fishes of the Pacific coast of the United States. Proc. U.S. Natl. Mus. 4:29-70 (doi: https://doi.org/10.5479/si.00963801.4191.29). and

1881b. Ob-

servations on the salmon of the Pacific. Am. Nat. 15:177-186 (doi: https://doi org/10.1086/272773).

$$
\text { and }
$$

1882. Synop-

sis of the fishes of North America. Bull. U.S. Natl. Mus. 16, 1018 p. (doi: https://doi. org/10.5479/si.03629236.16.i). and H. W. Henshaw. 1878. Report upon the fishes collected during the years 1875,1876 , and 1877 , in California and $\mathrm{Ne}-$ vada, appendix K. In Annu. Rep. U.S. Chief of Engineers for 1878, part III, p. 1609-1622, Wash., D.C.

Kaczynski, V. W., and F. Alvarado. 2006. Assessment of the southern range limit of North American coho salmon: difficulties in establishing natural range boundaries. Fisheries 31(8):374-391 (doi: https://doi. org/10.1577/1548-8446(2006)31[374:AOTS RL]2.0.CO;2)

Kelley, R. L. 1954. Forgotten giant: the hydraulic gold mining industry in California. Pac. Hist. Rev. 23(4):343-356.

1989. Battling the inland sea:

floods, public policy, and the Sacramento Valley. Univ. Calif. Press, Berkeley, 395 p.

Kerry, M. 1874. The Salmonidae of the Pacific. Forest Stream 2(24):369-370.

Koch, M. 1973. Santa Cruz County, parade of the past. Valley Publ., Fresno, Calif., 254 p

Krasheninnikov, S. P. 1764. The history of Kamtschatka, and the Kurilski Islands, with the countries adjacent (transl. from Russ. by J. Grieves), R. Raikes, Gloucester, Scotland. $280 \mathrm{p}$

Krause, A., P. Wilcock, and D. Gaeuman. 2010. One hundred and fifty years of sediment manipulation on the Trinity River, CA. Proceedings of the $2^{\text {nd }}$ Joint Federal Interagency Conference on Sedimentation and Hydrologic Modeling, June 27-July10, Las Vegas, NV (avail. at https://acwi.gov/sos/pubs/2ndJFIC/ Contents/3D Krause 311 10.pdf).

Larson-Praplan, S. 2016. History of rangeland livestock production. In M. R. George (Editor), Ecology and management of annual rangelands, p. 60-72. Dep. Plant Sci., Univ. Calif., Davis (avail. at http://rangelandarchive.ucdavis.edu/files/252894.pdf).

Lehmann, S. 2000. Economic development of the city of Santa Cruz 1850-1950. In Fully developed context statement for the City of Santa Cruz, p. 10-14. Prep. for City of Santa Cruz Plan. Develop. Dep., Santa Cruz, Calif. (excerpts avail. at http://scplweb.santacruzpl. org/history/work/edindtan.shtml).

Leitritz, E. 1970. A history of California's fish hatcheries 1870-1960. Calif. Dep. Fish Game, Fish Bull. 150, 125 p.

Lichatowich, J. A. 1999. Salmon without rivers. Island Press, Wash., D.C., 317 p.

Littlepage, D. 2006. Steller's Island: adventures of a pioneer naturalist in Alaska. Mountaineers Books, Seattle, 237 p.

Lockington, W. N. 1880. Report on the edible fishes of the Pacific Coast, U.S.A. In Report of the Commissioners of Fisheries of the State of California for the year 1880, p. 1666. Calif. Fish. Comm., Sacramento.

1882. Sketch of the progress of North American ichthyology in the years 1880-1881. Am. Nat. 16(10):765-772 (doi: https://doi.org/10.1086/273178).
McDonald, M. 1892. Report of the Commissioner. In Rep. Comm. Fish Fish. for 1888, p. ix-xxxix. U.S. Comm. Fish Fish. Wash., D.C.

McElhany, P., M. H. Ruckelshaus, M. J. Ford T. C. Wainwright, and E. P. Bjorkstedt. 2000 Viable salmonid populations and the recovery of evolutionarily significant units. U.S. Dep. Commer., NOAA Tech. Memo. NMFS-NWF$\mathrm{SC}-42,156 \mathrm{p}$

McEvoy, A. F. 1986. The fisherman's problem: ecology and law in the California fisheries 1850-1980. Camb. Univ. Press, Camb., 369

McPhail, J. D., and C. C. Lindsey. 1970. Freshwater fishes of northwestern Canada and Alaska. Bull. Fish. Res. Board Can. 173, 381

p.
Meehan, W. R. (Editor). 1991. Influences of forest and rangeland management on salmonid fishes and their habitats. Am. Fish. Soc. Bethesda, Md., Spec. Publ. 19, 751 p.

Meengs, C.C., and Lackey, R.T. 2005. Estimating the size of historical Oregon salmon runs. Rev. Fish. Sci. 13(1):51-66 (doi: https://doi. org/10.1080/10641260590921509).

Miller, D. J., and R. N. Lea. 1972. Guide to the coastal marine fishes of California. Calif. Dep. Fish Game, Fish Bull. 157, 249 p.

Minckley, W. L., D. A. Hendrickson, and C. E. Bong. 1986. Geography of western North American fishes: description and relationships to intracontinental tectonism. In C. H. Hocutt and E. O. Wiley (Editors), The zoogeography of North American freshwater fishes, p. 519-613. John Wiley \& Sons, N.Y.

Mitchell, M. D. 1994. Land and water policies in the Sacramento-San Joaquin Delta. Geogr. Rev. 84(4):411-423 (doi: https://doi. org/10.2307/215756)

Moore, J. A. 1986. Zoology of the Pacific Railroad Surveys. Am. Zool. 26(2):331-341.

Murphy, J. M. 1879. Rambles in north-western America from the Pacific Ocean to the Rocky Mountains. Chapman and Hall, Lond., 364 p. Myers, J. M., R. G. Kope, G. J. Bryant, D. Teel, L. J. Lierheimer, T. C. Wainwright, W. S. Grant, F. W. Waknitz, K. Neely, S. T. Lindley, and R. S. Waples. 1998. Status review of Chinook salmon from Washington, Idaho, Oregon, and California. U.S. Dep. Commer. NOAA Tech. Memo. NMFS-NWFSC-35, 443

Payne, S. M. 1978. A howling wilderness: a history of the Summit Road area of the Santa Cruz Mountains 1850-1906. Loma Prieta Publ. Co., Santa Cruz, Calif., 159 p.

Pearcy, W. G. 1992. Ocean ecology of North Pacific salmonids. Univ. Wash. Press, Seattle, 179 p.

Penaluna, B. E., A. Abadia-Cardoso, J. B. Dunham, F. J. Garcia De Leon, R. E. Gresswell, A. R. Luna, E. B. Taylor, B. B. Shepard, R. Al-Chokhachy, C. C. Muhlfeld, K. R. Bestgen, K. Rogers, M. A. Escalante, E. R. Keeley, G. M. Temple, J. E. Williams, K. R. Matthews, R. Pierce, R. L. Mayden, R. P. Kovach, J. C. Garza, and K. D. Fausch. 2016. Conservation of native Pacific trout in western North America. Fisheries 41(16):286-300 (doi: https://doi.org/10.1080/03632415.2016. 1175888).

PFMC. 1999. Amendment 14 to the Pacific Coast salmon plan, appendix A: identification and description of essential fish habitat, adverse impacts, and recommended conservation measures for salmon. Pac. Fish. Manage. 
Counc., Portland, Oreg. (https://www.pcouncil.org/wp-content/uploads/99efh1.pdf)

Pietsch, T. W., and J. R. Dunn. 1997. Early collection building in Puget Sound and adjacent waters: the 1880 expedition of David Starr Jordan (1851-1931) and Charles Henry Gilbert (1859-1928). In T. W. Pietsch and W. D. Anderson, Jr. (Editors), Collection building in ichthyology and herpetology, p. 279-290. Am. Soc. Ichthyol. Herpetol., Spec. Publ. 3, Lawrence, Kan.

Platts, W. S. 1991. Livestock grazing. In W. R. Meehan (Editor), Influences of forest and rangeland management on salmonid fishes and their habitats, p. 389-423. Am. Fish. Soc. Spec. Publ.19.

Poli, A. 1956. Ownership and use of forest land in northwestern California. Land Econ. 32(2):144-151 (doi: https://doi. org/10.2307/3159757).

Pulliam, H. R. 1988. Sources, sinks, and population regulation. Am. Nat. 132(5):652-661 (doi: https://doi.org/10.1086/284880).

Quinn, T. P. 1984. Homing and straying in Pacific salmon. In J. D. McCleave (Editor), Mechanisms of migration in fishes, p. 357-362. Plenum Press, N.Y.

2005. The behavior and ecology of Pacific salmon and trout. Univ. Wash. Press, Seattle, $378 \mathrm{p}$.

Ravenel, W. de C. 1896. Report on the propagation and distribution of food-fishes. In Rep. Comm. for the year ending June 30, 1895, p. 6-72. U.S. Comm. Fish Fish., Wash., D.C.

1898. Report on the propagation and distribution of food-fishes. In Rep. Comm. for the year ending June 30, 1897, p. xviii-xc. U.S. Comm. Fish Fish., Wash., D.C. 1899. Report on the propagation and distribution of food-fishes. In Rep. Comm. for the year ending June 30, 1898, p. xxxi-cxxii. U.S. Comm. Fish Fish., Wash., D.C

Rivinus, E. F., and E. M. Youssef. 1992. Spencer Baird of the Smithsonian. Smithson. Inst. Press., Wash., D.C., 228 p.

Rood, R.C. 1975. The historical geography and environmental impact of the lumber industry of the Santa Cruz Mountains. Senior thesis, Univ. Calif. Santa Cruz, 83 p

Rutter, C. 1902. A natural history of the quinnat salmon: a report of investigations in the Sacramento River, 1896-1901. Bull. U.S. Fish Comm. 22:65-141.

1903. The Pacific salmons. Country Life in Am. 4(2):124-127.

Scofield, N. B. 1916. The humpback and dog salmon taken in the San Lorenzo River. Calif. Fish Game 2(1):41.

Scofield, W. L. 1937. A silver salmon at Los Coronados Islands. Calif. Fish Game 23(3):245.

Scott, W. B., and E. J. Crossman. 1973. Freshwater fishes of Canada. Bull. Fish. Res. Board Can. 184, 966 p.

Sedell, J. R., F. N. Leone, and W. S. Duval. 1991. Water transportation and storage. In W. R. Meehan (Editor), Influences of forest and rangeland management on salmonid fishes and their habitats, p. 325-368. Am. Fish. Soc. Spec. Publ. 19.
Sexton, J. P., P. J. McIntyre, A. L. Angert, and K. J. Rice. 2009. Evolution and ecology of species range limits. Annu. Rev. Ecol., Evolution, and Systematics 40:415-436 (doi: https://doi.org/10.1146/annurev.ecolsys.110308.120317).

Shapovalov, L., and A. C. Taft. 1954. The life histories of the steelhead rainbow trout ( $\mathrm{Sal}$ mo gairdneri gairdneri) and silver salmon (Oncorhynchus kisutch) with special reference to Waddell Creek, California, and recommendations regarding their management. Calif. Dep. Fish Game, Fish Bull. 98, 303 p.

Shebley, W. H. 1922. A history of fishcultural operations in California. Calif. Fish Game $8(2): 62-99$

Skiles, T. D., R. M. Yoshiyama, and P. B. Moyle 2013. Pink salmon (Oncorhynchus gorbuscha) in the Salinas River, California: new record and historical perspectives. Calif. Fish Game 99(1):55-59.

Snyder, J. O. 1907. The fishes of the coastal streams of Oregon and northern California. U.S. Bur. Fish. Bull. 28:153-189.

1913.The fishes of the streams tributary to Monterey Bay, California. U.S. Bur. Fish. Bull. 32:47-72.

1931. The salmon and the fishery of Klamath River. Calif. Div. Fish Game, Fish Bull. 34, 122 p.

Spence, B. C., G. A. Lomnicky, R. M. Hughes, and R. P. Novitzki. 1995. An ecosystem approach to salmonid conservation. ManTech Environ. Res. Serv. Corp., Rep. TR-450196-60577, Corvallis, Oreg., 356 p. (avail. at http://www.westcoast.fisheries.noaa.gov/publications/reference_documents/the_mantech_ report.html).

Spence, B. C., W. G. Duffy, J. C. Garza, B. C. Harvey, S. M. Sogard, L. A. Weitkamp, T. H. Williams, and D. A. Boughton. 2011. Historical occurrence of coho salmon (Oncorhynchus kisutch) in streams of the Santa Cruz Mountain region of California: response to an Endangered Species Act petition to delist coho salmon south of San Francisco Bay. U.S. Dep. Commer., NOAA Tech. Memo. NMFS-SWFSC-472, $113 \mathrm{p}$

Stanger, F. 1963. South from San Francisco. San Mateo Co. Hist. Asso., San Mateo, Calif., $214 \mathrm{p}$.

1967. Sawmills in the redwoods. San Mateo Co. Hist. Asso., San Mateo, Calif., $160 \mathrm{p}$.

Stearley, R. F. and G. R. Smith 1993. Phylogeny of the Pacific trouts and salmons $(\mathrm{On}$ corhynchus) and genera of the family Salmonidae. Tran. Am. Fish. Soc. 122(1):133 (doi: https://doi.org/10.1577/1548-8659 (1993) $122<0001$ :POTPTA $>2.3 . C O ; 2)$.

Stone. L. 1875. Sacramento salmon. In Report of the Commissioners of Fish and Fisheries of the State of California for the years 1874 and 1875 , p. 16-21. (Letter sent to the Chairman of the California Fish Commission, San Francisco).

1880. Notes on letter of Mr. Horace Dunn to Prof. Spencer F. Baird, dated San Francisco, September 26, 1876. In Report of the Commissioner for 1878, p. 817-818. U.S. Comm. Fish Fish., Wash., D.C.
1885. Report of operations at the United States salmon-breeding station on the McCloud River, California, during the year 1883. In Report of the Commissioner for 1883, p. 989-1000. U.S. Comm. Fish Fish., Wash., D.C

1897. The artificial propagation of salmon on the Pacific Coast of the United States with notes on the natural history of the quinnat salmon. U.S. Fish Comm. Bull. $16: 205-235$.

Suckley, G. 1874. On the North American species of salmon and trout. In Rep. Comm. Fish Fish. for 1872 and 1873, p. 91-160. U.S. Comm. Fish Fish.,Wash., D.C. (Note: report was originally written in 1861.)

Sumner, F. H., and O. R. Smith. 1940. Hydraulic mining and debris dams in relation to fish life in the American and Yuba rivers of California. Calif. Fish Game 26(2):2-22

Swift, C., T. R. Haglund, M. Ruiz, and R. N. Fisher. 1993. The status and distribution of the freshwater fishes of southern California. Bull. S. Calif. Acad. Sci. 92(3):101-167.

Thompson, W. F. 1922. The fisheries of California and their care. Calif. Fish Game $8(3): 165-177$

Trotter, P. C., and P. A. Bisson. 1988. The history of the discovery of the cutthroat trout. Am. Fish Soc. Symposium 4:8-12.

USFC. 1874. Report of the Commissioner for 1872 and 1873. In Rep. Comm. Fish Fish., p. i-xcii. U.S. Comm. Fish Fish., Wash., D.C. 1876. Report of the Commissioner for 1873-4 and 1874-5. In Rep. Comm. Fish Fish., p. vii-xlvi. U.S. Comm. Fish Fish., Wash., D.C.

1893. Report of the United States Commissioner of Fish and Fisheries for the fiscal years 1890-90 and 1890-91. In Rep. Comm. for 1889 to 1891, p. 1-96. U.S. Comm. Fish Fish., Wash., D.C

1894. Report of the United States Commissioner of Fish and Fisheries for the fiscal year ending June 30, 1892. In Rep. Comm. for the year ending June 30, 1892, p. vii-cxci. U.S. Comm. Fish Fish., Wash., D.C.

Waples, R. S., G. R. Pess, and T. Beechie. 2008. Evolutionary history of Pacific salmon in dynamic environments. Evolutionary Applications 1(2):189-206 (doi: https://doi. org/10.1111/j.1752-4571.2008.00023.x).

Winans, G. A., D. Viele, A. Grover, M. Palmer-Zwahlen, D. Teel, and D. Van Doornik. 2001. An update of genetic stock identification of Chinook salmon in the Pacific Northwest: test fisheries in California. Rev. Fish. Sci. 9(4):213-237 (doi: https://doi. org/10.1080/20016491101753).

Wydoski, R. S., and R. R. Whitney 2003. Inland fishes of Washington, Second ed. Univ. Wash. Press, Seattle, 322 p.

Yoshiyama, R. M., E. R. Gerstung, F. W. Fisher, and P. B. Moyle. 2001. Historical and present distribution of Chinook salmon in the Central Valley drainage of California. In R. L. Brown (Editor), Contributions to the biology of Central Valley salmonids, vol.1., p. 71-176. Calif. Dep. Fish Game, Fish Bull. 179 